\title{
WestVirginiaUniversity
}

THE RESEARCH REPOSITORY @ WVU

Graduate Theses, Dissertations, and Problem Reports

2005

\section{Functional evaluation of cytochrome P450 2D6 allelic isoforms}

Weiyan Zhang

West Virginia University

Follow this and additional works at: https://researchrepository.wvu.edu/etd

\section{Recommended Citation}

Zhang, Weiyan, "Functional evaluation of cytochrome P450 2D6 allelic isoforms" (2005). Graduate Theses, Dissertations, and Problem Reports. 2270.

https://researchrepository.wvu.edu/etd/2270

This Dissertation is protected by copyright and/or related rights. It has been brought to you by the The Research Repository @ WVU with permission from the rights-holder(s). You are free to use this Dissertation in any way that is permitted by the copyright and related rights legislation that applies to your use. For other uses you must obtain permission from the rights-holder(s) directly, unless additional rights are indicated by a Creative Commons license in the record and/ or on the work itself. This Dissertation has been accepted for inclusion in WVU Graduate Theses, Dissertations, and Problem Reports collection by an authorized administrator of The Research Repository @ WVU.

For more information, please contact researchrepository@mail.wvu.edu. 


\title{
Functional Evaluation of Cytochrome P450 2D6 Allelic Isoforms
}

\author{
Weiyan Zhang
}

\author{
A DISSERTATION \\ Submitted to \\ The School of Pharmacy \\ at \\ West Virginia University
}

In partial fulfillment of the requirements

for the degree of

\section{DOCTOR OF PHILOSOPHY}

in

Basic Pharmaceutical Sciences

\author{
Robert L. Haining, Ph.D., Chair \\ Patrick S. Callery, Ph.D. \\ Michael Miller, Ph.D. \\ Yon Rojanasakul, Ph.D. \\ Timothy S. Tracy, Ph.D. \\ Department of Basic Pharmaceutical Sciences \\ Morgantown, West Virginia \\ 2005
}

Keywords: cytochromeP450, CYP2D6, alleles, CYP2D7 variant RNA alternative splicing 


\section{ABSTRACT \\ Functional Evaluation of Cytochrome P450 2D6 Allelic Isoforms}

\section{Weiyan Zhang}

Human CYP2D6 is one of the most important human P450s based on the number of its drug substrates. It shows an extensive genetic polymorphism that influences its expression and function. There are more than 80 different $C Y P 2 D 6$ alleles and allelic variants that have been identified in human. However, only a part of alleles have been characterized with respect to enzyme activity and substrate specificity. In the first project, three alleles CYP2D6*24 (I297L), CYP2D6*27 (E410K) and CYP2D6*26 (I369T) were constructed and expressed. The enzymatic activities were evaluated by the metabolic rates for dextromethorphan $O$-demethylation and $N$-demethylation; codeine $O$-demethylation and $N$-demethylation. For DXM $O$-demethylation, CYP2D6*24 has the highest intrinsic clearance value, as estimated by $\operatorname{Vmax} / K m$ ratio, followed by *1, *26 and *27; For DXM $N$-demethylation, three allelic variants showed almost the same intrinsic clearance values as the wild type CYP2D6. For codeine $O$-demethylation, 2D6*26 and *27 have the same intrinsic clearance, it is around 2-fold higher than 2D6*1 as estimated by $V m a x / K m$ ratio. For codeine $N$-demethylation, the variant CYP2D6*26 exhibited higher enzyme efficiency for codeine $O$-demethylation than codeine $N$-demethylation compared to the wild type and other alleles.

The human $C Y P 2 D$ subfamily includes $C Y P 2 D 6, C Y P 2 D 7$ and $C Y P 2 D 8 P$, which locate at the $C Y P 2 D$ locus of chromosome 22 . It was found that alternatively splicing of $C Y P 2 D$ pre-mRNA could occur and these splicing variants are tissue-specific. However, it is still unknown whether and how these alternatively splicing variants play important physiological or pathological roles in these tissues. In the second project, a human brain $C Y P 2 D 7$ variant was successfully constructed and expressed. However, the expressed protein does not have enzymatic activity of P450 based on CO-reduce activity when the heme was used as an iron source. Interestingly, the expressed protein restored the activity when $\triangle$-ALA, a precursor of heme, was used as an iron source. Metabolism studies show that this CYP2D7 variant is capable of metabolizing codeine and probably tyramine but not MPTP.

CYP2D6 polymorphism has been associated with various human cancer susceptibilities such as lung, breast, skin and prostate cancers. It has hypothesized that the existence of these alternatively splicing variants may impact the expression and functions of CYP2D6 in extrahepatic tissues, and the alternation of CYP2D6 might play an important role in determining cancer risk. However, the genotypes and function of these extrahepatic CYP2D6 are still unknown. In the third project, several alternatively splicing variants derived from different human tissues including liver, brain, skin, eye and prostate have been cloned and sequenced. Among these variants, a full-length skin variant were constructed and expressed. The results indicated that this variant can only express a $27 \mathrm{kD}$ truncated protein due to a deletion $91 \mathrm{bp}$ in exon 6, which terminates the translation of C-terminus. So far, several alternative splicing $C Y P 2 D$ variants have been identified in the different tissues of human. Except for a brain $C Y P 2 D 7$ variant, none of them have been shown to be functional. Nevertheless, the existence of these variants might cause the posttranscriptional downregulation of the expression of $C Y P 2 D 6$, and further influence the physiological or pathological functions of CYP2D6 in these tissues. 


\section{DEDICATION}

I dedicate this work to my husband for his special support and encouragement. 


\section{ACKNOWLEDGEMENTS}

I wish to acknowledge those people who have impacted my life during the journey of graduate school.

I extend my sincerest thanks to my advisor, Dr. Robert Haining, for his kind and guidance, for introducing me to the world of CYP2D6 and for allowing me to be part of his laboratory.

I appreciate the members of my committee for taking an active interest in my graduate career. I thank Dr. Callery for helping me overcome unusual circumstances during my study process and helping me improve my presentation skill. I thank Dr. Yon Rojanasakul for demonstrating excellence in writing and genuine interest in student success. I thank Dr. Michael Miller for being approachable, friendly, warm and caring. I thank Dr. Timothy Tracy for his excellent teaching, and he is so knowledgeable that I learned a lot from him.

Special thanks for Dr. Diaa Shakley and graduate students Islam Younis, Nissa Thomsen, and Youbin Tu for their kindly help in the lab. Your efforts are very much appreciated. 


\section{TABLE OF CONTENTS}

TITLE PAGE--------------------------------------------------------------------------------------------i

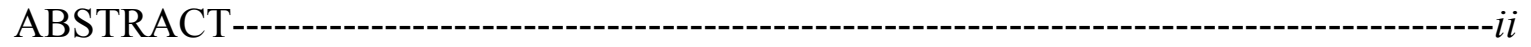

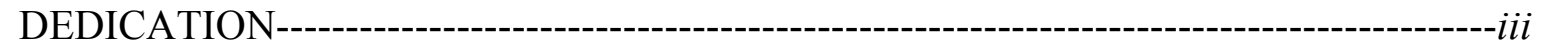

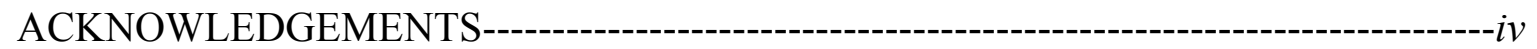

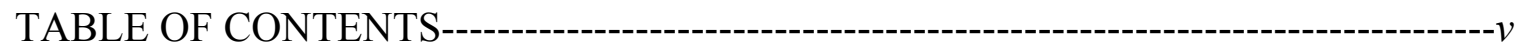

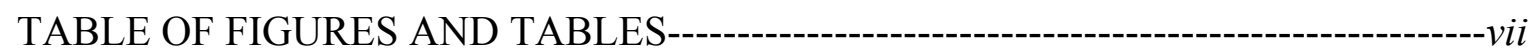

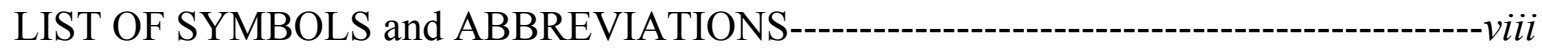

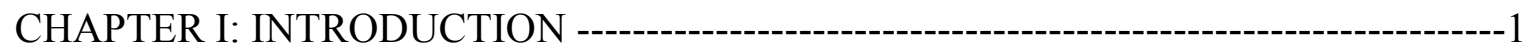

I. Overview --------------------------------------------------------------------------------------------1

II. CYP2D6 Genetic Polymorphism and Alternative Splicing ---------------------------2

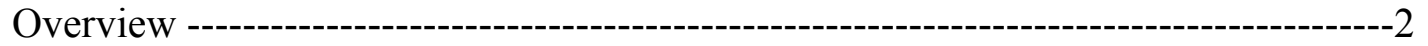

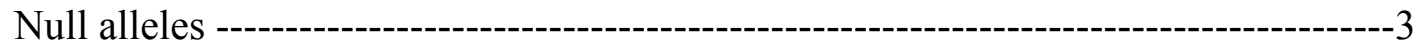

Alleles associated with decreased enzyme activity ----------------------------------------4

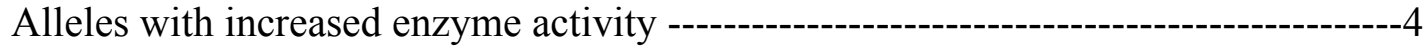

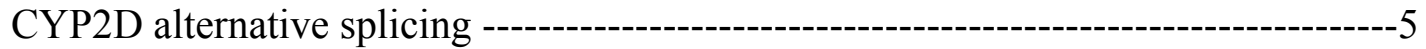

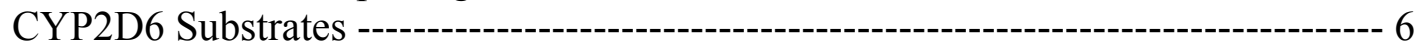

III. Impacts of CYP2D6 polymorphism on drug metabolism --------------------------12

IV. Extrahepatic expression of CYP2D6 and its clinical significance--------------------- 14

V. CYP2D6 and cancer susceptibility ------------------------------------------- 19

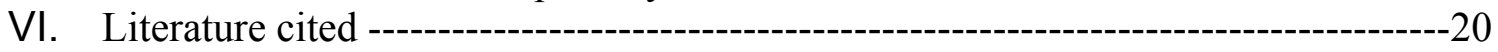

CHAPTER II: Creation, Expression and Functional Analysis of Human Cytochrome

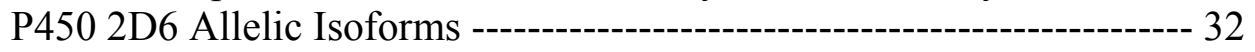

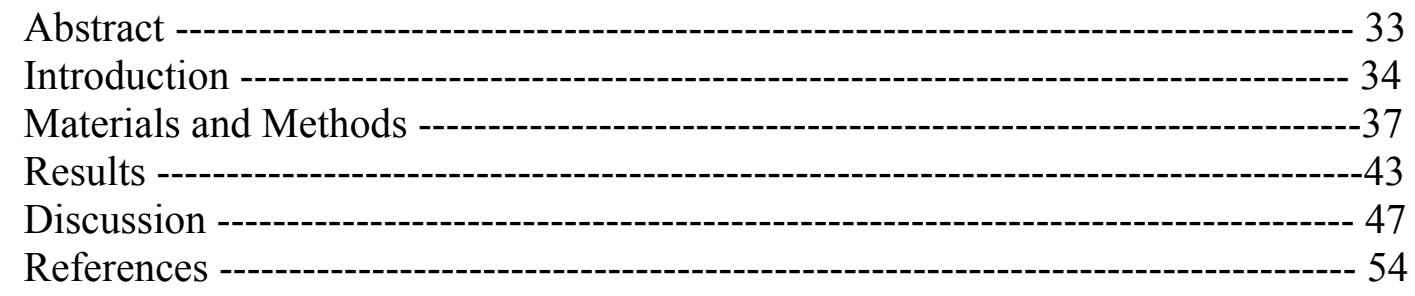

CHAPTER III: Creation, Expression and Functional Analysis of Human Brain Cytochrome P450 2D7 Variant ---------------------------------------------72 


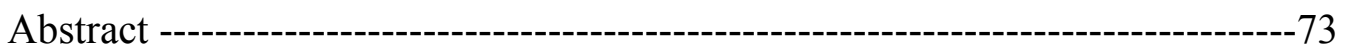

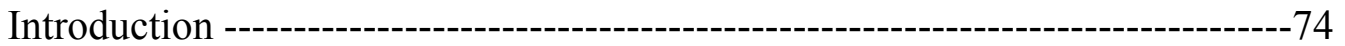

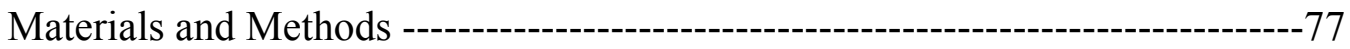

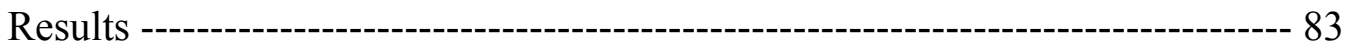

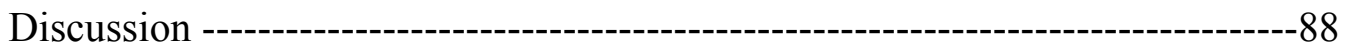

References -----------------------------------------------------------------------------------96

CHAPTER IV: Cloning and Sequencing of CYP2D Genes from EST Library of

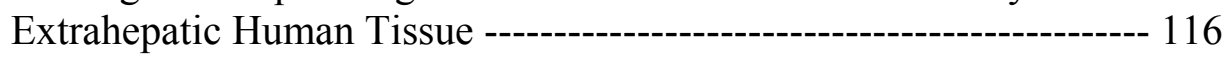

Abstract -------------------------------------------------------------------------------117

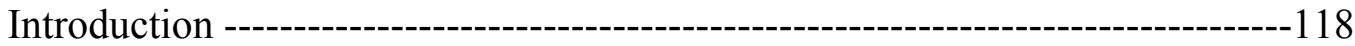

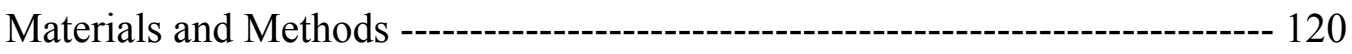

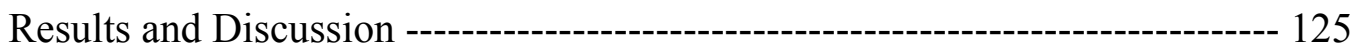

References -------------------------------------------------------------------------------132 


\section{TABLE of FIGURES and TABLES}

\section{Chapter II}

Figure 1. Four constructed alleles confirmed by DNA sequencing analysis -----------------61

Figure 2. Generation of recombinant bacmid DNA ----------------------------------- 62

Figure 3. Confirmation of recombinant bacmid DNA by PCR-------------------------------- 63

Figure 4. Analysis of four alleles by western blot---------------------------------------------- 64

Figure 5. Carbon monoxide difference spectroscopy of CYP2D6 allelic isoforms--------- 65

Figure 6. Dextromethorphan $O$-demethylation by CYP2D6 allelic isoform----------------- 66

Figure 7. Dextromethorphan $N$-demethylation by CYP2D6 allelic isoforms----------------- 67

Figure 8. Codeine $O$-demethylation by CYP2D6 allelic isoforms ---------------------------- 69

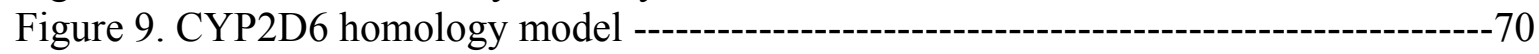

Figure 10. Ratio of MEM and DXO produced by the wild type and three alleles-----------71

Table 1. Kinetic parameters for DXM $O$-demethylation and codeine $O$-demethylation -- 68

\section{$\underline{\text { Chapter III }}$}

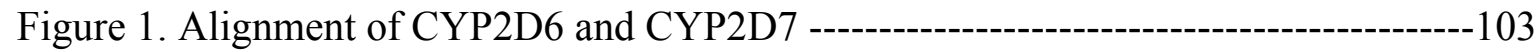

Figure 2. Construction and expression of brain variant CYP2D7----------------------------104

Figure 3. Carbon monoxide difference spectroscopy of CYP2D7 variant-------------------105

Figure 4. Analysis of CYP2D7 in different subcellular fraction by Western blot ---------106

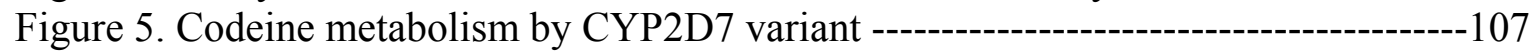

Figure 6. M-tyramine metabolism by CYP2D7 variant -----------------------------------109

Figure 7. MS analysis of tyramine metabolized by CYP2D7 variant----------------------112

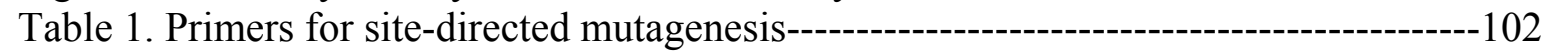

Table 2. Kinetics of m-tyramine and codeine metabolism by CYP2D7 and CYP2D6-----115

\section{Chapter IV}

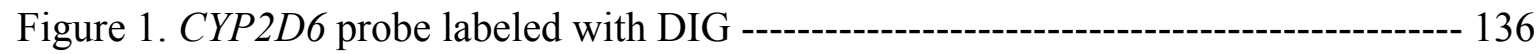

Figure 2. Human brain cDNA library screening -----------------------------------------------137

Figure 3. EST clones amplification and DNA sequencing ----------------------------------138

Figure 4. Full-length human skin $C Y P 2 D$ cDNA construction--------------------------------139

Figure 5. Full-length human skin $C Y P 2 D$ cDNA construction and PCR amplification---140

Figure 6. Western blot analysis of human skin CYP2D protein expression ----------------141 


\title{
LIST OF SYMBOLS and ABBREVIATIONS
}

\author{
$\triangle \mathrm{ALA}-\delta$-aminolevulinic acid \\ BNF - $\beta$-naphthoflavone \\ CNS - central nervous system \\ $\mathrm{CuOOH}$ - cumene hydroperoxide \\ DXM - dextromethorphan \\ DXO - dextrorphan \\ ESTs - expressed sequence tags \\ MEM - 3-methoxymorphinan \\ $\mathrm{MPP}^{+}$- 1-mithyl-4-phenylpyridinium ion \\ MPTP - methyl-phenythetra hydropyridine \\ PTP - phenyl-tetrahydropyridine \\ SRSs - substrate recognition sites \\ TFA - trifluoroacetic acid \\ TIQ - tetrahydroisoquinoline
}




\section{Chapter I}

\section{Genetic Polymorphism of P450 CYP2D6 and its Clinical Significance}

\section{Overview}

CYP2D6 is one of the most important human P450s based on the number of its drug substrates, which include more than 50 commonly used drugs (13). It shows a very high degree of inter-individual variability, which is primarily due to the extensive genetic polymorphism that influences its expression and function (20). There are more than 80 different $C Y P 2 D 6$ alleles and allelic variants that have been identified (57). Genetic polymorphism has been linked to four classes of phenotype based on the extent of drug metabolism: "Poor Metabolizers" (PM) phenotypes are characterized by their failure to use CYP2D6-dependent metabolic pathway for drug elimination, which affect up to $20 \%$ of all clinically used drugs $(39,61)$; "Ultrarapid Metabolizers" (UM) phenotype can be caused by alleles carrying multiple gene copies (57); "Intermediate Metabolizers" (IM) phenotypes are severely deficient in their metabolism capacity compared to normal "Extensive Metabolizers" (EM) since they express a low amount of residual activity due to the presence of at least one partially deficient allele compared to PMs $(21,61)$. Different capacity in metabolism of drugs can lead to severe toxicity or therapeutic failure by altering the relation between dose and blood concentration of pharmacologically active drug or metabolite (31). Individual difference in the expression of $C Y P 2 D 6$ is reportedly a factor related to the susceptibility of cancer and other diseases 
where environmental chemicals are implicated $(35,37,40,50,118)$. For example, defects in CYP2D6 have been associated with a number of CNS diseases such as Parkinson's disease $(69,90,103,106,109)$ and the polymorphism of CYP2D6 is likely associated with genetic susceptibility to melanoma (110).

The human $C Y P 2 D$ subfamily includes $C Y P 2 D 6, C Y P 2 D 7$ and $C Y P 2 D 8 P$, which locate at the $C Y P 2 D$ locus of chromosome $22(43,64)$. It was found that alternative splicing of $C Y P 2 D$ pre-mRNA could occur and these splicing variants are tissue-specific $(52,53)$. It is still unknown whether and how these alternative splicing variants play roles in these tissues in terms of physiological and pathological functions.

\section{CYP2D6 Genetic Polymorphism and Alternative Splicing}

(a). Overview: The $C Y P 2 D 6$ polymorphism, which was first discovered in the genetic deficiency of debrisoquine and sparteine metabolism $(75,80)$, was shown to affect the metabolism of a variety of structurally different drugs such as metoprolol and bufuralol $(24,74)$. CYP2D6 polymorphism exhibits pronounced interethnic variation. While initial observation and studies focused on Caucasian population (8), later on the same phenomenon was also observed in other populations such as African-American, Chinese and Japanese $(7,48,108)$. The nomenclature homepage (http://www. imm.ki.se/CYPalleles/) currently lists 44 alleles with a total number of currently 78 distinct alleles. 
The CYP2D6 polymorphism has been linked to four classes of phenotypes including EM, PM, IM and UM. CYP2D6 polymorphism has high clinical significance, e.g., difference in drug metabolism can lead to severe toxicity and therapeutic failure by changing the relation between the dose and blood concentration. Thus, knowledge of an individual's CYP2D6 status can provide a rational approach to drug prescription.

(b). Null alleles: Null alleles were determined by the loss of enzymatic activity, which cause the PM phenotype only if they present in homozygous or compound heterozygous constellations. So far, there are about 20 different null alleles that have been identified (http://www.imm.ki.se/CYPalleles/). These null alleles are caused by the following factors: site mutations, insertion and deletion mutations or a deletion of the larger chromosome that contains the entire CYP2D6 locus. Among those null alleles, most alleles have single base pair mutations or small insertion/deletions that interrupt the reading frame or that interfere with correct splicing, leading ultimately to prematurely terminated protein products $(29,111,126)$. These alleles include CYP $2 D 6 * 3, * 4, * 6$, *8, $* 11, * 15, * 19, * 20, * 38, * 40, * 42$, and $* 44$. Only few alleles code for full-length but nonfunctional proteins $(2 D 6 * 7 ; 2 D 6 * 12, * 14, * 18)(34)$. There are at least three alleles caused by a large chromosomal deletion resulting in deletion of the entire CYP2D6 gene $(2 D 6 * 5)(39)$ or by the interruption of open reading frame caused by the splice of CYP2D6/2D7 (2D6*13 and $2 D 6 * 16)(22,23)$. Among those null alleles, $C Y P 2 D 6 * 4$ is the most frequent null allele identified in Caucasians $(60,102)$. It occurs with an allele frequency of about 20 to $25 \%$ and it is responsible for 70 to $90 \%$ of all PMs. 
(c). Alleles associated with decreased enzyme activity: Alleles associated with decreased enzyme activity include CYP2D6*2, *9, *10,*17,*36,*41 (http://www.imm. ki.se/CYPalleles). These alleles were characterized with IM phenotypes (94). For $C Y P 2 D 6 * 2$, a mutation was identified in the promoter region of CYP2D6 $(-1584 C>G)$. In a family study, the $C Y P 2 D 6 * 2[-1584 G]$ allele co-segregated with the EM phenotype for sparteine, whereas $* 2[-1584 C]$ co-segregated with the IM phenotype (94). Thus, the allele $2 D * 2[-1584 C]$ was renamed $2 D 6 * 41$. The frequency of $2 D 6 * 41$ in the entire population is approximately $8 \%$ and the $* 41$ genotype allows to identify more than $50 \%$ of all IM in Caucasians. CYP2D $6 * 9$ was characterized initially in a family with IM phenotypes. Although this allele lacks codon $281\left(\Delta \mathrm{K}^{281}\right)$, it still shows enzymatic activity (114). This allele exhibits a frequency of about 1 to $2 \%$ in Caucasians $(60,102)$. The C100T mutation leading to $\operatorname{Pro}^{34} \mathrm{Ser}$ is a functionally dominant mutation in $2 D 6 * 10$ and probably also in $* 36$ and $* 37$. Pro ${ }^{34}$ is part of a proline-rich region that is highly conserved between the hydrophobic membrane anchor and the globular heme-binding portion of the enzyme $(84,122)$. In Caucasians, the $2 D 6 * 10$ allele has a frequency of about $2 \%$ and accounts for 10 to $20 \%$ of individuals with IM phenotype $(46,101)$. The $2 D 6 * 1$ allele has two non-synonymous substitutions: one is the mutation identified in $2 D 6 * 2$ and the other mutation is T107I, which results in a decrease of activity (84). This allele is practically absent from European Caucasians, but it is predominantly present in African or African -American populations with a frequency of about $30 \%$ (46).

(d). Alleles with increased enzyme activity: Ultra-rapid metabolism is caused by occurrence of duplicated, multi-duplicated or amplified CYP2D6 genes. The 2D6xN 
alleles ( $N$ including $* 1, * 2, * 35, * 41$ ) were shown to occur with allele frequencies of approximately 1 to $2 \%$ in northern European populations $(5,18,46,101)$, whereas much higher frequencies were observed in Ethiopians and Saudi Arabians $(3,84)$. An intermediate frequency was found in Spanish populations (2). In human liver, a significantly elevated level of CYP2D6 protein and enzymatic activity was described with $2 D 6 * 1 / * 2 x 2$ genotype.

(e). CYP2D alternative splicing: The human $C Y P 2 D$ genes are located on chromosome 22q13.1. The CYP2D subfamily includes CYP2D6 and two related genes, CYP2D7 and CYP2D8P at its locus. These three genes display 92\%-97\% similarities with each other across their introns and exons. Each $C Y P 2 D$ gene consists of 9 exons and 8 introns. CYP2D8P is a pseudogene with multiple deletions and insertions that disrupts the open reading frame. The $C Y P 2 D 7$ gene is more similar to $C Y P 2 D 6$ than to $C Y P 2 D 8 P$. Its coding sequence contains an insertion (T138) mutation in the first exon, which causes a frame shift mutation and premature translation termination $(43,64)$. Alternative splicing of these genes has been detected in human liver, lung, brain and breast tissues $(44,45,52,53,121)$. Such alternative splicing could regulate the expression of CYP2D6 and result in different $C Y P 2 D$ variants. These variants include a (intron 5 included); $\mathbf{b}$ (intron 6 included); b' (3' portion of exon 6 deleted); c (exon 6 deleted); d (3' 57-bp portion of intron 6 included); e (3' portion of exon 6 deleted, 3' 57-bp potion of intron 6 included). Variant $\mathbf{c}$ was derived from CYP2D6, variants $\mathbf{d}, \mathbf{e}$, and $\mathbf{b}$ derived from CYP2D7, and variant b' derived from both $C Y P 2 D 6$ and $C Y P 2 D 7$. An alternatively spliced functional transcript of CYP2D7 containing a partial inclusion of intron 6 was 
recently reported in human brain but not in liver or kidney from the same individual.

Further study indicated that this brain variant $C Y P 2 D 7$ is functional, and it can metabolize codeine to morphine with greater efficiency compared to CYP2D6 (88).

\section{CYP2D6 Substrates}

(a). Substrates metabolized by CYP2D6: Although CYP2D6 substrates are structurally diverse, they all contain a basic nitrogen atom that is involved in an electrostatic interaction between the substrates and a negatively charged amino acid in the substrate-binding site of the enzyme (42). Since the polymorphism of the enzyme results in poor, intermediate, efficient or ultrarapid metabolizers of CYP2D6 drugs, Kirchheiner et al. provided approximate dose adjustments according to the CYP2D6 phenotype as based on the meta-analysis (65). The following table shows the drugs metabolized by CYP2D6 and clinical consequences for the PM, IM, EM and UM phenotypes (56).

\begin{tabular}{|c|c|c|c|c|c|c|}
\hline Therapeutic class & Drug & $\begin{array}{c}\text { Pathway catalyzed } \\
\text { by CYP2D6 }\end{array}$ & PM & IM & EM & UM \\
\hline \multirow{7}{*}{ Analgesica/antitussives } & Codeine & O-demethylation & & & & \\
\hline & Dextromethorphan & O-demethylation & & & & \\
\hline & Dihydrocodeine & O-demethylation & & & & \\
\hline & Ethylmorphine & O-deethylation & & & & \\
\hline & Hydrocodone & N-demethylation & & & & \\
\hline & Norcodeine & O-demethylation & & & & \\
\hline & Oxycodone & O-demethylation & & & & \\
\hline Anti-ADHD drug & Atomoxetine & Aromatic & & & & \\
\hline
\end{tabular}




\begin{tabular}{|c|c|c|c|c|c|c|}
\hline Therapeutic class & Drug & $\begin{array}{c}\text { Pathway catalyzed } \\
\text { by CYP2D6 }\end{array}$ & PM & IM & EM & UM \\
\hline & & hydroxylation & & & & \\
\hline \multirow{8}{*}{ Antiarrhythmics } & Aprindine & $\begin{array}{l}\text { Aromatic } \\
\text { hydroxylation }\end{array}$ & & & & \\
\hline & Encainide & O-demethylation & & & & \\
\hline & Flecainide & O-dealkylation (?) & & & & \\
\hline & Mexiletine & $\begin{array}{l}\text { Aromatic } \\
\text { hydroxylation }\end{array}$ & & & & \\
\hline & N-propylajmaline & $\begin{array}{l}\text { Benzylic } \\
\text { hydroxylation }\end{array}$ & & & & \\
\hline & Procainamide & $\begin{array}{l}\text { Arylamine N- } \\
\text { oxidation }\end{array}$ & & & & \\
\hline & Propafenone & $\begin{array}{l}\text { Aromatic } \\
\text { hydroxylation }\end{array}$ & & & & \\
\hline & Sparteine & $\begin{array}{l}\text { Aliphatic } \\
\text { hydroxylation }\end{array}$ & & & & \\
\hline \multirow{2}{*}{ Antidementia drugs } & Galanthamine & O-demethylation & & & & \\
\hline & Nicergoline & N-demethylation & & & & \\
\hline \multirow[t]{4}{*}{$\begin{array}{l}\text { Tricyclic } \\
\text { antidepressants }\end{array}$} & Amitriptyline & $\begin{array}{l}\text { Benzylic } \\
\text { hydroxylation }\end{array}$ & 70 & 90 & 105 & 135 \\
\hline & Clomipramine & $\begin{array}{l}\text { Aromatic } \\
\text { hydroxylation }\end{array}$ & 60 & 85 & 112 & 145 \\
\hline & Desipramine & $\begin{array}{l}\text { Aromatic } \\
\text { hydroxylation }\end{array}$ & 40 & 76 & 117 & 165 \\
\hline & Imipramine & $\begin{array}{l}\text { Aromatic } \\
\text { hydroxylation }\end{array}$ & 30 & 75 & 130 & 180 \\
\hline
\end{tabular}




\begin{tabular}{|c|c|c|c|c|c|c|}
\hline Therapeutic class & Drug & $\begin{array}{c}\text { Pathway catalyzed } \\
\text { by CYP2D6 }\end{array}$ & PM & IM & EM & UM \\
\hline & Nortriptyline & $\begin{array}{l}\text { Benzylic } \\
\text { hydroxylation }\end{array}$ & 48 & 90 & 115 & 155 \\
\hline \multirow{10}{*}{ Other antidepressants } & Citalopram & N-demethylation & & & & \\
\hline & Desmethylcitalopram & N-demethylation & & & & \\
\hline & Fluoxetine & N-demethylation & & & & \\
\hline & Fluvoxamine & unclear & & & & \\
\hline & Maprotiline & unclear & 35 & 77 & 120 & 170 \\
\hline & Mianserin & $\begin{array}{l}\text { Aromatic } \\
\text { hydroxylation }\end{array}$ & 70 & 87 & 110 & 135 \\
\hline & Minaprine & $\begin{array}{l}\text { Aromatic } \\
\text { hydroxylation }\end{array}$ & & & & \\
\hline & Mirtazapine & $\begin{array}{l}\text { Aromatic } \\
\text { hydroxylation }\end{array}$ & & & & \\
\hline & Paroxetine & Demethylenation & 65 & 90 & 108 & 143 \\
\hline & Venlafaxine & O-demethylation & 68 & 85 & 105 & 130 \\
\hline Antidiabetic & Phenformine & $\begin{array}{l}\text { Aromatic } \\
\text { hydroxylation }\end{array}$ & & & & \\
\hline Antiestrogen & Tamoxifen & $\begin{array}{l}\text { Aromatic } \\
\text { hydroxylation }\end{array}$ & & & & \\
\hline \multirow{3}{*}{ Antihypertensives } & Debrisoquine & $\begin{array}{l}\text { Benzylic } \\
\text { hydroxylation }\end{array}$ & & & & \\
\hline & Guanoxan & $\begin{array}{l}\text { Aromatic } \\
\text { hydroxylation }\end{array}$ & & & & \\
\hline & Indoramin & $\begin{array}{l}\text { Aromatic } \\
\text { hydroxylation }\end{array}$ & & & & \\
\hline
\end{tabular}




\begin{tabular}{|c|c|c|c|c|c|c|}
\hline Therapeutic class & Drug & $\begin{array}{c}\text { Pathway catalyzed } \\
\text { by CYP2D6 }\end{array}$ & PM & IM & EM & UM \\
\hline \multirow{3}{*}{ Antiemetics } & Dolasetron & $\begin{array}{l}\text { Aromatic } \\
\text { hydroxylation }\end{array}$ & & & & \\
\hline & Ondansetron & $\begin{array}{l}\text { Aromatic } \\
\text { hydroxylation }\end{array}$ & & & & \\
\hline & Tropisetron & $\begin{array}{l}\text { Aromatic } \\
\text { hydroxylation }\end{array}$ & & & & \\
\hline \multirow{2}{*}{ Antihistamines } & Mequitazine & $\begin{array}{l}\text { Aromatic } \\
\text { Hydroxylation }\end{array}$ & & & & \\
\hline & Promethazine & $\begin{array}{l}\text { Aromatic } \\
\text { hydroxylation }\end{array}$ & & & & \\
\hline \multirow{5}{*}{ Antipsychotics } & Haloperidol & N-dealkylation & 67 & 90 & 108 & 126 \\
\hline & Perphenazine & N-dealkylation & 30 & 80 & 130 & 170 \\
\hline & Risperidone & $\begin{array}{l}\text { Aliphatic } \\
\text { hydroxylation }\end{array}$ & & & & \\
\hline & Thioridazine & Sulfoxidation & 37 & 82 & 127 & 165 \\
\hline & Zuclopenthixol & N-dealkylation & 55 & 85 & 115 & 142 \\
\hline Appetite suppressant & Dexfenfluramine & N-dealkylation & & & & \\
\hline \multirow[t]{4}{*}{$\begin{array}{l}\text { Beta adrenergic } \\
\text { blocking agents }\end{array}$} & Alprenolol & $\begin{array}{l}\text { Aromatic } \\
\text { hydroxylation }\end{array}$ & & & & \\
\hline & Bufuralol & $\begin{array}{l}\text { Benzylic } \\
\text { hydroxylation }\end{array}$ & & & & \\
\hline & Bunitrolol & $\begin{array}{l}\text { Aromatic } \\
\text { hydroxylation }\end{array}$ & & & & \\
\hline & Bupranolol & $\begin{array}{l}\text { Aromatic } \\
\text { hydroxylation }\end{array}$ & & & & \\
\hline
\end{tabular}




\begin{tabular}{|c|c|c|c|c|c|c|}
\hline Therapeutic class & Drug & $\begin{array}{c}\text { Pathway catalyzed } \\
\text { by CYP2D6 }\end{array}$ & PM & IM & EM & UM \\
\hline & Carvedilol & $\begin{array}{l}\text { Aromatic } \\
\text { hydroxylation }\end{array}$ & & & & \\
\hline & Metoprolol & $\begin{array}{l}\text { Aliphatic } \\
\text { hydroxylation }\end{array}$ & & & & \\
\hline & Propranolol & $\begin{array}{l}\text { Aromatic } \\
\text { hydroxylation }\end{array}$ & & & & \\
\hline & Timolol & O-dealkylation & & & & \\
\hline Calcium antagonist & Perhexiline & $\begin{array}{l}\text { Aliphatic } \\
\text { hydroxylation }\end{array}$ & & & & \\
\hline \multirow{2}{*}{ MAO-inhibitors } & Amiflamine & N-demethylation & & & & \\
\hline & Brofaromine & O-demethylation & & & & \\
\hline \multirow{2}{*}{ Recreational drugs } & Methoxyamphetamine & O-demethylation & & & & \\
\hline & MDMA, MDME & Demethylenation & & & & \\
\hline \multirow{2}{*}{ Vasodilatators } & Cinnarizine & $\begin{array}{l}\text { Aromatic } \\
\text { hydroxylation }\end{array}$ & & & & \\
\hline & Flunarizine & $\begin{array}{l}\text { Aromatic } \\
\text { hydroxylation }\end{array}$ & & & & \\
\hline
\end{tabular}

(b). Inhibition and induction: Quinidine is the most potent inhibitor of CYP2D6 (107). Fluoxetine $(9,10,58)$, paroxetine (58), and propofenone (68) are also potent inhibitors of CYP2D6 with inhibition constant in the low nanomolar range. In contrast to other members of CYP enzymes, CYP2D6 is not affected by classic enzyme inducers such as phenobarbitone (30). Rifampicin treatment has given only $30 \%$ increase in 
clearance of sparteine, but metabolic ration was not significantly changed (30). About $33 \%$ reduction in the metabolic ratio of debrisoquine has been observed in female EM using contraceptives (62) . During the menstrual cycle, insignificant decrease in debrisoquine metabolic ration was observed during the luteal phase compared to preovulatory phase (63). Heavy cigarette smoking and ovariectomy induced this enzyme activity but only to a minor extent (73). In contrast, there is evidence that pregnancy has a profound influence on CYP2D6 activity. Marked increase in metabolism of metoprolol (51) and dextromethorphan has been reported during pregnancy (117).

(c). Protein structures and the specificity of substrates: Although the crystal structure of CYP2D6 has not been solved, its structure has been modeled based on the crystal structure of bacterial soluble P450 enzymes such as P450 101 (p450cam), P450 102 (P450BM3) and P450 108 (P450terp) (25, 87). It was found that CYP2D6 contains five $\beta$-sheets ( $\beta 1$ to $\beta 5$ ) and ten $\alpha$-helixes (B, B', C, F, G, I, J, I', K and L). The hemebinding domain locates between Residues 400 to 444 . In addition, several functional residues have been identified in terms of the drug-enzyme interaction. Residue Asp301 (I-helix, residues 292 -324) has been characterized as being involved in electrostatic interactions with substrates on the basis of homology modeling and site-directed mutagenesis (32). Residue Glu216 (F-helix, residues 205 -229) also plays an important role in the binding of the basic nitrogen of CYP2D6 substrates (89). One recent study indicated that Phe120, located on the B'-C loop, contributes to determining the specificity of substrate oxidation by CYP2D6 (36). Thus, it will be important to take into account the influential role of Phe120 in substrate orientation along with the roles of Glu216 and 
Asp301 in selecting basic nitrogen compounds for the future development of predictive models of the specificity of CYP2D6.

\section{Impacts of CYP2D6 Polymorphism on Drug Metabolism}

The CYP2D6 PM phenotype is characterized clinically by an impressive deficiency in formation of the relevant metabolites of affected substrate, which can result in either drug toxicity or inefficacy. The reverse effects occur in the cases of UEM (76). The polymorphism of CYP2D6 is clinically more significant for tricyclic antidepressants, certain neuroleptics, antiarrhythmics, antihypertensives, $\beta$-blockers and morphine derivatives (83). For tricyclic antidepressants, both PM and UEM phenotypes of CYP2D6 are at risk of adverse reactions (31). PM individuals given standard doses of these drugs will develop toxic plasma concentrations, potentially leading to unpleasant side effects including dry mouth, sedation and tremor or in some cases life threatening cardiotoxicity (76). In contrast, usage of CYP2D6 substrates to UEM individuals results in therapeutic failure since plasma concentrations of active drug at standard doses will be far too low to effect (19). The clinical presentation of UEM and PM patients are at times similar, leading to confusion in understanding the basis of adverse drug reaction. Due to the lack of dose individualization, patients may be subjected to recurrent depressive episodes and may not respond to treatment. Patients requiring treatment with antidepressant or antipsychotic substrates of CYP2D6 may begin the normal treatment regimen. Because of the long half-life of these drugs, toxic drug concentrations may take 
5-7 weeks to develop. Therefore, it is suggested that the patients be phenotyped before starting treatment with drugs mainly metabolized by CYP2D6 (76).

A recent study showed that, in patients prescribed with psychiatric drugs that are metabolized by CYP2D6, adverse drug reactions were observed in patient with inherited mutations inactivating CYP2D6 (120). A lack of CYP2D6 enzyme would be expected to result in reduced drug therapy effectiveness in instances where the prodrugs requiring activation by CYP2D6 are used. For example, the analgesic effect of tramadol is severely reduced in PMs (92). Similarly, following administration of the prodrug codeine, morphine could not be detected in the plasma of CYP2D6 PMs $(91,92,113)$. On the contrary, severe abdominal pain, a typical adverse effect of morphine, was observed in all UEM treated with codeine (57). Moreover, codeine produced prolongation of the orocaecal transit time only in EM subjects (86).

Due to the clinical importance of CYP2D6 polymorphism on drug metabolism, it may be considered to identify the genotypes of patients before they receive drugs mainly metabolized by CYP2D6. Recently, Pedro Dorado et al (28) developed a PCR-based strategy for CYP2D6 genotyping. This genotyping method is based on extra long PCR (XL-PCR) and PCR restriction fragment-length polymorphism (PCR-RFLP) method, it provided a rapid, straightforward, and inexpensive identification of 90\%-95\% of CYP2D6 PM or UM genotypes in a clinical routine, independent of the individual's ethnic group. 


\section{Extrahepatic Expression of CYP2D6 and its Clinical significance}

$C Y P 2 D 6$ is predominantly expressed in human liver. However, $C Y P 2 D$ mRNA was also detected in a variety of extrahepatic tissues such as brain, lung, skin and other tissues using reverse transcription followed by PCR amplification (RT-PCR). Problems common to all these investigations are the generally low expression levels, the occurrence of differentially spliced transcripts, and the possible interference with the CYP2D7/8 pseudogene expression $(33,52)$. So far, only one functional CYP2D7 variant has been reported in human brain. It is still unclear whether there are other types of functional CYP2D expressed in other tissues. In addition, the functions of these tissue specific CYP2D have not yet been investigated.

(a). Gastrointestinal tract: In the gastrointestinal tract, the expression of cytochromes P450 and of other xenobiotic metabolizing enzymes is confined to the single cell layer of the mucosal enterocytes (127). Their concentrations in homogenates of intestinal tissue samples are therefore much lower as compared to liver. Nevertheless, intracellular enterocytic expression levels may be as high as in hepatocytes. It has been shown that a number of Phase I and phase II enzymes are expressed in the intestine with CYP3A constituting the major P450 form (78). CYP2D6 was characterized at both

protein and enzyme activity level in human and rhesus monkey intestinal microsomes and it was qualitatively similar to the liver enzyme (93). In addition, inter-individual variability of CYP2D6 in human intestinal mucosa was at the low abundance and 
activity, its contribution to the first-pass effect of orally administered CYP2D6 substrates was estimated to be minimal (79).

(b). Brain: Several lines of evidence have indicated that $C Y P 2 D$ genes are expressed in human brain. First, cDNA cloning and Western blotting analyses indicated both mRNA and protein of CYP2D are present in human brain $(38,115)$. Second, microsomal preparations from human brain are capable of metabolizing dextromethorphan, a specific substrate of CYP2D6 (116). Third, immunohistochemical analysis and in situ hybridization of brain sections showed that expression of CYP2D is confined to certain regions and distinct neuronal cell types throughout the human brain, including the pigmented neurons of the substantia nigra (104). Finally, a functional CYP2D7 variant was recently cloned from human brain but not in liver or kidney from the same individual. This brain variant $C Y P 2 D 7$ is functional, and it can metabolize codeine to morphine with greater efficiency compared to CYP2D6 (88).

The expression of $C Y P 2 D$ in the brain is of particular interest since CYP2D6 could metabolize many centrally active drugs and endogenous substances $(49,82,124,125)$. In addition, neurotoxin MPTP is potent inducer of Parkinson's disease $(38,41)$. Recent studies indicated that CYP2D6 is involved in the detoxification of MPTP, which implies that CYP2D6 may be a susceptibility factor for Parkinsonism as initially suggested by Barbeau et al (4). However, the link between CYP2D6 and Parkinson's disease is controversial. Phenotypic studies have failed to support the relationship between CYP2D6 and Parkinson's disease. The genetic studies initially indicated a link between 
CYP2D6B mutations and Parkinson's disease $(15,71,100)$, but critical analysis of the literature and studies emerging from independent laboratories fail to confirm this (97).

Higher expression of CYP2D6 in brain was detected in alcoholics compared to nonalcoholics, possibly explaining altered sensitivity of alcoholics to centrally acting drugs and to the mediation of neurotoxic and behavioral effects of alcohol (85). The possible endogenous substrates of CYP2D6 in brain were recently investigated in a broad and systematic way by $\mathrm{Yu}$ et al $(86,87)$. In two consecutive papers, the authors describe first that 5-methoxytryptamine, a metabolite and precursor of melatonin, is a specific and high turnover substrate of CYP2D6 that is being converted to serotonin. In the second article, a systematic screen identified two related 5-methoxytryptamines as additional highaffinity, high-capacity, endogenous CYP2D6 substrates. The biological roles of these substrates in the central nervous system are poorly understood (125). To explore the significance of these findings for the control of mood, the origin of psychiatric disorders or the development of personality traits are fascinating directions for future research.

(c). Skin: Several lines of evidence showed that $C Y P 2 D 6$ is most likely expressed in human skin tissues as variants that may have specific roles with respect to the physiology of normal skin and genesis of skin cancers (110). First, clinical studies indicated that CYP2D6 was significantly associated with human skin cancers. Second, BLAST analysis indicated that cDNA of $C Y P 2 D 6$ was present in the EST libraries from human skin tissues (EST name 602634230F1). Third, the messenger RNA of CYP2D6 was found in human skin tissues (123). These results suggest that $C Y P 2 D 6$ is probably expressed as a 
functional form in human skin tissues. However, the genotypes and functions of CYP2D6 in human skin are still unknown since a complete and functional CYP2D6 variant has not yet been obtained.

Ultraviolet B radiation (UVB) is experimentally demonstrated to be the most effective light to induce skin cancer in animals, and can cause DNA damage, particularly cyclobutane pyrimidine dimers (CPDs) and photoproducts which induce mutation in the epidermal cell, and further lead to the development of cancer cells (55). CYP2D6 has the interesting potential to act in opposing biological ways: detoxifying certain lipophilic ultraviolet radiation or activating them to carcinogenic forms (59). Therefore, polymorphism of CYP2D6 is likely to be associated with genetic susceptibility to wide variety of cancers, including melanoma.

There are three well documented inactivating polymorphism at CYP2D6: gene deletion, a splice site mutation and a nucleotide deletion in the coding region $(81,121)$. Wolf et al found that there was no significant difference in the frequency of PMs, but they did observe a significant increase in mutant alleles in the melanoma cohort (119). Strange et al found a significantly higher frequency of mutant alleles and PMs in the melanoma cases. In contrast, Dolzan et al found that there was no increase in mutant CYP2D6 alleles in melanoma cases, but rather a non-significantly lower frequency of poor metabolizers in the melanoma cohort (27). These studies are contradictory to each other, thus it is unclear whether CYP2D6 is related to the genesis of melanoma. Strange 
proposed that CYP2D6 was possibly involved in detoxifying potentially carcinogenic compounds rather than activating certain carcinogens (110).

(d). Lung and other tissues: Data concerning expression of CYP2D6 in lung is still controversial as it was only observed in one study (47) whereas others reported undetectably low levels $(66,96)$. The interesting aspect about a possible pulmonary expression of CYP2D6 is its potential contribution to the in situ activation of lung carcinogens. However, definitive proof for the activation of procarcinogens by CYP2D6 is still lacking and association studies between the CYP2D6 polymorphism and lung cancer risk have been controversial $(11,14,99)$. CYP2D6 mRNA detected by RT-PCR in blood mononuclear cells was reported to be correlated to the in vivo debrisoquine MR (metabolic ratio), suggesting that it might serve as a surrogate marker for systemic drug oxidation capacity (12).

CYP2D6 mRNA was also detected by RT-PCR in human breast and breast tumor tissue (52). If mRNA is being translated into an active enzyme in breast tumors, the enzyme may contribute to the local metabolism of tamoxifen $(17,26)$. A correlation between the amount of mRNA and the in vivo phenotype for debrisoquine hydroxylation was also reported for bladder mucosa and tumor tissue (98). CYP2D6 mRNA was furthermore detected by RT-PCR in the right ventricular tissue of the heart where it may contribute to the metabolism of $\beta$-blockers (112). 


\section{CYP2D6 and Cancer Susceptibility}

Cutaneous basal cell carcinomas (BCCs) are a major burden to health care agencies worldwide. The cancer is the most common in Caucasians and the estimated lifetime risk for a North American child born in 1994 is about 30\% (16, 54, 67, 95). Several studies have identified some relevant genes to BCCs, CYP2D6 is one of the relevant genes, with homozygosity for wild-type alleles (CYP2D6 EM) being associated with BCC risk, although the mechanism is unclear (72).

A significant proportion of human cancers are initiated by environmental chemicals acting as carcinogens. Previous studies showed the relationship between polymorphic CYP2D6 and human pulmonary carcinogenesis. They determined the frequency of PMs and EMs of debrisoquine in Slovene population of healthy individuals $(n=107)$, lung cancer patients $(n=200)$, and melanoma patients $(n=121)$. They indicated that PM individuals appear to be less susceptible to lung cancer than EM individuals $(1,27)$. Other studies have also indicated that PM phenotype is associated with reduced cancer susceptibility, including bladder (6), liver (105), kidney (77) and breast cancer (70). All these findings suggested that there is an influence of genetic polymorphism of $C Y P 2 D 6$ on the susceptibility to cancers, possibly by detoxifying certain chemicals involved in the pathogenesis of cancers or linkage to another cancer-causing gene. Further research may allow the identification of risk factors and contribute towards understanding the molecular mechanisms underlying the process of carcinogenesis. 


\section{Reference List}

1. Agundez, J. A., L. Gallardo, M. C. Ledesma, L. Lozano, A. RodriguezLescure, J. C. Pontes, M. C. Iglesias-Moreno, J. Poch, J. M. Ladero, and J. Benitez. 2001. Functionally active duplications of the CYP2D6 gene are more prevalent among larynx and lung cancer patients. Oncology 61:59-63.

2. Agundez, J. A., M. C. Ledesma, J. M. Ladero, and J. Benitez. 1995. Prevalence of CYP2D6 gene duplication and its repercussion on the oxidative phenotype in a white population. Clin Pharmacol.Ther. 57:265-269.

3. Aklillu, E., I. Persson, L. Bertilsson, I. Johansson, F. Rodrigues, and M. Ingelman-Sundberg. 1996. Frequent distribution of ultrarapid metabolizers of debrisoquine in an ethiopian population carrying duplicated and multiduplicated functional CYP2D6 alleles. J Pharmacol.Exp.Ther. 278:441-446.

4. Barbeau, A., T. Cloutier, M. Roy, L. Plasse, S. Paris, and J. Poirier. 1985. Ecogenetics of Parkinson's disease: 4-hydroxylation of debrisoquine. Lancet 2:1213-1216.

5. Bathum, L., K. Andersen-Ranberg, J. Boldsen, K. Brosen, and B. Jeune. 1998. Genotypes for the cytochrome P450 enzymes CYP2D6 and CYP2C19 in human longevitY. Role of CYP2D6 and CYP2C19 in longevity. Eur.J Clin Pharmacol. 54:427-430.

6. Benitez, J., J. M. Ladero, M. J. Fernandez-Gundin, A. Llerena, J. Cobaleda, C. Martinez, J. J. Munoz, E. Vargas, J. Prados, F. Gonzalez-Rozas, and . 1990. Polymorphic oxidation of debrisoquine in bladder cancer. Ann.Med. 22:157-160.

7. Bertilsson, L., Y. Q. Lou, Y. L. Du, Y. Liu, T. Y. Kuang, X. M. Liao, K. Y. Wang, J. Reviriego, L. Iselius, and F. Sjoqvist. 1992. Pronounced differences between native Chinese and Swedish populations in the polymorphic hydroxylations of debrisoquin and S-mephenytoin. Clin Pharmacol.Ther. 51:388397.

8. Broly, F., A. Gaedigk, M. Heim, M. Eichelbaum, K. Morike, and U. A. Meyer. 1991. Debrisoquine/sparteine hydroxylation genotype and phenotype: analysis of common mutations and alleles of CYP2D6 in a European population. DNA Cell Biol 10:545-558.

9. Brosen, K. 1996. Drug-metabolizing enzymes and therapeutic drug monitoring in psychiatry. Ther.Drug Monit. 18:393-396. 
10. Brynne, N., C. Svanstrom, A. Aberg-Wistedt, B. Hallen, and L. Bertilsson. 1999. Fluoxetine inhibits the metabolism of tolterodine-pharmacokinetic implications and proposed clinical relevance. Br.J Clin Pharmacol. 48:553-563.

11. Caporaso, N., M. R. DeBaun, and N. Rothman. 1995. Lung cancer and CYP2D6 (the debrisoquine polymorphism): sources of heterogeneity in the proposed association. Pharmacogenetics 5 Spec No:S129-S134.

12. Carcillo, J. A., R. A. Parise, A. Adedoyin, R. Frye, R. A. Branch, and M. Romkes. 1996. CYP2D6 mRNA expression in circulating peripheral blood mononuclear cells correlates with in vivo debrisoquine hydroxylase activity in extensive metabolizers. Res Commun.Mol Pathol.Pharmacol. 91:149-159.

13. Cholerton, S., A. K. Daly, and J. R. Idle. 1992. The role of individual human cytochromes P450 in drug metabolism and clinical response. Trends Pharmacol.Sci. 13:434-439.

14. Christensen, P. M., P. C. Gotzsche, and K. Brosen. 1997. The sparteine/debrisoquine (CYP2D6) oxidation polymorphism and the risk of lung cancer: a meta-analysis. Eur.J Clin Pharmacol. 51:389-393.

15. Christensen, P. M., P. C. Gotzsche, and K. Brosen. 1998. The sparteine/debrisoquine (CYP2D6) oxidation polymorphism and the risk of Parkinson's disease: a meta-analysis. Pharmacogenetics 8:473-479.

16. Chuang, T. Y., A. Popescu, W. P. Su, and C. G. Chute. 1990. Basal cell carcinoma. A population-based incidence study in Rochester, Minnesota. J Am.Acad.Dermatol. 22:413-417.

17. Coller, J. K., N. Krebsfaenger, K. Klein, K. Endrizzi, R. Wolbold, T. Lang, A. Nussler, P. Neuhaus, U. M. Zanger, M. Eichelbaum, and T. E. Murdter. 2002. The influence of CYP2B6, CYP2C9 and CYP2D6 genotypes on the formation of the potent antioestrogen Z-4-hydroxy-tamoxifen in human liver. Br.J Clin Pharmacol. 54:157-167.

18. Dahl, M. L., I. Johansson, L. Bertilsson, M. Ingelman-Sundberg, and F. Sjoqvist. 1995. Ultrarapid hydroxylation of debrisoquine in a Swedish population. Analysis of the molecular genetic basis. J Pharmacol.Exp.Ther. 274:516-520.

19. Dalen, P., M. L. Dahl, M. L. Ruiz, J. Nordin, and L. Bertilsson. 1998. 10Hydroxylation of nortriptyline in white persons with $0,1,2,3$, and 13 functional CYP2D6 genes. Clin Pharmacol.Ther. 63:444-452.

20. Daly, A. K. 1995. Molecular basis of polymorphic drug metabolism. J Mol Med. 73:539-553. 
21. Daly, A. K., J. Brockmoller, F. Broly, M. Eichelbaum, W. E. Evans, F. J. Gonzalez, J. D. Huang, J. R. Idle, M. Ingelman-Sundberg, T. Ishizaki, E. Jacqz-Aigrain, U. A. Meyer, D. W. Nebert, V. M. Steen, C. R. Wolf, and U. M. Zanger. 1996. Nomenclature for human CYP2D6 alleles. Pharmacogenetics 6:193-201.

22. Daly, A. K., K. S. Fairbrother, O. A. Andreassen, S. J. London, J. R. Idle, and V. M. Steen. 1996. Characterization and PCR-based detection of two different hybrid CYP2D7P/CYP2D6 alleles associated with the poor metabolizer phenotype. Pharmacogenetics 6:319-328.

23. Daly, A. K., V. M. Steen, K. S. Fairbrother, and J. R. Idle. 1996. CYP2D6 multiallelism. Methods Enzymol. 272:199-210.

24. Dayer, P., A. Kubli, A. Kupfer, F. Courvoisier, L. Balant, and J. Fabre. 1982. Defective hydroxylation of bufuralol associated with side-effects of the drug in poor metabolisers. Br.J Clin Pharmacol. 13:750-752.

25. de Groot, M. J., N. P. Vermeulen, J. D. Kramer, F. A. van Acker, and DonneOp den Kelder GM. 1996. A three-dimensional protein model for human cytochrome P450 2D6 based on the crystal structures of P450 101, P450 102, and P450 108. Chem.Res Toxicol. 9:1079-1091.

26. Dehal, S. S. and D. Kupfer. 1997. CYP2D6 catalyzes tamoxifen 4-hydroxylation in human liver. Cancer Res 57:3402-3406.

27. Dolzan, V., Z. Rudolf, and K. Breskvar. 1995. Human CYP2D6 gene polymorphism in Slovene cancer patients and healthy controls. Carcinogenesis 16:2675-2678.

28. Dorado, P., M. C. Caceres, E. Pozo-Guisado, M. L. Wong, J. Licinio, and A. Llerena. 2005. Development of a PCR-based strategy for CYP2D6 genotyping including gene multiplication of worldwide potential use. Biotechniques 39:571574.

29. Douglas, A. M., B. A. Atchison, A. A. Somogyi, and O. H. Drummer. 1994. Interpretation of a simple PCR analysis of the CYP2D6(A) and CYP2D6(B) null alleles associated with the debrisoquine/sparteine genetic polymorphism. Pharmacogenetics 4:154-158.

30. Eichelbaum, M. 1986. Polymorphic oxidation of debrisoquine and sparteine. Prog.Clin Biol Res 214:157-167.

31. Eichelbaum, M. and A. S. Gross. 1990. The genetic polymorphism of debrisoquine/sparteine metabolism--clinical aspects. Pharmacol.Ther. 46:377-394.

32. Ellis, S. W., G. P. Hayhurst, G. Smith, T. Lightfoot, M. M. Wong, A. P. Simula, M. J. Ackland, M. J. Sternberg, M. S. Lennard, G. T. Tucker, and . 
1995. Evidence that aspartic acid 301 is a critical substrate-contact residue in the active site of cytochrome P450 2D6. J Biol Chem. 270:29055-29058.

33. Endrizzi, K., J. Fischer, K. Klein, M. Schwab, A. Nussler, P. Neuhaus, M. Eichelbaum, and U. M. Zanger. 2002. Discriminative quantification of cytochrome P4502D6 and 2D7/8 pseudogene expression by TaqMan real-time reverse transcriptase polymerase chain reaction. Anal.Biochem. 300:121-131.

34. Evert, B., M. Eichelbaum, H. Haubruck, and U. M. Zanger. 1997. Functional properties of CYP2D6 1 (wild-type) and CYP2D6 7 (His324Pro) expressed by recombinant baculovirus in insect cells. Naunyn Schmiedebergs Arch.Pharmacol. 355:309-318.

35. Febbo, P. G., P. W. Kantoff, E. Giovannucci, M. Brown, G. Chang, C. H. Hennekens, and M. Stampfer. 1998. Debrisoquine hydroxylase (CYP2D6) and prostate cancer. Cancer Epidemiol.Biomarkers Prev. 7:1075-1078.

36. Flanagan, J. U., J. D. Marechal, R. Ward, C. A. Kemp, L. A. McLaughlin, M. J. Sutcliffe, G. C. Roberts, M. J. Paine, and C. R. Wolf. 2004. Phe120 contributes to the regiospecificity of cytochrome P450 2D6: mutation leads to the formation of a novel dextromethorphan metabolite. Biochem J 380:353-360.

37. Fleming, C. M., A. Kaisary, G. R. Wilkinson, P. Smith, and R. A. Branch. 1992. The ability to 4-hydroxylate debrisoquine is related to recurrence of bladder cancer. Pharmacogenetics 2:128-134.

38. Fonne-Pfister, R., M. J. Bargetzi, and U. A. Meyer. 1987. MPTP, the neurotoxin inducing Parkinson's disease, is a potent competitive inhibitor of human and rat cytochrome P450 isozymes (P450bufI, P450db1) catalyzing debrisoquine 4-hydroxylation. Biochem Biophys.Res Commun. 148:1144-1150.

39. Gaedigk, A., M. Blum, R. Gaedigk, M. Eichelbaum, and U. A. Meyer. 1991. Deletion of the entire cytochrome P450 CYP2D6 gene as a cause of impaired drug metabolism in poor metabolizers of the debrisoquine/sparteine polymorphism. Am.J.Hum.Genet. 48:943-950.

40. Gao, Y. and Q. Zhang. 1999. Polymorphisms of the GSTM1 and CYP2D6 genes associated with susceptibility to lung cancer in Chinese. Mutat.Res. 444:441-449.

41. Gilham, D. E., W. Cairns, M. J. Paine, S. Modi, R. Poulsom, G. C. Roberts, and C. R. Wolf. 1997. Metabolism of MPTP by cytochrome P4502D6 and the demonstration of 2D6 mRNA in human foetal and adult brain by in situ hybridization. Xenobiotica 27:111-125.

42. Gillam, E. M., Z. Guo, M. V. Martin, C. M. Jenkins, and F. P. Guengerich. 1995. Expression of cytochrome P450 2D6 in Escherichia coli, purification, and spectral and catalytic characterization. Arch.Biochem Biophys. 319:540-550. 
43. Gonzalez, F. J., R. C. Skoda, S. Kimura, M. Umeno, U. M. Zanger, D. W. Nebert, H. V. Gelboin, J. P. Hardwick, and U. A. Meyer. 1988.

Characterization of the common genetic defect in humans deficient in debrisoquine metabolism. Nature 331:442-446.

44. Gonzalez, F. J., F. Vilbois, J. P. Hardwick, O. W. McBride, D. W. Nebert, H. V. Gelboin, and U. A. Meyer. 1988. Human debrisoquine 4-hydroxylase (P450IID1): cDNA and deduced amino acid sequence and assignment of the CYP2D locus to chromosome 22. Genomics 2:174-179.

45. Gough, A. C., J. S. Miles, N. K. Spurr, J. E. Moss, A. Gaedigk, M. Eichelbaum, and C. R. Wolf. 1990. Identification of the primary gene defect at the cytochrome P450 CYP2D locus. Nature 347:773-776.

46. Griese, E. U., U. M. Zanger, U. Brudermanns, A. Gaedigk, G. Mikus, K. Morike, T. Stuven, and M. Eichelbaum. 1998. Assessment of the predictive power of genotypes for the in-vivo catalytic function of CYP2D6 in a German population. Pharmacogenetics 8:15-26.

47. Guidice, J. M., D. Marez, N. Sabbagh, M. Legrand-Andreoletti, C. Spire, E. Alcaide, J. J. Lafitte, and F. Broly. 1997. Evidence for CYP2D6 expression in human lung. Biochem.Biophys.Res.Commun. 241:79-85.

48. He, N., H. I. Daniel, L. Hajiloo, and D. Shockley. 1999. Dextromethorphan Odemethylation polymorphism in an African-American population. Eur.J Clin Pharmacol. 55:457-459.

49. Hiroi, T., S. Imaoka, and Y. Funae. 1998. Dopamine formation from tyramine by CYP2D6. Biochem.Biophys.Res.Commun. 249:838-843.

50. Hirvonen, A., K. Husgafvel-Pursiainen, S. Anttila, A. Karjalainen, and $H$. Vainio. 1993. Polymorphism in CYP1A1 and CYP2D6 genes: possible association with susceptibility to lung cancer. Environ.Health Perspect. 101 Suppl 3:109-112.

51. Hogstedt, S., B. Lindberg, D. R. Peng, C. G. Regardh, and A. Rane. 1985. Pregnancy-induced increase in metoprolol metabolism. Clin Pharmacol.Ther. 37:688-692.

52. Huang, Z., M. J. Fasco, and L. S. Kaminsky. 1997. Alternative splicing of CYP2D mRNA in human breast tissue. Arch.Biochem.Biophys. 343:101-108.

53. Huang, Z., M. J. Fasco, S. Spivack, and L. S. Kaminsky. 1997. Comparisons of CYP2D messenger RNA splice variant profiles in human lung tumors and normal tissues. Cancer Res. 57:2589-2592. 
54. Hunter, D. J., G. A. Colditz, M. J. Stampfer, B. Rosner, W. C. Willett, and F. E. Speizer. 1990. Risk factors for basal cell carcinoma in a prospective cohort of women. Ann.Epidemiol. 1:13-23.

55. Ichihashi, M., M. Ueda, A. Budiyanto, T. Bito, M. Oka, M. Fukunaga, K. Tsuru, and T. Horikawa. 2003. UV-induced skin damage. Toxicology 189:2139.

56. Ingelman-Sundberg, M. 2005. Genetic polymorphisms of cytochrome P450 2D6 (CYP2D6): clinical consequences, evolutionary aspects and functional diversity. Pharmacogenomics.J 5:6-13.

57. Ingelman-Sundberg, M., M. Oscarson, and R. A. McLellan. 1999. Polymorphic human cytochrome P450 enzymes: an opportunity for individualized drug treatment. Trends Pharmacol.Sci. 20:342-349.

58. Jeppesen, U., L. F. Gram, K. Vistisen, S. Loft, H. E. Poulsen, and K. Brosen. 1996. Dose-dependent inhibition of CYP1A2, CYP2C19 and CYP2D6 by citalopram, fluoxetine, fluvoxamine and paroxetine. Eur.J Clin Pharmacol. 51:7378.

59. Jhappan, C., F. P. Noonan, and G. Merlino. 2003. Ultraviolet radiation and cutaneous malignant melanoma. Oncogene 22:3099-3112.

60. Jurima-Romet, M., B. C. Foster, W. L. Casley, A. Rode, P. Vloshinsky, H. S. Huang, and S. Geertsen. 1997. CYP2D6-related oxidation polymorphism in a Canadian Inuit population. Can.J Physiol Pharmacol. 75:165-172.

61. Kagimoto, M., M. Heim, K. Kagimoto, T. Zeugin, and U. A. Meyer. 1990. Multiple mutations of the human cytochrome P450IID6 gene (CYP2D6) in poor metabolizers of debrisoquine. Study of the functional significance of individual mutations by expression of chimeric genes. J Biol Chem. 265:17209-17214.

62. Kallio, J., R. Lindberg, R. Huupponen, and E. Iisalo. 1988. Debrisoquine oxidation in a Finnish population: the effect of oral contraceptives on the metabolic ratio. Br.J Clin Pharmacol. 26:791-795.

63. Kashuba, A. D., A. N. Nafziger, G. L. Kearns, J. S. Leeder, R. Gotschall, M. L. Rocci, Jr., R. W. Kulawy, D. J. Beck, and J. S. Bertino, Jr. 1998. Effect of fluvoxamine therapy on the activities of CYP1A2, CYP2D6, and CYP3A as determined by phenotyping. Clin Pharmacol.Ther. 64:257-268.

64. Kimura, S., M. Umeno, R. C. Skoda, U. A. Meyer, and F. J. Gonzalez. 1989. The human debrisoquine 4-hydroxylase (CYP2D) locus: sequence and identification of the polymorphic CYP2D6 gene, a related gene, and a pseudogene. Am.J.Hum.Genet. 45:889-904. 
65. Kirchheiner, J., K. Nickchen, M. Bauer, M. L. Wong, J. Licinio, I. Roots, and J. Brockmoller. 2004. Pharmacogenetics of antidepressants and antipsychotics: the contribution of allelic variations to the phenotype of drug response. Mol Psychiatry 9:442-473.

66. Kivisto, K. T., E. U. Griese, T. Stuven, P. Fritz, G. Friedel, H. K. Kroemer, and U. M. Zanger. 1997. Analysis of CYP2D6 expression in human lung: implications for the association between CYP2D6 activity and susceptibility to lung cancer. Pharmacogenetics 7:295-302.

67. Kricker, A., B. K. Armstrong, and D. M. Parkin. 1993. Measurement of skin cancer incidence. Health Rep 5:63-66.

68. Kroemer, H. K., G. Mikus, T. Kronbach, U. A. Meyer, and M. Eichelbaum. 1989. In vitro characterization of the human cytochrome P-450 involved in polymorphic oxidation of propafenone. Clin Pharmacol.Ther. 45:28-33.

69. Kurth, M. C. and J. H. Kurth. 1993. Variant cytochrome P450 CYP2D6 allelic frequencies in Parkinson's disease. Am.J Med.Genet. 48:166-168.

70. Ladero, J. M., J. Benitez, C. Jara, A. Llerena, M. J. Valdivielso, J. J. Munoz, and E. Vargas. 1991. Polymorphic oxidation of debrisoquine in women with breast cancer. Oncology 48:107-110.

71. Landi, M. T., M. Ceroni, E. Martignoni, P. A. Bertazzi, N. E. Caporaso, and G. Nappi. 1996. Gene-environment interaction in parkinson's disease. The case of CYP2D6 gene polymorphism. Adv.Neurol. 69:61-72.

72. Lear, J. T., A. H. Heagerty, A. Smith, B. Bowers, C. R. Payne, C. A. Smith, P. W. Jones, J. Gilford, L. Yengi, J. Alldersea, A. A. Fryer, and R. C. Strange. 1996. Multiple cutaneous basal cell carcinomas: glutathione S-transferase (GSTM1, GSTT1) and cytochrome P450 (CYP2D6, CYP1A1) polymorphisms influence tumour numbers and accrual. Carcinogenesis 17:1891-1896.

73. Lennard, M. S. 1990. Genetic polymorphism of sparteine/debrisoquine oxidation: a reappraisal. Pharmacol.Toxicol. 67:273-283.

74. Lennard, M. S., J. H. Silas, S. Freestone, L. E. Ramsay, G. T. Tucker, and H. F. Woods. 1982. Oxidation phenotype--a major determinant of metoprolol metabolism and response. N.Engl.J Med. 307:1558-1560.

75. Lennard, M. S., J. H. Silas, S. Freestone, and J. Trevethick. 1982. Defective metabolism of metoprolol in poor hydroxylators of debrisoquine. Br.J Clin Pharmacol. 14:301-303.

76. Linder, M. W., R. A. Prough, and R. Valdes, Jr. 1997. Pharmacogenetics: a laboratory tool for optimizing therapeutic efficiency. Clin Chem. 43:254-266. 
77. Longuemaux, S., C. Delomenie, C. Gallou, A. Mejean, M. Vincent-Viry, R. Bouvier, D. Droz, R. Krishnamoorthy, M. M. Galteau, C. Junien, C. Beroud, and J. M. Dupret. 1999. Candidate genetic modifiers of individual susceptibility to renal cell carcinoma: a study of polymorphic human xenobiotic-metabolizing enzymes. Cancer Res 59:2903-2908.

78. Lown, K. S., D. G. Bailey, R. J. Fontana, S. K. Janardan, C. H. Adair, L. A. Fortlage, M. B. Brown, W. Guo, and P. B. Watkins. 1997. Grapefruit juice increases felodipine oral availability in humans by decreasing intestinal CYP3A protein expression. J Clin Invest 99:2545-2553.

79. Madani, S., M. F. Paine, L. Lewis, K. E. Thummel, and D. D. Shen. 1999. Comparison of CYP2D6 content and metoprolol oxidation between microsomes isolated from human livers and small intestines. Pharm.Res 16:1199-1205.

80. Mahgoub, A., J. R. Idle, L. G. Dring, R. Lancaster, and R. L. Smith. 1977. Polymorphic hydroxylation of Debrisoquine in man. Lancet 2:584-586.

81. Marez, D., M. Legrand, N. Sabbagh, J. M. Guidice, C. Spire, J. J. Lafitte, U. A. Meyer, and F. Broly. 1997. Polymorphism of the cytochrome P450 CYP2D6 gene in a European population: characterization of 48 mutations and 53 alleles, their frequencies and evolution. Pharmacogenetics 7:193-202.

82. Martinez, C., J. A. Agundez, G. Gervasini, R. Martin, and J. Benitez. 1997. Tryptamine: a possible endogenous substrate for CYP2D6. Pharmacogenetics 7:85-93.

83. May, D. G. 1994. Genetic differences in drug disposition. J Clin Pharmacol. 34:881-897.

84. McLellan, R. A., M. Oscarson, J. Seidegard, D. A. Evans, and M. IngelmanSundberg. 1997. Frequent occurrence of CYP2D6 gene duplication in Saudi Arabians. Pharmacogenetics 7:187-191.

85. Miksys, S., Y. Rao, E. Hoffmann, D. C. Mash, and R. F. Tyndale. 2002. Regional and cellular expression of CYP2D6 in human brain: higher levels in alcoholics. J Neurochem. 82:1376-1387.

86. Mikus, G., B. Trausch, C. Rodewald, U. Hofmann, K. Richter, T. Gramatte, and M. Eichelbaum. 1997. Effect of codeine on gastrointestinal motility in relation to CYP2D6 phenotype. Clin Pharmacol.Ther. 61:459-466.

87. Modi, S., M. J. Paine, M. J. Sutcliffe, L. Y. Lian, W. U. Primrose, C. R. Wolf, and G. C. Roberts. 1996. A model for human cytochrome P450 2 D6 based on homology modeling and NMR studies of substrate binding. Biochemistry 35:4540-4550. 
88. Pai, H. V., R. P. Kommaddi, S. J. Chinta, T. Mori, M. R. Boyd, and V. Ravindranath. 2004. A frameshift mutation and alternate splicing in human brain generate a functional form of the pseudogene cytochrome P4502D7 that demethylates codeine to morphine. J Biol Chem. 279:27383-27389.

89. Paine, M. J., L. A. McLaughlin, J. U. Flanagan, C. A. Kemp, M. J. Sutcliffe, G. C. Roberts, and C. R. Wolf. 2003. Residues glutamate 216 and aspartate 301 are key determinants of substrate specificity and product regioselectivity in cytochrome P450 2D6. J Biol Chem. 278:4021-4027.

90. Pang, C. P., J. Zhang, J. Woo, D. Chan, L. K. Law, S. F. Tong, T. Kwok, and R. Kay. 1998. Rarity of debrisoquine hydroxylase gene polymorphism in Chinese patients with Parkinson's disease. Mov Disord. 13:529-532.

91. Persson, K., S. Sjostrom, I. Sigurdardottir, V. Molnar, M. HammarlundUdenaes, and A. Rane. 1995. Patient-controlled analgesia (PCA) with codeine for postoperative pain relief in ten extensive metabolisers and one poor metaboliser of dextromethorphan. Br.J Clin Pharmacol. 39:182-186.

92. Poulsen, L., L. Arendt-Nielsen, K. Brosen, and S. H. Sindrup. 1996. The hypoalgesic effect of tramadol in relation to CYP2D6. Clin Pharmacol.Ther. 60:636-644.

93. Prueksaritanont, T., L. M. Dwyer, and A. E. Cribb. 1995. (+)-bufuralol 1'hydroxylation activity in human and rhesus monkey intestine and liver. Biochem Pharmacol. 50:1521-1525.

94. Raimundo, S., J. Fischer, M. Eichelbaum, E. U. Griese, M. Schwab, and U. M. Zanger. 2000. Elucidation of the genetic basis of the common 'intermediate metabolizer' phenotype for drug oxidation by CYP2D6. Pharmacogenetics 10:577-581.

95. Ramachandran, S., J. T. Lear, H. Ramsay, A. G. Smith, B. Bowers, P. E. Hutchinson, P. W. Jones, A. A. Fryer, and R. C. Strange. 1999. Presentation with multiple cutaneous basal cell carcinomas: association of glutathione Stransferase and cytochrome P450 genotypes with clinical phenotype. Cancer Epidemiol.Biomarkers Prev. 8:61-67.

96. Raunio, H., J. Hakkola, J. Hukkanen, O. Pelkonen, R. Edwards, A. Boobis, and S. Anttila. 1998. Expression of xenobiotic-metabolizing cytochrome P450s in human pulmonary tissues. Arch.Toxicol.Suppl 20:465-469.

97. Riedl, A. G., P. M. Watts, P. Jenner, and C. D. Marsden. 1998. P450 enzymes and Parkinson's disease: the story so far. Mov Disord. 13:212-220.

98. Romkes-Sparks, M., A. Mnuskin, H. D. Chern, R. Persad, C. Fleming, G. N. Sibley, P. Smith, G. R. Wilkinson, and R. A. Branch. 1994. Correlation of 
polymorphic expression of CYP2D6 mRNA in bladder mucosa and tumor tissue to in vivo debrisoquine hydroxylase activity. Carcinogenesis 15:1955-1961.

99. Roots, I., J. Brockmoller, N. Drakoulis, and R. Loddenkemper. 1992. Mutant genes of cytochrome P-450IID6, glutathione S-transferase class $\mathrm{Mu}$, and arylamine N-acetyltransferase in lung cancer patients. Clin Investig. 70:307-319.

100. Rostami-Hodjegan, A., M. S. Lennard, H. F. Woods, and G. T. Tucker. 1998. Meta-analysis of studies of the CYP2D6 polymorphism in relation to lung cancer and Parkinson's disease. Pharmacogenetics 8:227-238.

101. Sachse, C., J. Brockmoller, S. Bauer, and I. Roots. 1997. Cytochrome P450 2D6 variants in a Caucasian population: allele frequencies and phenotypic consequences. Am.J Hum.Genet. 60:284-295.

102. Sachse, C., J. Brockmoller, S. Bauer, and I. Roots. 1997. Cytochrome P450 2D6 variants in a Caucasian population: allele frequencies and phenotypic consequences. Am.J Hum.Genet. 60:284-295.

103. Saitoh, T., Y. Xia, X. Chen, E. Masliah, D. Galasko, C. Shults, L. J. Thal, L. A. Hansen, and R. Katzman. 1995. The CYP2D6B mutant allele is overrepresented in the Lewy body variant of Alzheimer's disease. Ann.Neurol. 37:110-112.

104. Siegle, I., P. Fritz, K. Eckhardt, U. M. Zanger, and M. Eichelbaum. 2001. Cellular localization and regional distribution of CYP2D6 mRNA and protein expression in human brain. Pharmacogenetics 11:237-245.

105. Silvestri, L., L. Sonzogni, A. De Silvestri, C. Gritti, L. Foti, C. Zavaglia, M. Leveri, A. Cividini, M. U. Mondelli, E. Civardi, and E. M. Silini. 2003. CYP enzyme polymorphisms and susceptibility to $\mathrm{HCV}$-related chronic liver disease and liver cancer. Int.J Cancer 104:310-317.

106. Smith, C. A., A. C. Gough, P. N. Leigh, B. A. Summers, A. E. Harding, D. M. Maraganore, S. G. Sturman, A. H. Schapira, A. C. Williams, and . 1992. Debrisoquine hydroxylase gene polymorphism and susceptibility to Parkinson's disease. Lancet 339:1375-1377.

107. Smith, D. A. and B. C. Jones. 1992. Speculations on the substrate structureactivity relationship (SSAR) of cytochrome P450 enzymes. Biochem Pharmacol. 44:2089-2098.

108. Sohn, D. R., S. G. Shin, C. W. Park, M. Kusaka, K. Chiba, and T. Ishizaki. 1991. Metoprolol oxidation polymorphism in a Korean population: comparison with native Japanese and Chinese populations. Br.J Clin Pharmacol. 32:504-507.

109. Stefanovic, M., E. Topic, A. M. Ivanisevic, M. Relja, and M. Korsic. 2000. Genotyping of CYP2D6 in Parkinson's disease. Clin Chem.Lab Med. 38:929-934. 
110. Strange, R. C., T. Ellison, F. Ichii-Jones, J. Bath, P. Hoban, J. T. Lear, A. G. Smith, P. E. Hutchinson, J. Osborne, B. Bowers, P. W. Jones, and A. A. Fryer. 1999. Cytochrome P450 CYP2D6 genotypes: association with hair colour, Breslow thickness and melanocyte stimulating hormone receptor alleles in patients with malignant melanoma. Pharmacogenetics 9:269-276.

111. Stuven, T., E. U. Griese, H. K. Kroemer, M. Eichelbaum, and U. M. Zanger. 1996. Rapid detection of CYP2D6 null alleles by long distance- and multiplexpolymerase chain reaction. Pharmacogenetics 6:417-421.

112. Thum, T. and J. Borlak. 2000. Gene expression in distinct regions of the heart. Lancet 355:979-983.

113. Tseng, C. Y., S. L. Wang, M. D. Lai, M. L. Lai, and J. D. Huang. 1996. Formation of morphine from codeine in Chinese subjects of different CYP2D6 genotypes. Clin Pharmacol.Ther. 60:177-182.

114. Tyndale, R., T. Aoyama, F. Broly, T. Matsunaga, T. Inaba, W. Kalow, H. V. Gelboin, U. A. Meyer, and F. J. Gonzalez. 1991. Identification of a new variant CYP2D6 allele lacking the codon encoding Lys-281: possible association with the poor metabolizer phenotype. Pharmacogenetics 1:26-32.

115. Tyndale, R. F., R. Sunahara, T. Inaba, W. Kalow, F. J. Gonzalez, and H. B. Niznik. 1991. Neuronal cytochrome P450IID1 (debrisoquine/sparteine-type): potent inhibition of activity by (-)-cocaine and nucleotide sequence identity to human hepatic P450 gene CYP2D6. Mol Pharmacol. 40:63-68.

116. Voirol, P., M. Jonzier-Perey, F. Porchet, M. J. Reymond, R. C. Janzer, C. Bouras, H. W. Strobel, M. Kosel, C. B. Eap, and P. Baumann. 2000. Cytochrome P-450 activities in human and rat brain microsomes. Brain Res 855:235-243.

117. Wadelius, M., E. Darj, G. Frenne, and A. Rane. 1997. Induction of CYP2D6 in pregnancy. Clin Pharmacol.Ther. 62:400-407.

118. Wolf, C. R., C. A. Smith, T. Bishop, D. Forman, A. C. Gough, and N. K. Spurr. 1994. CYP2D6 genotyping and the association with lung cancer susceptibility. Pharmacogenetics 4:104-106.

119. Wolf, C. R., C. A. Smith, A. C. Gough, J. E. Moss, K. A. Vallis, G. Howard, F. J. Carey, K. Mills, W. McNee, J. Carmichael, and . 1992. Relationship between the debrisoquine hydroxylase polymorphism and cancer susceptibility. Carcinogenesis 13:1035-1038.

120. Wolf, C. R. and G. Smith. 1999. Pharmacogenetics. Br.Med.Bull. 55:366-386. 
121. Woo, S. I., L. A. Hansen, X. Yu, M. Mallory, and E. Masliah. 1999. Alternative splicing patterns of CYP2D genes in human brain and neurodegenerative disorders. Neurology 53:1570-1572.

122. Yamazaki, H., M. Mimura, Y. Oda, Y. Inui, T. Shiraga, K. Iwasaki, F. P. Guengerich, and T. Shimada. 1993. Roles of different forms of cytochrome P450 in the activation of the promutagen 6-aminochrysene to genotoxic metabolites in human liver microsomes. Carcinogenesis 14:1271-1278.

123. Yengi, L. G., Q. Xiang, J. Pan, J. Scatina, J. Kao, S. E. Ball, R. Fruncillo, G. Ferron, and W. C. Roland. 2003. Quantitation of cytochrome P450 mRNA levels in human skin. Anal.Biochem 316:103-110.

124. Yu, A. M., J. R. Idle, L. G. Byrd, K. W. Krausz, A. Kupfer, and F. J. Gonzalez. 2003. Regeneration of serotonin from 5-methoxytryptamine by polymorphic human CYP2D6. Pharmacogenetics 13:173-181.

125. Yu, A. M., J. R. Idle, T. Herraiz, A. Kupfer, and F. J. Gonzalez. 2003. Screening for endogenous substrates reveals that CYP2D6 is a 5methoxyindolethylamine O-demethylase. Pharmacogenetics 13:307-319.

126. Zanger, U. M., S. Raimundo, and M. Eichelbaum. 2004. Cytochrome P450 2D6: overview and update on pharmacology, genetics, biochemistry. Naunyn Schmiedebergs Arch.Pharmacol. 369:23-37.

127. Zeldin, D. C., J. Foley, S. M. Goldsworthy, M. E. Cook, J. E. Boyle, J. Ma, C. R. Moomaw, K. B. Tomer, C. Steenbergen, and S. Wu. 1997. CYP2J subfamily cytochrome P450s in the gastrointestinal tract: expression, localization, and potential functional significance. Mol Pharmacol. 51:931-943. 


\title{
Chapter II
}

\section{Creation, Expression and Functional Analysis of Human Cytochrome P450 2D6 Allelic isoforms}

\author{
Weiyan Zhang, Youbin Tu, Robert L Haining*
}

Department of basic pharmaceutical science, school of pharmacy, Robert C. Byrd Health Sciences Center, West Virginia University, Morgantown, West Virginia 26506

Running title: Human Cytochrome P450

Key words (cytochrome P450/CYP2D6/allelic variants)

* Corresponding author mailing address, Department of basic pharmaceutical science, school of pharmacy, Robert C. Byrd Health Sciences Center, West Virginia University, Morgantown, West Virginia 26506. Phone: (304) 293-1479, Fax: (304) 293- 2576

Electronic mail address: rhaining@hsc.wvu.edu 


\begin{abstract}
CYP2D6 is one of the most important human cytochrome P450s. It is not only involved in the metabolism of a variety of widely used therapeutic drugs, but also is related to certain environment-induced diseases. CYP2D6 shows a very high degree of inter-individual variation, primarily due to its extensive genetic polymorphism. Some alleles and allelic variants of CYP2D6 have been identified in humans. Most alleles have yet to be characterized with respect to enzyme activity and substrate specificity.
\end{abstract}

The objective of our current study is to determine the effects of CYP2D6 allelic isoforms on enzyme activity and substrate specificity. To achieve these goals, four alleles, CYP2D6*24 (encoding the amino acid change I297L), CYP2D6*27 (E410K), CYP2D6*26 (I369T) and CYP2D6*33(A237S) were selected to test if the functional consequences of allelic variation found in human CYP2D6 are substrate-dependent. The genes encoding these allelic isoforms were created by site-directed mutagenesis and further over-expressed in a baculovirus-mediated expression system. The activities of the enzymes were evaluated based on the metabolic rates for dextromethorphan $O$ demethylation, codeine $O$-demethylation and dextromethorphan $N$-demethylation. For DXM $O$-demethylation, 2D6.24 has the highest intrinsic clearance value, as estimated by $\mathrm{Vmax} / \mathrm{Km}$ ratio, followed by 2D6.1, .26 and .27; For codeine $O$-demethylation, CYP2D6.26 and .27 have the same intrinsic clearance, they are around 2-fold higher than wild type CYP2D6 based on Vmax/Km ratio. CYP2D6.24 exhibited lower enzyme efficiency for codeine $O$-demethylation compared to the wild type CYP2D6 and the other 
allelic isoforms. For DXM N-demethylation, CYP2D6.26 and .27 show simple Michaelis-Menten saturation kinetics, but CYP2D6.1 and .24 demonstrate atypical kinetic profiles. Overall the enzymatic consequences of human CYP2D6 allelic variations are substrate dependent. These date provide a solid basis for future epidemiological, clinical as well as interethnic studies of the CYP2D6 polymorphism.

\section{Introduction}

Cytochrome P450 enzymes, a superfamily of heme proteins, are responsible for the oxidative metabolism of a diverse range of xenobiotics and endobiotics (16-18). CYP2D6, one of the first well characterized phase I enzymes, is involved in the oxidation of over 40 commonly prescribed drugs such as antiarrhythmics, antihypertensives, $\beta$ blockers, opioids, antipsychotics and tricyclic antidepressants $(7,12,13,25,37)$. CYP2D6 is polymorphically expressed in the general population, with over 70 known allelic variants (http://www.imm.ki.se/CYPalleles/ cyp2d6.htm). Individuals who take the drugs that are mainly metabolized by CYP2D6 have greatly difference in the occurrence of side effects, therapeutic efficiency and drug interactions $(30,47)$. CYP2D6 also metabolizes certain neurotoxins $(8,11)$, endogenous substances $(35,38)$ and environmental agents such as procarcinogens (4). As a consequence, the expression of CYP2D6 is related to the susceptibility of some human diseases $(11,24,52)$. 
CYP2D6 genetic polymorphism has been linked to four classes of phenotypes based on the extent of drug metabolism. The "Poor Metabolizers" (PM) phenotype is characterized by the inability to use CYP2D6-dependent metabolic pathways for drug elimination, which affect up to $20 \%$ of all clinically used drugs. The "Ultrarapid Metabolizers" (UM) phenotype can be caused by alleles carrying multiple gene copies. "Intermediate Metabolizers" (IM) are severely deficient in their metabolism capacity compared to normal "Extensive Metabolizers" (EM). In contrast to PM, IM express a low amount of residual activity due to the presence of at least one partially deficient allele (34). The difference in metabolism of drugs can lead to severe toxicity or therapeutic failure by altering the relation between dose and blood concentration of pharmacologically active drug or metabolite.

The human $C Y P 2 D$ genes are located on chromosome 22q13.1. CYP2D subfamily includes $C Y P 2 D 6$ and two related genes $C Y P 2 D 7$ and $C Y P 2 D 8 P$ at the $C Y P 2 D$ locus. The three CYP2D genes display 92\%-97\% nucleotide similarities with each other across their introns and exons. CYP2D6 genes consist of 9 exons and 8 introns. CYP2D $8 P$ is a pseudogene with multiple deletions and insertions. The CYP2D7 gene is more similar to CYP2D6 than to CYP2D8P. Its coding sequence contains only a single insertion (T138) mutation in the first exon, which causes a frame shift mutation resulting in the premature translation termination (29). Alternative splicing of these genes has been detected in human liver, lung, brain and breast tissues $(12,15,23,24,52)$. Such alternative splicing could regulate the expression of CYP2D6 protein and result in different $C Y P 2 D$ variants: $\mathbf{a}$ (intron 5 included); b (intron 6 included); b' (3' portion of exon 6 deleted); $\mathbf{c}$ (exon 6 
deleted); d (3' 57-bp portion of intron 6 included); e (3' portion of exon 6 deleted, 3' 57bp potion of intron 6 included) $(23,52)$. Variant c was derived from CYP2D6; variants d, e, and b from CYP2D7; variant b' from both $C Y P 2 D 6$ and $C Y P 2 D 7$. Recent study indicated that an alternatively spliced functional transcript of $C Y P 2 D 7$ containing partial inclusion of intron 6 was identified in human brain but not in liver or kidney from the same individual. This brain variant CYP2D7 can metabolize codeine to morphine with greater efficiency compared to the corresponding activity in cells expressing CYP2D6 (40).

Various CYP2D6 alleles including a point mutation or multiple mutations as well as rearrangements of genes and pseudogenes of the CYP2D6 gene cluster on chromosome have been associated with deficient, decreased or increased enzymatic activity $(9,27)$. Among the over 70 alleles and allelic variants, some of the allelic isoforms such as CYP2D6*2, *10 and *17 have been well studied. The correlation between the presence of 2D6 allelic variants and decreased in vivo capacity for marker reactions was well established $(41,43,55)$. The enzyme efficiencies for the metabolism of each substrate decreased in the order of $2 \mathrm{~d} 6.1>2 \mathrm{~d} 6.2>2 \mathrm{~d} 6.17>2 \mathrm{~d} 6.10(54)$. In some cases, specific ethnic populations appear to correspond with specific metabolize ranges. For example, CYP2D6*2 is mainly present in Caucasian populations $(42,56)$; CYP2D6*10 is present at a high frequency in Asia populations (6, 10, 45, 46, 55); CYP2D6*17 is commonly present in African-Americans and Black Africans (1, 33, 36, 49, 51). 
In this study, we selected four CYP2D6 alleles, CYP2D6*33(A237), CYP2D6*24(I297L), CYP2D6*26(I369T) and CYP2D6*27(E410K), to test the hypothesis that the functional consequences of alleles found in human CYP2D6 are substrate-dependent. The nucleotide substitutions and the combinations of predicted amino acid changes of these alleles are listed in the web site maintained by M. Oscarson (http:// www.imm.ki.se/CYPalleles/cyp2d6.htm). These alleles were constructed from CYP $2 D 6 * 1$ cDNA and over-expressed in a baculovirus expression system. The enzymatic activity of these allelic variations was evaluated by metabolizing two clinically important drugs including dextromethorphan (DXM) and codeine. The results further confirmed that the effects of these allelic variations on enzyme activity are substrate dependent.

\section{Materials and Methods}

\section{Bacterial strains, cell lines and culture conditions: Escherichia coli BMh 71-81}

mutS strain (Clontech) was used for regular amplification of plasmids; E. coli XL1-Blue supercompetent cell (Stratagene) was used to perform site-directed mutagenesis; E. coli DH10B ${ }_{\mathrm{AC}}$ strain (Invitrogen) was used to construct and select recombinant bacmid DNA. The E. coli $\mathrm{BMH} 71-81$ mutS and $\mathrm{DH} 10 \mathrm{~B}_{\mathrm{AC}}$ strains were cultured in Luria Bertani medium and XL1-Blue strain was cultured in $\mathrm{NZY}^{+}$broth at $37^{\circ} \mathrm{C}$. The insect cell line $T$. $n i$ was used for infection of baculovirus and expression of recombinant proteins. The cell line was cultured in SFX-INSECT medium (HyClone) containing 10\% fetal bovine serum at $27^{\circ} \mathrm{C}$. Penicillin-G $(100 \mu \mathrm{g} / \mathrm{ml})$, streptomycin sulfate $(61 \mu \mathrm{g} / \mathrm{ml})$ and ampho- 
terecin-B $(0.6 \mu \mathrm{g} / \mathrm{ml})$ were routinely added to the medium to reduce contamination by bacteria or fungi.

Chemicals: Dextromethorphan, dextrorphan, 3-methoxymorphinan, reduced NADPH were purchased from Sigma/RBI (Natick, MA). Codeine, norcodeine, morphine, trifluoroacetic acid (TFA), and 60\% perchloric acid were purchased from Sigma-Aldrich (St. Louis, MO). Methanol Orthophosphoric acid were purchased from Fischer Scientific.

Electrophoresis, immunoblotting and PCR conditions: Sodim dodecyl sulfatepolyacrylamide gel eletrophoresis (SDS-PAGE) was carried out as previously reported. Monoclonal antibody against CYP2D6 was purchased from BD GeneTest ${ }^{\mathrm{TM}}$. Westernblot assays were performed as previously described, using the Amersham ECL system. For site-directed mutagenesis, the PCR condition is: $95^{\circ} \mathrm{C} 1$ minute for 1 cycle (predenature) followed by $95^{\circ} \mathrm{C} 1$ minute (denature), $55^{\circ} \mathrm{C} 1$ minute (annealing) and $65^{\circ} \mathrm{C} 12$ minutes (elongation) for total 30 cycles. For confirmation of recombinant bacmid DNA and virus, the GeneAmp ${ }^{\circledR}$ XL PCR Kit (Applied Biosystems) was used. The PCR condition is: $94^{\circ} \mathrm{C} 4$ minute for 1 cycle followed by $94^{\circ} \mathrm{C} 45$ seconds, $55^{\circ} \mathrm{C} 45$ seconds and $72^{\circ} \mathrm{C} 5$ minutes for total 35 cycles.

Site-directed mutagenesis and DNA sequencing: Human CYP2D6 cDNA was

obtained from F. Gonzalez (National Cancer Institute, National Institutes of Health, Bethesda, MD) (Gonzalez et. al., 1988). This cDNA sequence was reverted to CYP2D6*I(Yu et al., 2002), which was further subcloned into the plasmid pFastBac I (Invitrogen) at the restriction endonuclease cut sites of Hind III/BamH I and resulted in 
the plasmid $\mathrm{pFB} 2 \mathrm{D} 6 * 1$. The obtained plasmid were used as template to create these alleles by using QuickChange Multi site-directed Mutagenesis Kit according to the manufacture's recommendation (Stratagene). The oligonucleotides for site-directed mutagenesis were listed as the follows: A237S

5'CCCAGCGCTGTCTGGCAAGGTCC3'; I297L 5'GAACCTGCGCCTAGTGGTGGCTG3'; I369T 5'GCTTTGGGGACACCGTCCC CCTGGG3'; E410K 5'GGCCGTCTGGAAGAAGCCCTTCC3'. The resultant constructs pFB2D6*24 (I297L), pFB2D6*26 (I369T), pFB2D6*27 (E410K) and pFB2D6*33 (A237S) were confirmed by DNA sequencing analysis with the following primers: 2D6 (5'-GGATTATTCATA CCGTCC-3'); C82 (5'-CGCTGGGCTGCACGC-3'); C534 (5'GGACAAAGCCGTG AG-3') and C1011 (5'-CGTGATAGGGCAGG-3').

Construction of recombinant baculovirus: To create the recombinant baculovirus, the above constructs were transformed into competent cell $\mathrm{DH} 10 \mathrm{~B}_{\mathrm{AC}}$ containing the bacmid with mini-att $\operatorname{Tn} 7$ target site and the help plasmid as manufacture's recommendation (Invitrogen). The recombinant clones were selected on LB agar plates containing respective antibiotics (kanamycin $50 \mu \mathrm{g} / \mathrm{ml}$, gentamycin $7 \mu \mathrm{g} / \mathrm{ml}$ and tetracycline $10 \mu \mathrm{g} / \mathrm{ml}$ ). After incubating on the LB agar plates for 24 to 48 hours at $37^{\circ} \mathrm{C}$, the white clones containing recombinant bacmid DNA were picked up and transferred into LB medium containing the same antibiotics as LB agar plates. The recombinant bacmid DNA was purified by using DNA Purification System (Promega) and further confirmed by PCR analysis (Figure 2). 
The resultant recombinant bacmid DNA was transfected into the seed T. ni cells (9x10 $T$. ni cells per 35-mm of a 6-well plate) by using GenePORTER ${ }^{\mathrm{TM}}$ transfection reagent (Gene Therapy Systems). The recombinant virus were harvested at 72 hours after transfection and further confirmed by PCR analysis (Figure 3).

Baculovirus-mediated CYP2D6 variants expression: $T$. $n i$ cells were maintained on $100-\mathrm{mm}$ culture dishes (Sarstedt, Newton NC) at $27^{\circ} \mathrm{C}$ using HyQCCM-SFM medium as described previously. Baculovirus stocks were amplified by subsequent "passages" (up to two as necessary to achieve suitably high P450 expression) of viral supernatant onto a new 100-mm dish of $T$. $n i$ with excess (30ml) medium followed by incubation for 7 to 8 days. Suspension culture were inoculated directly from culture dishes and were grown in batches of $250 \mathrm{ml}$ in a 2-liter Erlenmeyer flasks using a spin bar on a magnetic stir platform. Vigorous string was used to reduce cell clumping and to ensure adequate oxygenation of the medium. Infection was carried out at a cell density of 0.8 to $1.6 \times 10^{6}$ cells/ml using 1-10 $\mathrm{ml}$ of amplified viral supernatant. Freshly prepared heme solution (1$5 \mathrm{mg} / \mathrm{ml}$ dissolved in $10 \mathrm{mM} \mathrm{NH}_{4} \mathrm{OH}$ ) was added 2 days postinfection at a 1:1000 dilution (final heme concentration is $1-5 \mu \mathrm{g} / \mathrm{ml}$ ). Cells were pelleted 3 to 4 days postinfection, resuspended and washed once in glycerol-containing buffer $(100 \mathrm{mM}$ potassium phosphate, $20 \%$ glycerol, $0.33 \mathrm{mM}$ dithiothreitol, $1 \mathrm{mM}$ EDTA, PH 7.4), repelleted, and stored at $-80^{\circ} \mathrm{C}$ until further use.

\section{Microsomes preparation and carbon monoxide difference spectroscopy analysis}

of recombinant CYP2D6 variants: $250 \mathrm{ml}$ suspension culture of recombinant $T$. $n i$ cells 
were harvested at $3000 \mathrm{rpm}$ for 10 minutes, the pellets were washed in once in glycerolcontaining buffer (100 Mm potassium phosphate, 20\% glycerol, 0.33 dithiothreitol, $1 \mathrm{mM}$ EDTA, $\mathrm{pH}$ 7.4). The pellets were resuspended in homogenization buffer $(320 \mathrm{mM}$ sucrose, $10 \mathrm{mM} \mathrm{KH}_{2} \mathrm{PO}_{4}, 1 \mathrm{mM}$ EDTA, $1 \mathrm{mM}$ PMSF, $\mathrm{pH}$ 7.4) and further lysated by French Press. Microsomes of recombinant cells were isolated by series of centrifuges at $9,000 \mathrm{rpm}$ and 40,000 rpm. The microsomal pellets were finally resuspended in freezing buffer (100mM Kpi, 20\% (v/v) glycerol, $1 \mathrm{mM}$ EDTA, 1mM PMSF, pH 7.4). In all cases, carbon monoxide difference spectroscopy analysis was used to determine the enzymatic activity and concentration of CYP2D6 variants as previously described (39).

Kinetic studies of CYP2D6 allelic isoforms: Incubation reactions were carried out in $100 \mathrm{mM}$ potassium phosphate buffer (pH 7.4) in a final volume of $200 \mu 1$. , containing CYP2D6 allelic isoforms, P450 reductase, NADPH and substrate. CYP2D6 and exogenous reductase were added together incubated at room temperature for $15 \mathrm{~min}$. Substrate and Kpi buffer were then added and incubated at $37^{\circ} \mathrm{C}$ for $5 \mathrm{~min}$. Reactions were initiated by the addition of NADPH and terminated by the addition of $10 \mu \mathrm{l}$ of $60 \%$ perchloric acid. The mixtures were subjected to centrifugation at 14,000g for $5 \mathrm{~min}$ before HPLC injection and analysis. Dextromethorphan concentrations ranged from 0 to $50 \mu \mathrm{M}$ for the $O$-demethylation reaction, the incubations were carried out for $15 \mathrm{~min}$ at $37^{\circ} \mathrm{C}$. dextromethorphan concentrations ranged from 0 to $10,000 \mu \mathrm{M}$ for $N$-demethylation reaction, the incubations were carried out for $15 \mathrm{~min}$ at $37^{\circ} \mathrm{C}$. Codeine concentrations ranged from 0 to $3000 \mu \mathrm{M}$, and the incubations were carried out for $30 \mathrm{~min}$ at $37^{\circ} \mathrm{C}$. In the current study, the reaction time and the amount of enzyme were determined by pre- 
test. Using fixed substrate concentration and the same amount of enzyme but a series of reaction times carried out the time dependency experiment. The reaction time was selected within linear part. Using fixed substrate concentration and reaction time but different amount of enzyme did the enzyme concentration dependency experiment. The amount of enzyme was selected within the linear part.

Metabolite analyses: HPLC analyses were carried out on a Waters Alliance system (Milford, MA) consisting of the 2690 separation module, the 2487 dual $\lambda$ absorbance detector, and the 474 scanning fluorescence detector. The Alliance HPLC system was controlled with Millennium 32 software. A 4.6 x $250 \mathrm{~mm}, 5 \mathrm{~mm}$ zorbax phenyl column (Agilent Technologies) was used to separate the substrates and the metabolites. The flow rate through the column at room temperature was $1 \mathrm{ml} / \mathrm{min}$. Separation of DXM and its metabolites were achieved with a mobile phase containing $75 \%$ acetonitrile and methanol mixture $(250 / 200, \mathrm{v} / \mathrm{v})$ and $25 \% 10 \mathrm{mM}$ potassium phosphate buffer adjusted to $\mathrm{pH} 3.5$ with orthophosphoric acid. DXM, DXO (dextrorphan) and MEM (3-methoxymorphinan) were eluted at 21.992, 10.597 and 17.313 minutes respectively. The excitation and emission wavelengths, the gain, and the attenuation of the fluorescence detector were set at 280 and $310 \mathrm{~nm}, 10$, and 32, respectively. A mobile phase consisting of 50\% water (with $0.1 \%$ TFA) and 50\% acetonitrile and water (400:600, v/v) was used to separate codeine and its metabolites nor-codeine and morphine, which eluted at 16.891, 12.543 and 7.699 respectively. The excitation and emission wavelengths of the fluorescence detector were set at 280 and $335 \mathrm{~nm}$ for the analysis of codeine and its metabolites. 
Data Analysis and Molecular modeling: Michaelis-Menten Enzyme parameters

( $K_{\mathrm{m}}$ and $V_{\max }$ ) were estimated by nonlinear regression (GraphPad Prism v3.02, GraphPad Software, San Diego, CA). The Homology models of CYP2D6 and its mutants have been achieved from Swiss-Model $(19,44)$. The coordinates of the heme cofactor of $1 \mathrm{pq} 2 \mathrm{~b}$ and the crystal structure of human cytochrome P450 2C8 were used for the homology models. Structural alignments of three homology models were performed in Homology Module of Insight II.

\section{Results}

Creation of cDNA of CYP2D6 alleles: $2 D 6 * 24$ (I297L), 2D6*26 (I369T), 2D6*27

(E410K) and 2D6*33 (A237S). To obtain the cDNA of these alleles, the cDNA of CYP $2 D 6^{*} 1$ was used as template to create these mutations by site-directed mutagenesis. After mutagenesis, the target mutations were confirmed by DNA sequencing analysis with the primers located at the flank region of these mutagenesis sites. As shown in Figure 1, these mutations were successfully created in the respective alleles. For example, ATA (isoleucine) was changed to CTA (lucine) in 2D6*24; ATC (isoleucine) was changed to ACC (threonine) in 2D6*26; GAG (glutamate) was changed to AAG (lysine) in $2 D 6 * 27$; GCT (alanine) was changed to TCT (serine) in $2 D 6 * 33$. In addition, the fulllength cDNA was sequenced in these alleles and the results indicated the mutations only occurred in the target sites (data not shown). 
cDNA expression of the CYP2D6 wild type and four allelic isoforms. The creation of high titer baculovirus stock, the growth of baculovirus, the media conditions, the infection of T.ni cells with baculovirus and the addition of heme were carried out as previously described $(21,53)$. The expression of the $C Y P 2 D 6$ variant cDNA mediated by baculovirus was confirmed by immuno-blot analysis with monoclonal antibody against CYP2D6. As shown in Figure 4, the proteins were successfully expressed in the respective recombinant cell lines but not in the negative control of $T$. $n i$ cell. In addition, the molecular weight of these variant proteins is the same as that of the wild type. These data indicated that the alleles were successfully constructed and expressed in the T. ni cell lines infected by the recombinant baculovirus.

Enzyme analysis of CYP2D6 alleles. At first, the recombinant baculovirus containing the cDNA of these alleles were transfected in $T . n i$ insect cells cultured on serum-fortified plates. The enzymatic activity and yields of CYP2D6 alleles was measured by carbon monoxide difference spectra. The reduced carbon monoxide difference spectra of the expressed protein exhibited Soret maxima at $450 \mathrm{~nm}$ characteristic of $\mathrm{P} 450$, which indicated that the mutation in these four alleles did not resulted in the inactivation of CYP2D6 (Figure 5). In addition, the wild type and these four alleles showed absorbance at $420 \mathrm{~nm}$, indicating the denaturation of some active enzyme.

In order to obtain sufficient quantities of enzyme for enzymatic analysis, the alleles were expressed in suspension cultures as previously described (53). Western-blot and 
carbon monoxide difference spectra analysis indicated that these alleles and the wild type were also successfully expressed in suspension cultures (data not shown). To perform enzymatic analysis, microsomes were isolated from the suspension culture respectively expressing these alleles as previously described $(32,50)$. The activity and concentration of the enzymes was measure by carbon monoxide difference spectra analysis. The results indicated that all the enzymes but 2D6.33 behaved in a chromatographically similar manner throughout the membrane preparation, which means that these enzymes located in microsomes and are still active after preparation (data not shown). However, 2D6.33 failed to produce absorbance at $450 \mathrm{~nm}$. Instead, it showed strong absorbance at $420 \mathrm{~nm}$, which implied that the enzyme might be denatured after preparation due to improper $\mathrm{pH}$ and other unknown factors. Thus, only three alleles were prepared for the kinetic studies.

\section{Dextromethorphan $O$-demethylation by CYP2D6 allelic isoforms. Reconstitution} conditions were described previously (53). Though the addition of lipid is essential for the metabolic turnover of cytochrome P450s, we did not choose it because we use membrane preparation. We set exogenous reductase concentration and 2D6 isoforms at a fixed ration of 2:1 (21). Following incubation (see methods), reaction mixtures were injected directly onto the column for the HPLC assay to identify the metabolites by comparison with retention times of authentic standards. Using the HPLC conditions described, the two metabolites DXO and MEM were eluted at 10.597 minutes and 17.313 minutes respectively, and were verified by fluorescence detection. Kinetic analysis of DXM $O$-demethylation activities was carried out with CYP2D6 allelic isoenzymes (Figure 6). The DXM concentrations range from 0-50 $\mu \mathrm{M}$. At the low concentration the 
mainly metabolite is DXO, and it follows simple Michaelis-Menten saturation kinetics. Kinetic parameters estimated from CYP2D6 alleles ( Km and $\mathrm{Vmax}$ ) are given in Table1. Apparently, for DXM $O$-demethylation, 2D6.24 have the highest intrinsic clearance value, as estimated by $\operatorname{Vmax} / \mathrm{Km}$ ratio, followed by $.1, .26$ and .27 .

Dextromethorphan $N$-demethylation by CYP2D6 alleles. Following the same incubation and HPLC conditions, the $N$-demethylation metabolite 3-MEM was formed from DXM. At the high concentration (the DXM concentration range from $0-10,000$ $\mu \mathrm{M})$, the main metabolite of DXM is 3-MEM, 2D6.26 and 2D6.27 appear to follow simple Michaelis-Menten saturation kinetics (Figure 7c,d). 2D6.1 and 2D6.24 exhibit atypical profile (Figure $7 \mathrm{a}, \mathrm{b}$ ) indicating that there is a second-order relationship between velocity and substrate concentration.

Codeine metabolism by CYP2D6 allelic isoforms. Following the reconstitution conditions, codeine was also used as a substrate to compare catalytic efficiencies of CYP2D6 allelic isoforms. Using the HPLC conditions described (see methods), the metabolites morphine and nor-codeine were clearly separated from substrate codeine. Morphine, nor-codeine and codeine eluted at 7.699, 12.543 and 16.891 minutes respectively. Kinetic analyses of codeine metabolism were carried out with the CYP2D6 allelic isoenzymes. For codeine $O$-demethylation, Michaelis-Menten plots for each allele are shown in Figure 8. Estimated $\mathrm{Km}$ and $V \max$ values for codeine $O$-demethylation are shown in Table 1. CYP2D6.26 and .27 have the same intrinsic clearance, they are around 2 fold higher than wild type CYP2D6 based on $\operatorname{Vmax} / \mathrm{Km}$ ratio. 
Molecular modeling. As shown in Figure 9, the residue I297 locates at the N terminal end of I helix, where is close to the active site of CYP2D6. The residue I369 is in the active site of the enzyme. The residue A237 is in G helix, where affects substrates entering into the active site. The residue E410 is far away from the active site and seems to be on the surface. The molecular modeling analysis is consistent with the kinetic analysis in 2D6.24 and .26 but not in 2D6.27.

\section{Discussion}

Although the molecular basis of the CYP2D6 polymorphism has been extensively investigated, the effects of these mutations in these alleles have not been elucidated in terms of enzymatic activity and metabolism of substrates. The $O$-demethylation of DXM is an established and widely used as an index reaction both in vivo $(2,5,20,48)$ and in vitro $(26,28)$ for the metabolic capacity of cytochrome P450 2D6 due to its relative specificity, safety and over-the-counter availability. Genetic polymorphisms in CYP2D6 result in nonfunctional genotype, thus these patients lack CYP2D6 enzyme ( $7 \%$ of Caucasians). Codeine can be converted to morphine by CYP2D6. However, the CYP2D6 poor metabolizers obtain minimal/no analgesia from codeine, so CYP2D6 PMs seem protected from oral opiate dependence. Studying pharmacogenetics of codeine and CYP2D6 shed light on clinical recommendations, patients with chronic pain to be treated with narcotic analgesics should be CYP2D6 genotyped to identify the PMs, and thus avoid giving them analgesics that will be completely ineffective. 
In the current study, we selected four CYP2D6 alleles to test if these allelic isoforms on enzyme activity are substrate dependent. Dextromethorphan is metabolized to 3methoxymorphinan through $\mathrm{N}$-demethylation as well as dextrorphan through $O$ demethylation by CYP2D6.1. These two metabolites were tested in reactions catalyzed by 2D6.24, .26, and .27. For 2D6.1 and three allelic isoforms, MEM/DXO increased with DXM concentration increasing (Figure 10). This is consistent with previous study reported that the DXM $N$-demethylation product continues to be formed at higher substrate concentration far beyond the point of saturation for the $O$-demethylation reaction (Figure 6). This result indicated the possibility that these reactions are achieved through an alternate binding orientation or active site.

DXM can be converted to DXO through $O$-demethylation and MEM through $N$ demethylation. In 2D6.24, isoleucine is replaced by leucine. Because MEM/DXO ratio increased with DXM concentration increasing, and MEM/DXO ratio produced by 2D6.24 is higher than MEM/DXO ratio produced by 2D6.1 (Figure 10), it can be predicted that residue isoleucine may play a role in dictating substrate orientation within the active site of CYP2D6. In 2D6.26, isoleucine is replaced by threonine, the hydrophobic amino acid (Ile) is changed to hydrophilic amino acid (Thr). In 2D6.27, glutamic acid is replaced by lysine, the negative charged rsidue (Glu) is changed to positive charged residue (Lys). According to amino acid structures, we can predict that CYP2D6.26 and .27 may have effect on enzyme activity. Based on our experimental results, CYP2D6.24 has higher enzyme efficiency for DXM $O$-demethylation compared to 2D6.1. 2D6.26 and .27 have 
the same intrinsic clearance for codeine $O$-demethylation, they are 2-fold higher than 2D6.1 based on $V / K$ ration.

In this study, membrane preparation wild type CYP2D6 formed DXO as the major metabolite with a $K m$ of $0.60 \pm 0.16 \mu \mathrm{M}$ and a $V \max$ of $0.73 \pm 0.04 \mathrm{pmol} / \mathrm{pmol} / \mathrm{min}$ (Table1). Ching (3) measured a $K m$ of $5.4 \mu \mathrm{M}$ and $V \max$ of $0.47 \mathrm{nmol} / \mathrm{nmol} / \mathrm{min}$ by using the extract of a yeast expression system containing CYP2D6*1 cDNA, which is similar to the $K m$ value of $8.5 \mu \mathrm{M}$ and $V \max$ of $0.7 \mathrm{nmol} / \mathrm{nmol} / \mathrm{min}$ reported by Krynetski et al. (31). Yu et al. also indicated a $K m$ of $6.2 \mu \mathrm{M}$ and $V \max$ of $14 \mathrm{nmol} / \mathrm{nmol} / \mathrm{min}$ with purified 2D6 and there was a steady decline in the apparent $K m$ and leveling off of $V \max$ using a relatively short assay time (53). Overall, there are many factors that might affect the values for the kinetics of dextromethorphan $O$-demethylation, e.g. different expression systems, different assay time and whether it is purified enzyme or membrane preparation.

In the current work, we found that these three allelic isoforms produce more morphine than nor-codeine compared to the wild type CYP2D6, which produces more nor-codeine than morphine, I369T exhibited higher enzyme efficiency for codeine $O$ demethylation than codeine $N$-demethylation compared to the wild type CYP2D6 and other alleles. However, according to the Michaelis-Menten curves, the formation of norcodeine reaches to saturation quickly, it does not show very good Michaelis-Menten kinetics (data not shown). One reason may be due to the higher substrate concentration since it is critical that kinetic studies should be performed at physiologically relevant substrate concentrations in order to relate in vitro findings to the clinical setting. 
Theoretically, about $10 \%$ of a dose of codeine is converted to morphine in the body by CYP2D6, a dose of approximately $200 \mathrm{mg}$ (oral) of codeine must be administered to give equivalent analgesia to $30 \mathrm{mg}$ (oral) of morphine (22). It is not used, however, in single doses of greater than $60 \mathrm{mg}$ (and no more than $240 \mathrm{mg}$ in 24 hours) since there is a ceiling effect. In this study, the concentration of codeine ranges from 0-3000 $\mu \mathrm{M}$, and we use membrane preparations that are not the purified enzyme and they may need higher substrate concentration to get good Mechaelis-Menten curves.

Gotoh provided six separate regions that were tentatively assigned as substrate recognition sites (SRSs) in CYP2D proteins according to the sequence alignment between representative CYP2D members and P450 101A. These sites include B' and flanking areas (103-126), the C-terminal end of Helix F (209-216), the N-terminal end of Helix G (248-255), the N-terminal half of Helix I (302-320), the 3 area (378-385) and a central region of 5 (485-493) (14). None of the mutations in these alleles locates at those regions, which suggested that these nucleotide substitutions probably do not influence the binding of specific substrates. This speculation is not consistent with our experimental results since these allelic isoforms except for CYP2D6.27 showed difference with the wild type CYP2D6 in terms of the intrinsic clearance of these two substrates.

CYP2D6.24 is around 5 fold higher than CYP2D6.1 in terms of the metabolism of dextromethorphan (Table1). According to the structural model of CYP2D6, the mutation in CYP2D6.24 is located at the end of I helix (Figure 9), which may affect I helix and further influence the binding specificity of dextromethorphan. However, it has no effect on codeine binding. The 2D6.26 shows 2 -fold increase in the $O$-demethylation of codeine 
but not for DXM (Table 1). Based on molecular modeling analysis, 2D6.26 is located in the active site, which may influence codeine binding but not on dextromorphan metabolism. These results imply that the effect of these allelic variations on enzyme activity is substrate dependent. 2D6.27 has the same enzyme efficiency as 2D6.26 for codeine $O$-demethylation. This result is not consistent with molecular modeling analysis because the substitute residue E410 in 2D6.27 is far away from active site. Molecular docking study may be necessary for further study. For 2D6.33, mutation from $\mathrm{A} \rightarrow \mathrm{S}$ will change the hydrophobic propensity and further affect the stability of the secondary and tertiary structure, this might be one of the reasons that this enzyme is not stable during membrane preparation process.

In summary, there are several strategies and methods for CYP2D6 genotyping, such as PCR-SSCP, real-time PCR, microarrays for DNA analysis, TaqMan real-time PCR, and XL-PCR and PCR-RFLP. CYP2D6 genotyping is a useful tool in clinical medicine. At the meantime, the analysis of the various new mutations and alleles should lead to more information regarding their consequences on catalytic activity and substrate specificity of the CYP2D6 enzyme. In current study, CYP2D6.24 exhibited higher enzyme efficiency (estimated as $\operatorname{Vmax} / K_{m}$ ) for dextromethorphan $O$-demethylation compared to the wild type CYP2D6 and the other allelic isoforms. 2D6.26 and 2D6.27 showed higher enzyme efficiency for codeine $O$-demethylation compared to 2D6.1. Molecular modeling results indicated that residues I297 and I369 were located in the 
active site of 2D6 homology model, mutations (I297L) and (I369T) of these residues may affect substrate binding and further affect drug metabolism.

\section{Figure legends}

\section{Figure 1}

Creation of four alleles confirmed by DNA sequencing analysis. Four alleles were constructed based on CYP2D6*1 cDNA by site-directed mutagenesis. Four primers were used for sequence, 2D6 5', C82, C534 and C1011. A changed to C in CYP2D6*24 (I297L); T changed to C in CYP2D6*26 (I369T); G changed to A in CYP2D6*27 (E410k) and $\mathrm{G}$ changed to $\mathrm{T}$ in CYP2D*33 (A237S).

\section{Figure 2}

Generation of recombinant bacmid DNA. Four constructed alleles (in pFastBac I) were transformed into DH10Bac competent cells, these cells contain bacmid DNA. Recombinant bacmid DNA can be obtained after homogeneous recombination.

\section{Figure 3}

Confirmation of recombinant bacmid DNA by PCR. The recombinant bacmid DNAs were confirmed by PCR. For PCR reaction, the forward primer is 2D6 5'that can bind to 2D6 gene, the reverse primer is M13 reverse that can bind to bacmid DNA. The PCR condition is: $94^{\circ} \mathrm{C} 4$ minute for 1 cycle followed by $94^{\circ} \mathrm{C} 45$ seconds, $55^{\circ} \mathrm{C} 45$ seconds and $72^{\circ} \mathrm{C} 5$ minutes for total 35 cycles. The size of PCR product is $2074 \mathrm{bps}$. 


\section{Figure 4}

Analysis of four allelic variations by western blot. The four constructed alleles were over-expressed in T.ni insect cells using baculovirus expression system. The expressed protein were separated by SDS-PAGE, proteins were transferred into PVDF membrane. CYP2D6 monoclonal antibody was used for western blot.

\section{Figure 5}

Carbon monoxide difference spectroscopy of CYP2D6 allelic isoforms. Spectra were determined by the method of Omura and Sato (1964).

\section{Figure 6}

Dextromethorphan $\boldsymbol{O}$-demethylation by CYP2D6 allelic isoforms. Mmebrane

preparations of wild type CYP2D6 and the three allelic variants were isolated from insect cells. The enzymes were individually reconstituted in an environment with cytochrome P450 reductase and different concentrations of dextromethorphan (DXM). DXM concentration ranges from 0 to $50 \mu \mathrm{M}$. Reactions were initiated by the addition of NADPH and terminated by the addition of $60 \%$ perchloric acid. Michaelis-menten curves showed the rates of DXO formation from DXM catalyzed by the wild type CYP2D6.1 and CYP2D6.24, .26 and .27. • CYP2D6.1 (WT); $\nabla$, CYP2D6.24 (I297L); CYP2D6.26 (I369T); $\Delta$, CYP2D6.27 (E410K). 


\section{Figure 7}

Dextromethorphan $N$-demethylation by CYP2D6 allelic isoforms. The enzymes of CYP2D6.1 and three allelic isoforms were individually reconstituted in an environment with cytochrome P450 reductase and DXM. DXM concentration ranges from 0 to 10,000 $\mu \mathrm{M}$. the reactions were initiated by the addition of NADPH and terminated by the addition of $60 \%$ perchloric acid. Michaelis-menten curves showed the rates of MEM formation from DXM by CYP2D6.26 (Figure 7c) and CYP2D6.27 (Figure 7d). CYP2D6.1 (Figure 7a) and CYP2D6.24 (Figure 7b) exhibited atypical kinetic profiles.

\section{Figure 8}

Codeine $\boldsymbol{O}$-demethylation by CYP2D6 allelic isoforms. The enzymes of CYP2D6.1 and three allelic isoforms were individually reconstituted in an environment with cytochrome $\mathrm{P} 450$ reductase and codeine. Codeine concentration ranges from 0 to 3,000 $\mu \mathrm{M}$. the reactions were initiated by the addition of NADPH and terminated by the addition of $60 \%$ perchloric acid. Michaelis-menten curves showed the rates of morphine formation from codeine catalyzed by the wild type CYP2D6.1 and CYP2D6.24, .26, and .27. • , CYP2D6.1 (WT); $\nabla$, CYP2D6.24 (I297L); •, CYP2D6.26 (I369T); $\Delta$, CYP2D6.27 (E410K).

Figure 9

CYP2D6 homology model with four mutation sites marked. The Homology models of CYP2D6 and its allelic variations have been achieved from Swiss-Mode. The coordinates of the heme cofactor of $1 \mathrm{pq} 2 \mathrm{~b}$ and the crystal structure of human cytochrome $\mathrm{P} 4502 \mathrm{C} 8$ 
were used for the homology models. Structural alignments of four homology models were performed in Homology Module of Insight II. I297L (CYP2D6.24) and I369T (CYP2D6.26) are located in the active site of 2D6.1 homology model, 2D6.24 is located in I helix. A237S (CYP2D6.33) is located in G helix. E410K (CYP2D6.27) is located on the surface. Heme is indicated in red.

Figure 10

Ratio of MEM and DXO produced by CYP2D6.1 and three allelic isoforms. DXM concentration ranges from 0 to $10,000 \mu \mathrm{M}$ for dextromethorrphan $N$-demethylation. Three concentrations $(1000,1700$, and $2500 \mu \mathrm{M})$ were selected to determine the ratio of MEM ( $N$-demethylation product) and DXO ( $O$-demethylation product) catalyzed by CYP2D6.1 and three allelic isoforms. Different color represents different substrate concentration.

\author{
Reference List
}

1. Aklillu, E., I. Persson, L. Bertilsson, I. Johansson, F. Rodrigues, and M. Ingelman-Sundberg. 1996. Frequent distribution of ultrarapid metabolizers of debrisoquine in an ethiopian population carrying duplicated and multiduplicated functional CYP2D6 alleles. J Pharmacol.Exp.Ther. 278:441-446.

2. Baumann, P., J. W. Meyer, M. Amey, D. Baettig, C. Bryois, M. JonzierPerey, L. Koeb, C. Monney, and B. Woggon. 1992. Dextromethorphan and mephenytoin phenotyping of patients treated with thioridazine or amitriptyline. Ther.Drug Monit. 14:1-8.

3. Ching, M. S., C. L. Blake, H. Ghabrial, S. W. Ellis, M. S. Lennard, G. T. Tucker, and R. A. Smallwood. 1995. Potent inhibition of yeast-expressed CYP2D6 by dihydroquinidine, quinidine, and its metabolites. Biochem Pharmacol. 50:833-837.

4. Crespi, C. L., B. W. Penman, H. V. Gelboin, and F. J. Gonzalez. 1991. A tobacco smoke-derived nitrosamine, 4-(methylnitrosamino)-1-(3-pyridyl)-1- 
butanone, is activated by multiple human cytochrome P450s including the polymorphic human cytochrome P4502D6. Carcinogenesis 12:1197-1201.

5. Dayer, P., J. Desmeules, T. Leemann, and R. Striberni. 1988. Bioactivation of the narcotic drug codeine in human liver is mediated by the polymorphic monooxygenase catalyzing debrisoquine 4-hydroxylation (cytochrome P-450 dbl/bufI). Biochem Biophys.Res Commun. 152:411-416.

6. Droll, K., K. Bruce-Mensah, S. V. Otton, A. Gaedigk, E. M. Sellers, and R. F. Tyndale. 1998. Comparison of three CYP2D6 probe substrates and genotype in Ghanaians, Chinese and Caucasians. Pharmacogenetics 8:325-333.

7. Evans, W. E. and M. V. Relling. 1999. Pharmacogenomics: translating functional genomics into rational therapeutics. Science 286:487-491.

8. Fonne-Pfister, R., M. J. Bargetzi, and U. A. Meyer. 1987. MPTP, the neurotoxin inducing Parkinson's disease, is a potent competitive inhibitor of human and rat cytochrome P450 isozymes (P450bufI, P450db1) catalyzing debrisoquine 4-hydroxylation. Biochem Biophys.Res Commun. 148:1144-1150.

9. Gaedigk, A., M. Blum, R. Gaedigk, M. Eichelbaum, and U. A. Meyer. 1991. Deletion of the entire cytochrome P450 CYP2D6 gene as a cause of impaired drug metabolism in poor metabolizers of the debrisoquine/sparteine polymorphism. Am.J.Hum.Genet. 48:943-950.

10. Garcia-Barcelo, M., L. Y. Chow, H. F. Chiu, Y. K. Wing, D. T. Lee, K. L. Lam, and M. M. Waye. 2000. Genetic analysis of the CYP2D6 locus in a Hong Kong Chinese population. Clin Chem. 46:18-23.

11. Gilham, D. E., W. Cairns, M. J. Paine, S. Modi, R. Poulsom, G. C. Roberts, and C. R. Wolf. 1997. Metabolism of MPTP by cytochrome P4502D6 and the demonstration of 2D6 mRNA in human foetal and adult brain by in situ hybridization. Xenobiotica 27:111-125.

12. Gonzalez, F. J., R. C. Skoda, S. Kimura, M. Umeno, U. M. Zanger, D. W. Nebert, H. V. Gelboin, J. P. Hardwick, and U. A. Meyer. 1988.

Characterization of the common genetic defect in humans deficient in debrisoquine metabolism. Nature 331:442-446.

13. Gonzalez, M. V., V. Alvarez, M. F. Pello, M. J. Menendez, C. Suarez, and E. Coto. 1998. Genetic polymorphism of N-acetyltransferase-2, glutathione Stransferase-M1, and cytochromes P450IIE1 and P450IID6 in the susceptibility to head and neck cancer. J Clin Pathol. 51:294-298.

14. Gotoh, O. 1992. Substrate recognition sites in cytochrome P450 family 2 (CYP2) proteins inferred from comparative analyses of amino acid and coding nucleotide sequences. J Biol Chem. 267:83-90. 
15. Gough, A. C., J. S. Miles, N. K. Spurr, J. E. Moss, A. Gaedigk, M. Eichelbaum, and C. R. Wolf. 1990. Identification of the primary gene defect at the cytochrome P450 CYP2D locus. Nature 347:773-776.

16. Guengerich, F. P. 1995. Influence of nutrients and other dietary materials on cytochrome P-450 enzymes. Am.J Clin Nutr. 61:651S-658S.

17. Guengerich, F. P. 1997. Role of cytochrome P450 enzymes in drug-drug interactions. Adv.Pharmacol. 43:7-35.

18. Guengerich, F. P. 2001. Common and uncommon cytochrome P450 reactions related to metabolism and chemical toxicity. Chem.Res Toxicol. 14:611-650.

19. Guex, N. and M. C. Peitsch. 1997. SWISS-MODEL and the Swiss-PdbViewer: an environment for comparative protein modeling. Electrophoresis 18:2714-2723.

20. Guttendorf, R. J., P. J. Wedlund, J. Blake, and S. L. Chang. 1988. Simplified phenotyping with dextromethorphan by thin-layer chromatography: application to clinical laboratory screening for deficiencies in oxidative drug metabolism. Ther.Drug Monit. 10:490-498.

21. Haining, R. L., A. P. Hunter, M. E. Veronese, W. F. Trager, and A. E. Rettie. 1996. Allelic variants of human cytochrome P450 2C9: baculovirus-mediated expression, purification, structural characterization, substrate stereoselectivity, and prochiral selectivity of the wild-type and I359L mutant forms. Arch.Biochem Biophys. 333:447-458.

22. Hopkins, E., G. Rossi, and B. Kest. 2004. Sex differences in systemic morphine analgesic tolerance following intrathecal morphine injections. Brain Res 1014:244-246.

23. Huang, Z., M. J. Fasco, and L. S. Kaminsky. 1997. Alternative splicing of CYP2D mRNA in human breast tissue. Arch.Biochem.Biophys. 343:101-108.

24. Huang, Z., M. J. Fasco, S. Spivack, and L. S. Kaminsky. 1997. Comparisons of CYP2D messenger RNA splice variant profiles in human lung tumors and normal tissues. Cancer Res. 57:2589-2592.

25. Idle, J. R. and R. L. Smith. 1979. Polymorphisms of oxidation at carbon centers of drugs and their clinical significance. Drug Metab Rev 9:301-317.

26. Jacqz-Aigrain, E., C. Funck-Brentano, and T. Cresteil. 1993. CY. Pharmacogenetics 3:197-204.

27. Kagimoto, M., M. Heim, K. Kagimoto, T. Zeugin, and U. A. Meyer. 1990. Multiple mutations of the human cytochrome P450IID6 gene (CYP2D6) in poor metabolizers of debrisoquine. Study of the functional significance of individual mutations by expression of chimeric genes. J Biol Chem. 265:17209-17214. 
28. Kerry, N. L., A. A. Somogyi, G. Mikus, and F. Bochner. 1993. Primary and secondary oxidative metabolism of dextromethorphan. In vitro studies with female Sprague-Dawley and Dark Agouti rat liver microsomes. Biochem Pharmacol. 45:833-839.

29. Kimura, S., M. Umeno, R. C. Skoda, U. A. Meyer, and F. J. Gonzalez. 1989. The human debrisoquine 4-hydroxylase (CYP2D) locus: sequence and identification of the polymorphic CYP2D6 gene, a related gene, and a pseudogene. Am.J.Hum.Genet. 45:889-904.

30. Kroemer, H. K. and M. Eichelbaum. 1995. "It's the genes, stupid". Molecular bases and clinical consequences of genetic cytochrome P450 2D6 polymorphism. Life Sci. 56:2285-2298.

31. Krynetski, E. Y., V. L. Drutsa, I. E. Kovaleva, and V. N. Luzikov. 1995. High yield expression of functionally active human liver CYP2D6 in yeast cells. Pharmacogenetics 5:103-109.

32. Lang, T., K. Klein, T. Richter, A. Zibat, R. Kerb, M. Eichelbaum, M. Schwab, and U. M. Zanger. 2004. Multiple novel nonsynonymous CYP2B6 gene polymorphisms in Caucasians: demonstration of phenotypic null alleles. $\mathrm{J}$ Pharmacol.Exp.Ther. 311:34-43.

33. Leathart, J. B., S. J. London, A. Steward, J. D. Adams, J. R. Idle, and A. K. Daly. 1998. CYP2D6 phenotype-genotype relationships in African-Americans and Caucasians in Los Angeles. Pharmacogenetics 8:529-541.

34. Linder, M. W., R. A. Prough, and R. Valdes, Jr. 1997. Pharmacogenetics: a laboratory tool for optimizing therapeutic efficiency. Clin Chem. 43:254-266.

35. LLerena, A., G. Edman, J. Cobaleda, J. Benitez, D. Schalling, and L. Bertilsson. 1993. Relationship between personality and debrisoquine hydroxylation capacity. Suggestion of an endogenous neuroactive substrate or product of the cytochrome P4502D6. Acta Psychiatr.Scand. 87:23-28.

36. Masimirembwa, C., I. Persson, L. Bertilsson, J. Hasler, and M. IngelmanSundberg. 1996. A novel mutant variant of the CYP2D6 gene (CYP2D6*17) common in a black African population: association with diminished debrisoquine hydroxylase activity. Br.J Clin Pharmacol. 42:713-719.

37. Nebert, D. W. 1997. Polymorphisms in drug-metabolizing enzymes: what is their clinical relevance and why do they exist? Am.J Hum.Genet. 60:265-271.

38. Niznik, H. B., R. F. Tyndale, F. R. Sallee, F. J. Gonzalez, J. P. Hardwick, T. Inaba, and W. Kalow. 1990. The dopamine transporter and cytochrome P45OIID1 (debrisoquine 4-hydroxylase) in brain: resolution and identification of two distinct $[3 \mathrm{H}] \mathrm{GBR}-12935$ binding proteins. Arch.Biochem Biophys. 276:424432. 
39. OMURA, T. and R. SATO. 1964 . THE CARBON MONOXIDE-BINDING PIGMENT OF LIVER MICROSOMES. I. EVIDENCE FOR ITS HEMOPROTEIN NATURE. J Biol Chem. 239:2370-2378.

40. Pai, H. V., R. P. Kommaddi, S. J. Chinta, T. Mori, M. R. Boyd, and V. Ravindranath. 2004. A frame shift mutation and alternate splicing in human brain generates a functional form of the pseudogene, cytochrome P4502D7 that demethylates codeine to morphine. J.Biol.Chem.

41. Panserat, S., L. Sica, N. Gerard, H. Mathieu, E. Jacqz-Aigrain, and R. Krishnamoorthy. 1999. CYP2D6 polymorphism in a Gabonese population: contribution of the CYP2D6*2 and CYP2D6*17 alleles to the high prevalence of the intermediate metabolic phenotype. Br.J Clin Pharmacol. 47:121-124.

42. Raimundo, S., J. Fischer, M. Eichelbaum, E. U. Griese, M. Schwab, and U. M. Zanger. 2000. Elucidation of the genetic basis of the common 'intermediate metabolizer' phenotype for drug oxidation by CYP2D6. Pharmacogenetics 10:577-581.

43. Sachse, C., J. Brockmoller, S. Bauer, and I. Roots. 1997. Cytochrome P450 2D6 variants in a Caucasian population: allele frequencies and phenotypic consequences. Am.J Hum.Genet. 60:284-295.

44. Schwede, T., J. Kopp, N. Guex, and M. C. Peitsch. 2003. SWISS-MODEL: An automated protein homology-modeling server. Nucleic Acids Res 31:3381-3385.

45. Tateishi, T., M. Chida, N. Ariyoshi, Y. Mizorogi, T. Kamataki, and S. Kobayashi. 1999. Analysis of the CYP2D6 gene in relation to dextromethorphan O-demethylation capacity in a Japanese population. Clin Pharmacol.Ther. 65:570575.

46. Teh, L. K., R. Ismail, R. Yusoff, A. Hussein, M. N. Isa, and A. R. Rahman. 2001. Heterogeneity of the CYP2D6 gene among Malays in Malaysia. J Clin Pharm.Ther. 26:205-211.

47. Tucker, G. T., M. S. Lennard, S. W. Ellis, H. F. Woods, A. K. Cho, L. Y. Lin, A. Hiratsuka, D. A. Schmitz, and T. Y. Chu. 1994. The demethylenation of methylenedioxymethamphetamine ("ecstasy") by debrisoquine hydroxylase (CYP2D6). Biochem Pharmacol. 47:1151-1156.

48. Walker, J. and L. N. Yatham. 1993. Benylin (dextromethorphan) abuse and mania. BMJ 306:896.

49. Wan, Y. J., R. E. Poland, G. Han, T. Konishi, Y. P. Zheng, N. Berman, and K. M. Lin. 2001. Analysis of the CYP2D6 gene polymorphism and enzyme activity in African-Americans in southern California. Pharmacogenetics 11:489499. 
50. Wang, M. H., E. Brand-Schieber, B. A. Zand, X. Nguyen, J. R. Falck, N. Balu, and M. L. Schwartzman. 1998. Cytochrome P450-derived arachidonic acid metabolism in the rat kidney: characterization of selective inhibitors. J Pharmacol.Exp.Ther. 284:966-973.

51. Wennerholm, A., I. Johansson, A. Y. Massele, M. Lande, C. Alm, Y. AdenAbdi, M. L. Dahl, M. Ingelman-Sundberg, L. Bertilsson, and L. L. Gustafsson. 1999. Decreased capacity for debrisoquine metabolism among black Tanzanians: analyses of the CYP2D6 genotype and phenotype. Pharmacogenetics 9:707-714.

52. Woo, S. I., L. A. Hansen, X. Yu, M. Mallory, and E. Masliah. 1999. Alternative splicing patterns of CYP2D genes in human brain and neurodegenerative disorders. Neurology 53:1570-1572.

53. Yu, A., H. Dong, D. Lang, and R. L. Haining. 2001. Characterization of dextromethorphan $\mathrm{O}$ - and $\mathrm{N}$-demethylation catalyzed by highly purified recombinant human CYP2D6. Drug Metab Dispos. 29:1362-1365.

54. Yu, A., B. M. Kneller, A. E. Rettie, and R. L. Haining. 2002. Expression, purification, biochemical characterization, and comparative function of human cytochrome P450 2D6.1, 2D6.2, 2D6.10, and 2D6.17 allelic isoforms. J Pharmacol.Exp.Ther. 303:1291-1300.

55. Zanger, U. M., J. Fischer, S. Raimundo, T. Stuven, B. O. Evert, M. Schwab, and M. Eichelbaum. 2001. Comprehensive analysis of the genetic factors determining expression and function of hepatic CYP2D6. Pharmacogenetics 11:573-585.

56. Zanger, U. M., S. Raimundo, and M. Eichelbaum. 2004. Cytochrome P450 2D6: overview and update on pharmacology, genetics, biochemistry. Naunyn Schmiedebergs Arch.Pharmacol. 369:23-37. 


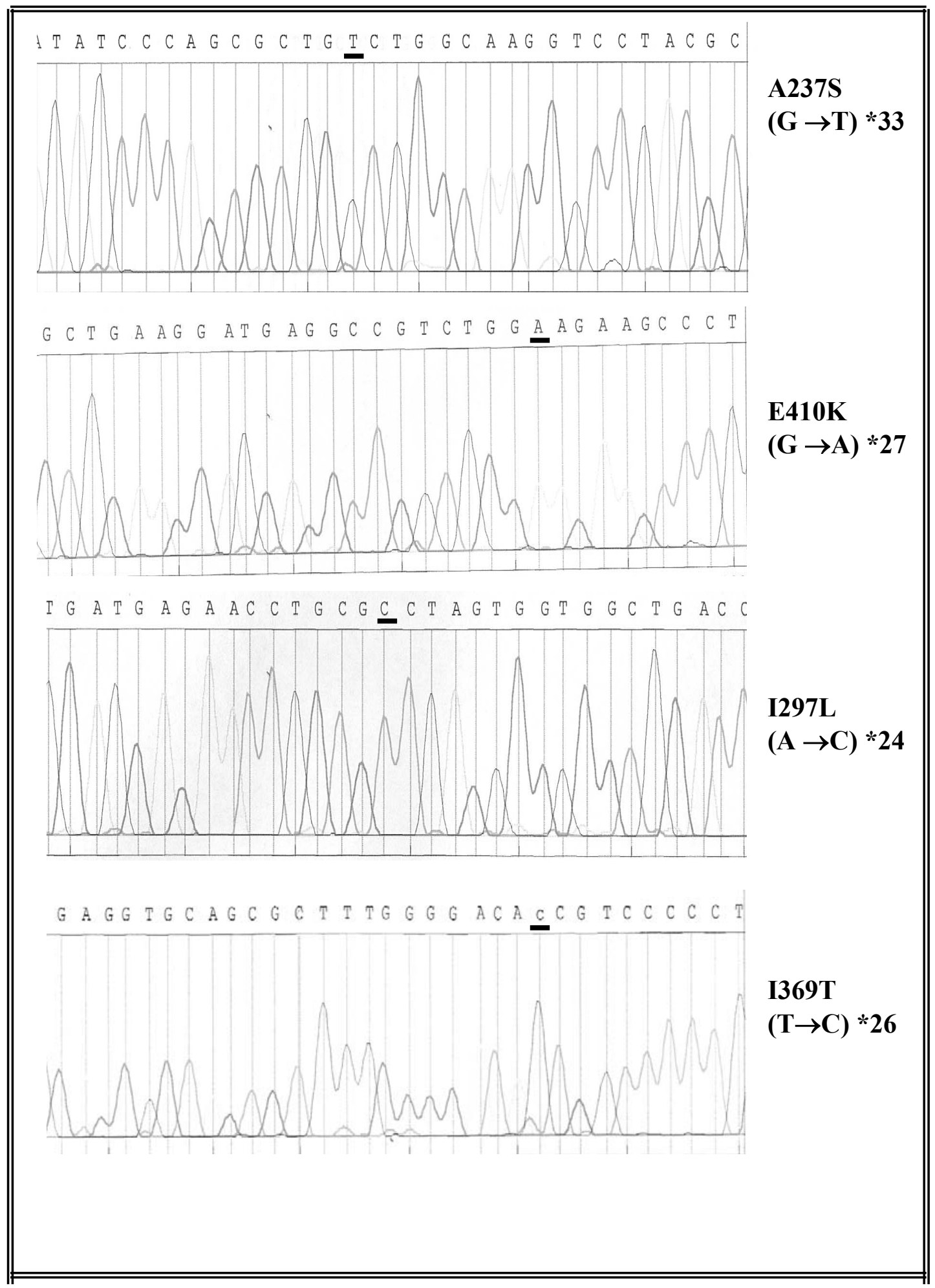

Figure 1 


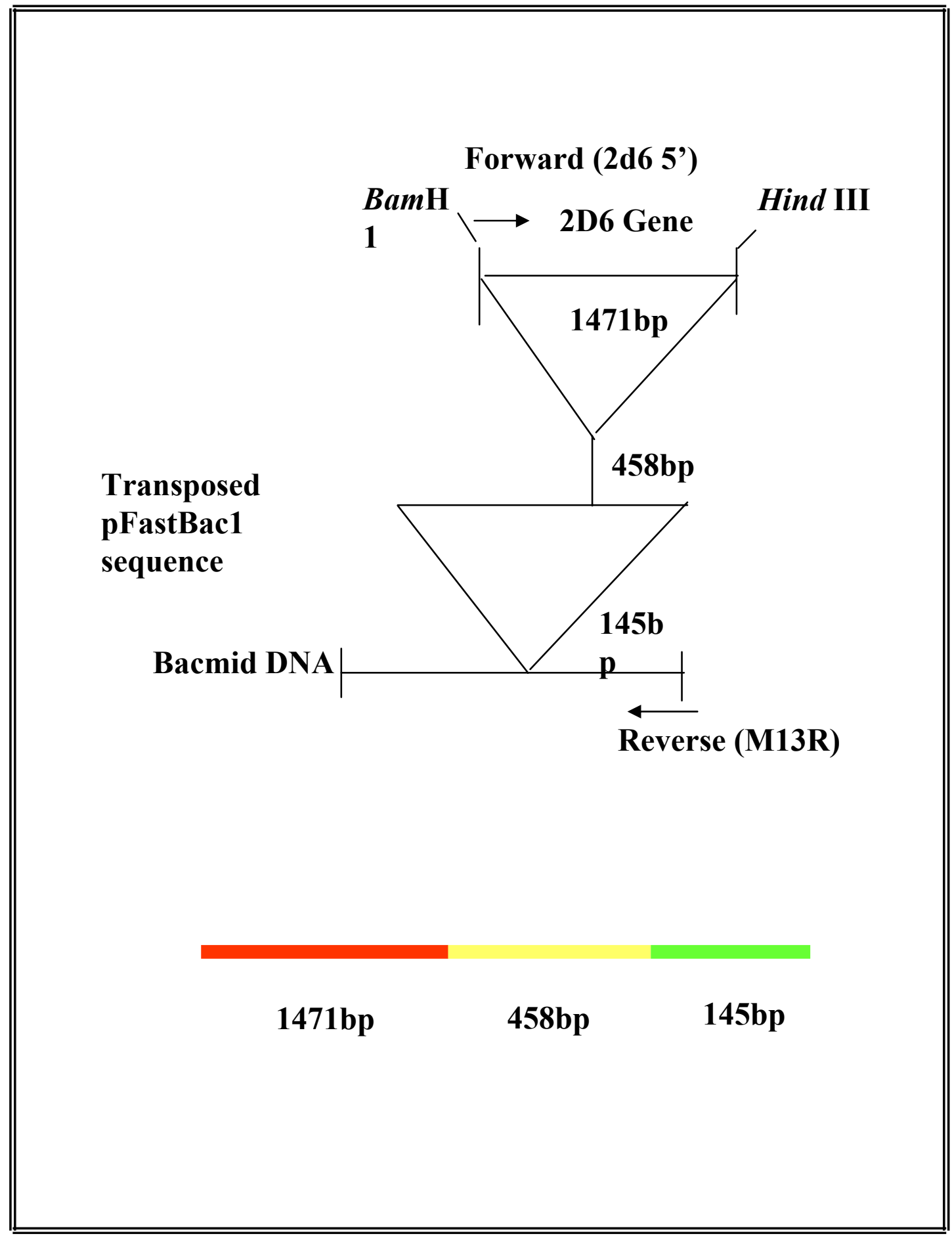

Figure 2 


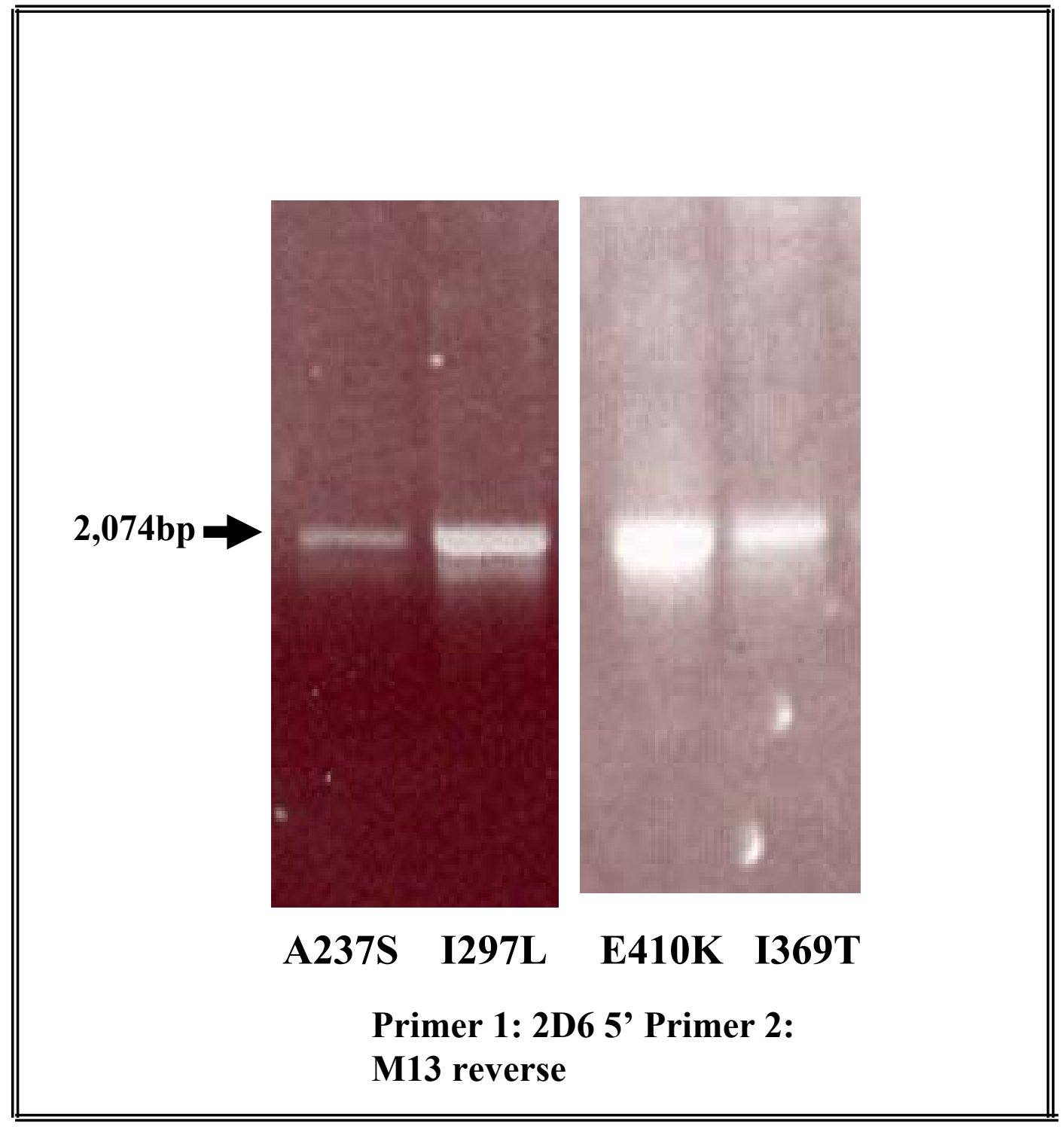

Figure 3 


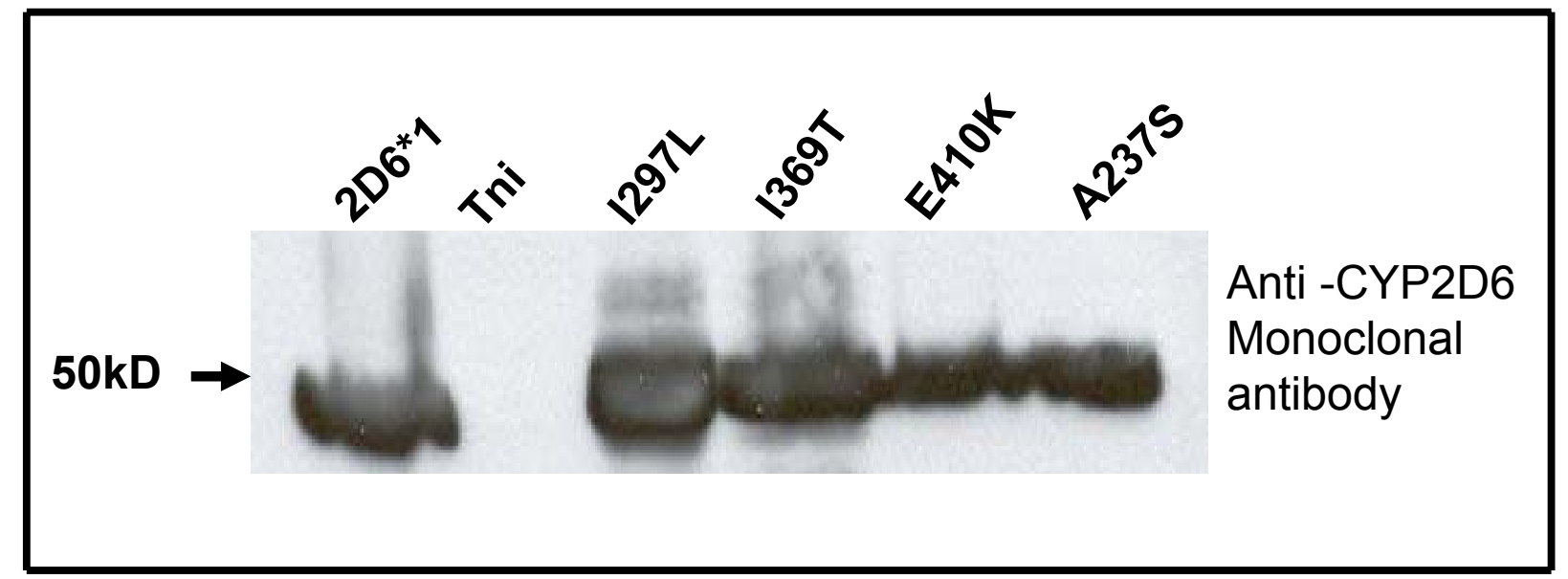

Figure 4 

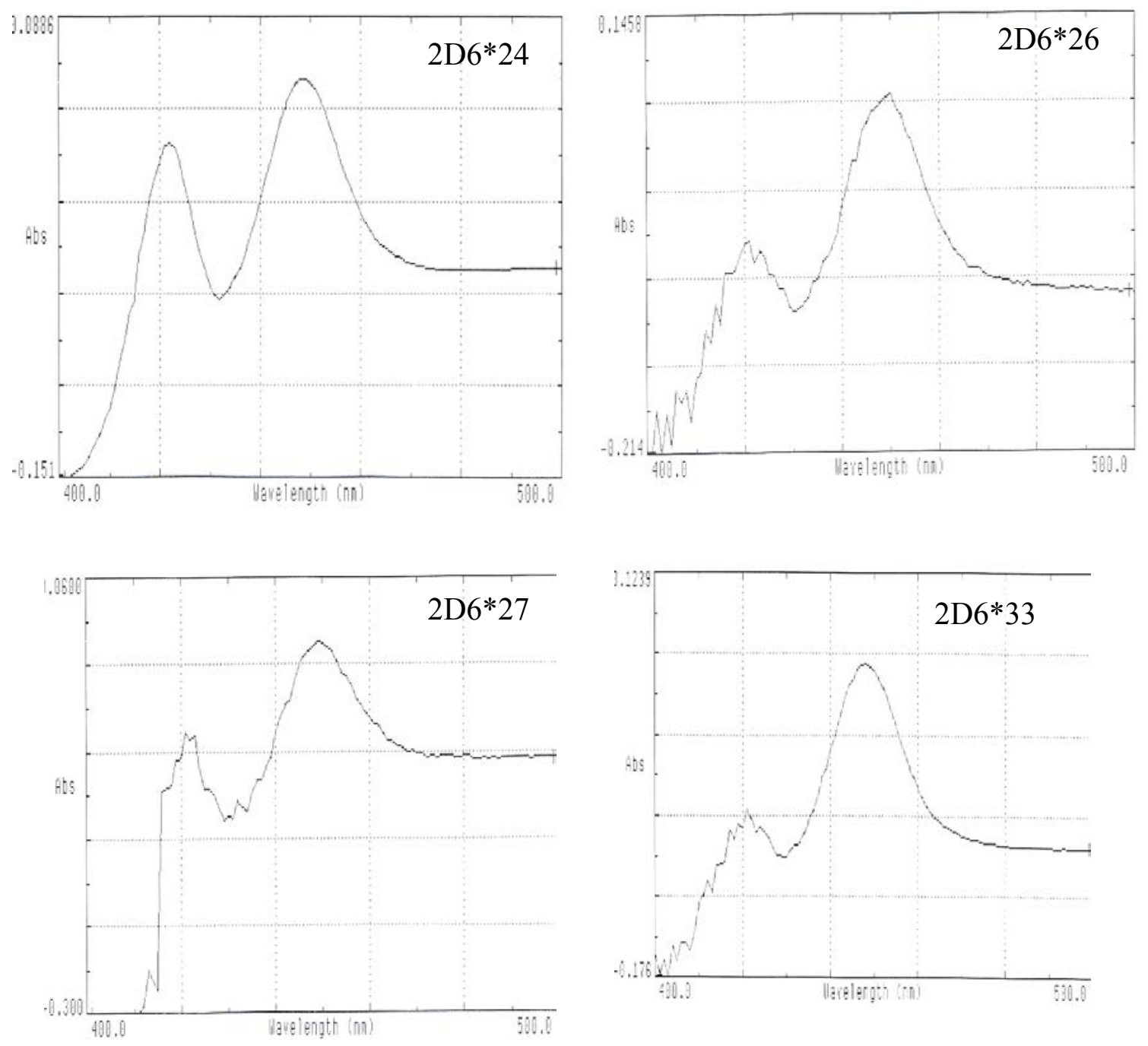

Figure 5 
[Substrate] vs. Velocity

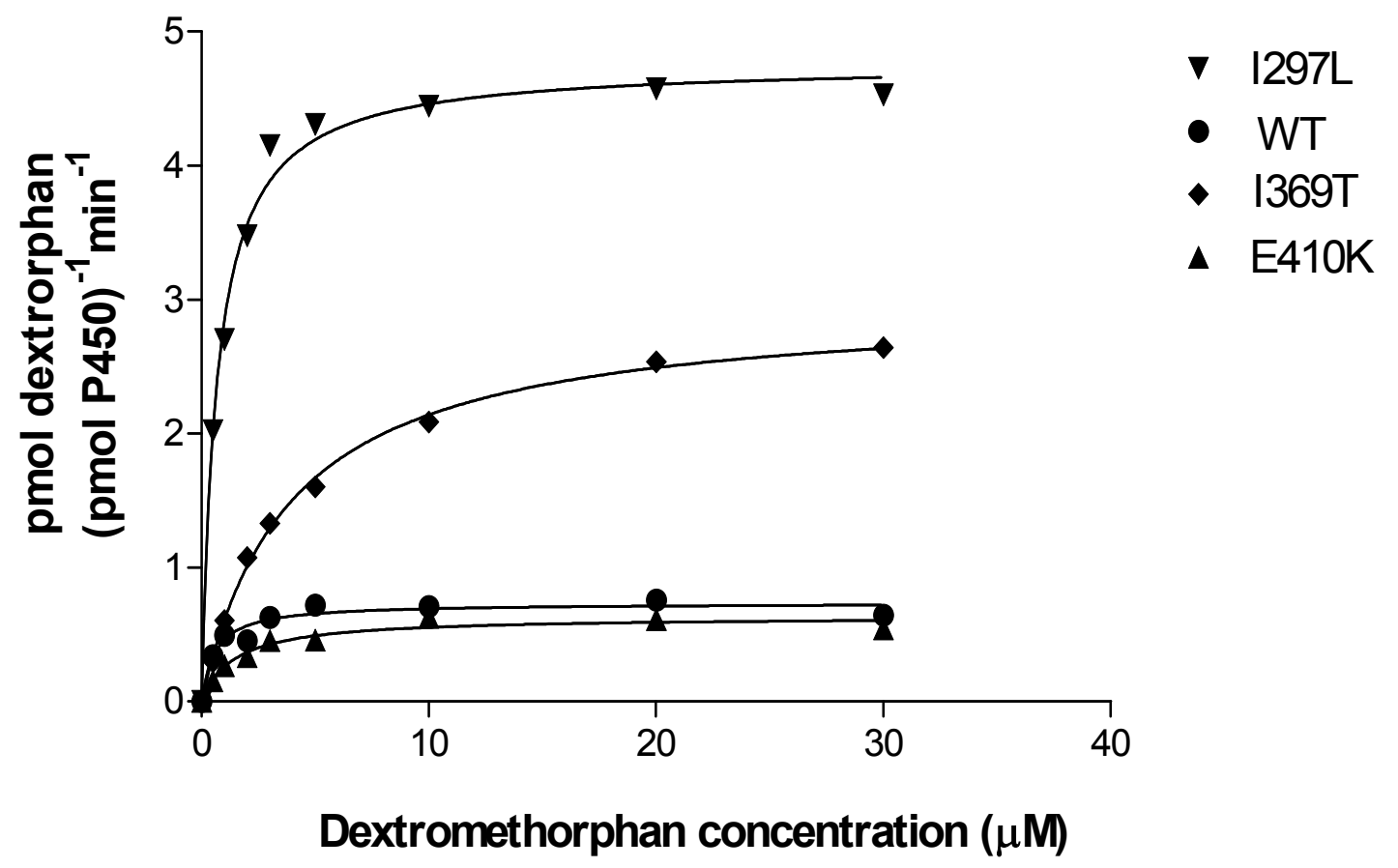

Figure 6 


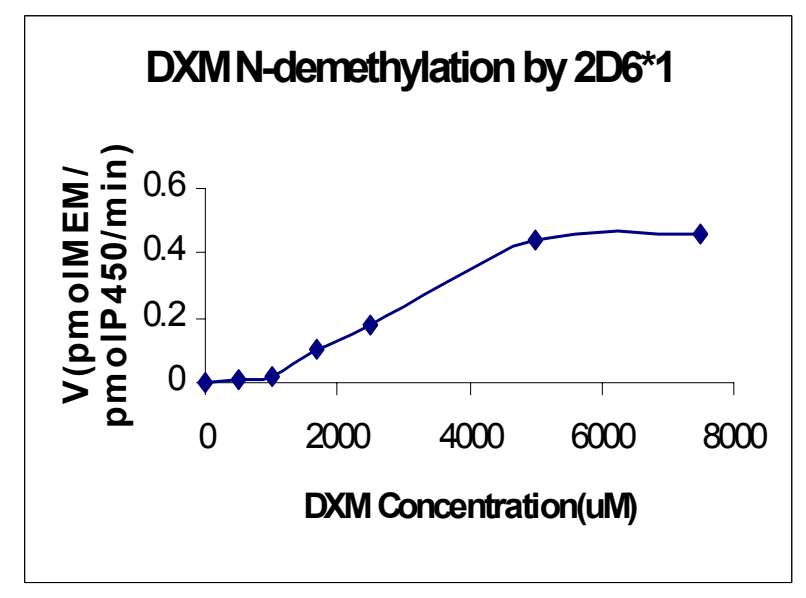

a

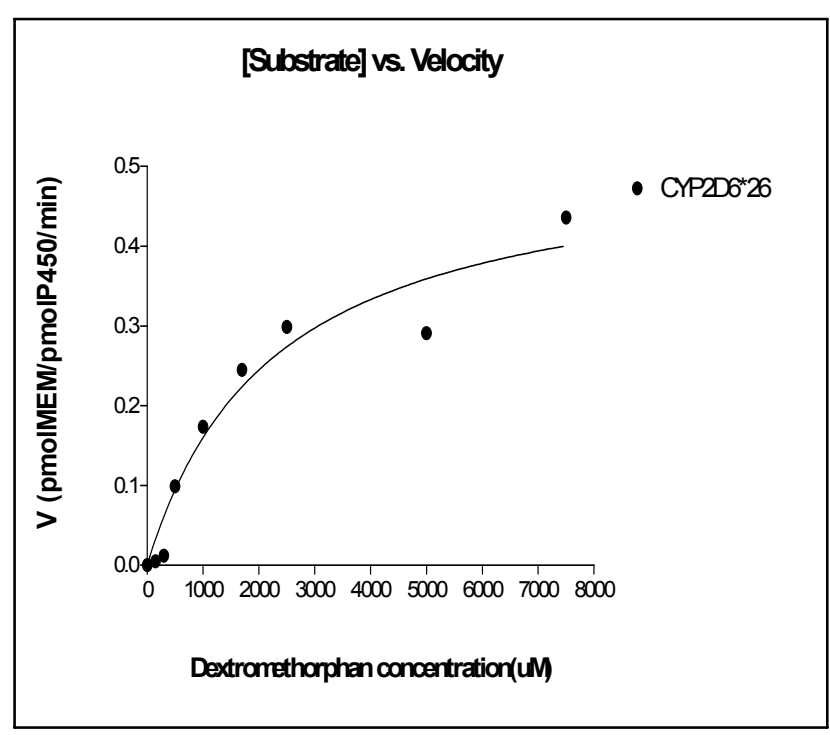

c

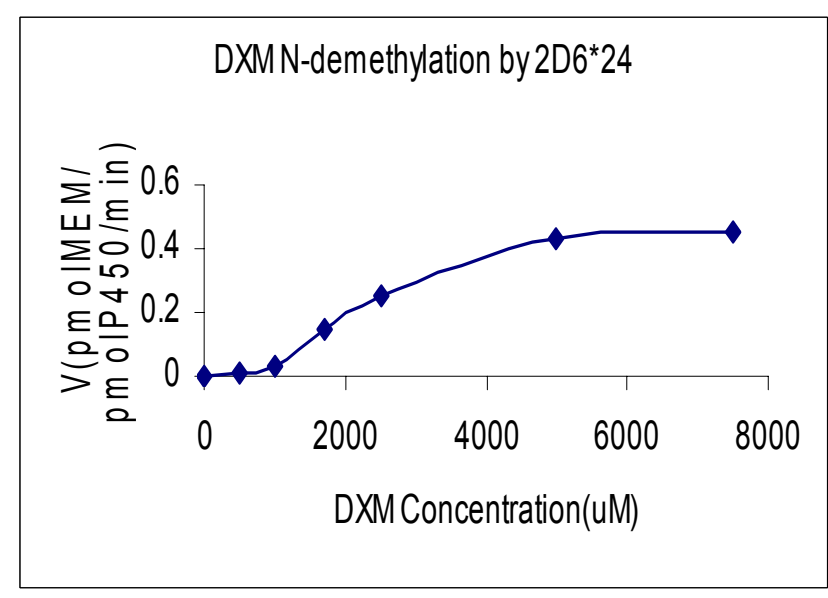

b

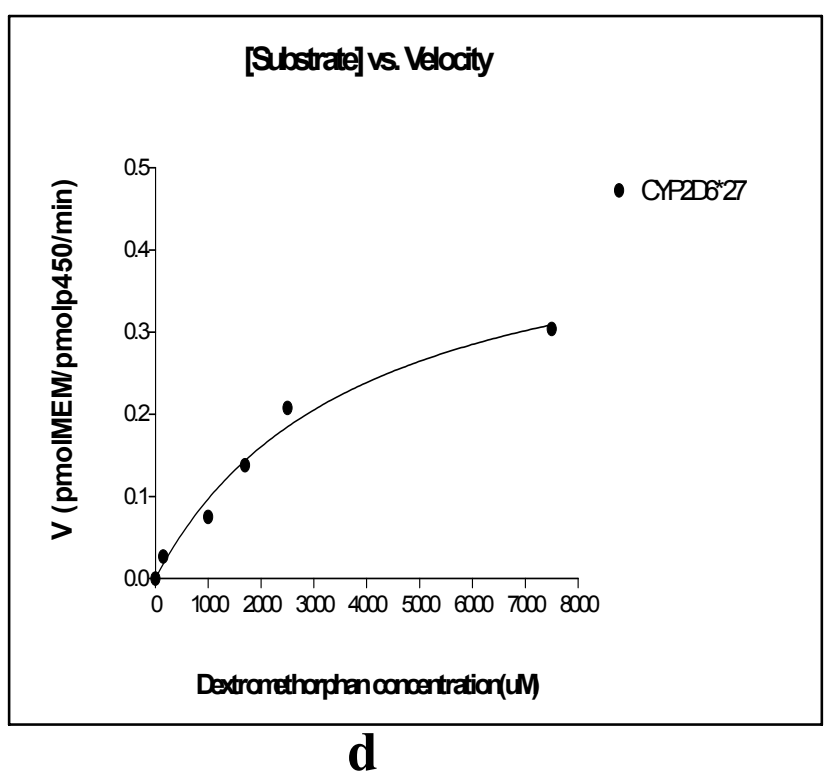

Figure 7 
Table 1. Kinetic parameters for DXM $O$-demethylation and codeine $O$-demethylation

\begin{tabular}{lllll}
\hline Reaction & Allelic variants & $K_{m}$ & $V_{\max }$ & $V / K$
\end{tabular}

Dextromethorphan $O$-demethylation

$\begin{array}{llll}\text { CYP2D6*1 } & 0.60 \pm 0.16 & 0.73 \pm 0.04 & 1.22\end{array}$

$\begin{array}{llll}\text { CYP2D6*24 } & 0.69 \pm 0.06 & 4.76 \pm 0.08 & 6.90\end{array}$

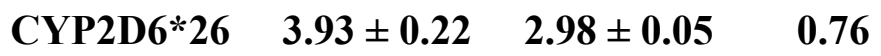

$\begin{array}{llll}\text { CYP2D6*27 } & 1.45 \pm 0.3 & 0.63 \pm 0.03 & 0.43\end{array}$

Codeine $\boldsymbol{O}$-demethylation

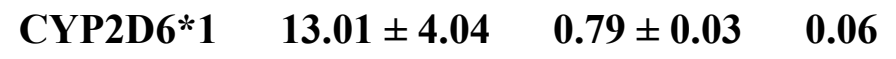

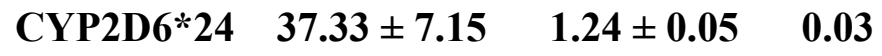

$\begin{array}{llll}\text { CYP2D6*26 } & 26.73 \pm 10.45 & 2.37 \pm 0.19 & 0.09\end{array}$

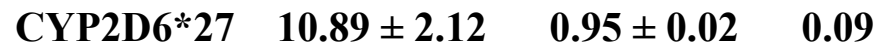


[Substrate] vs. Velocity

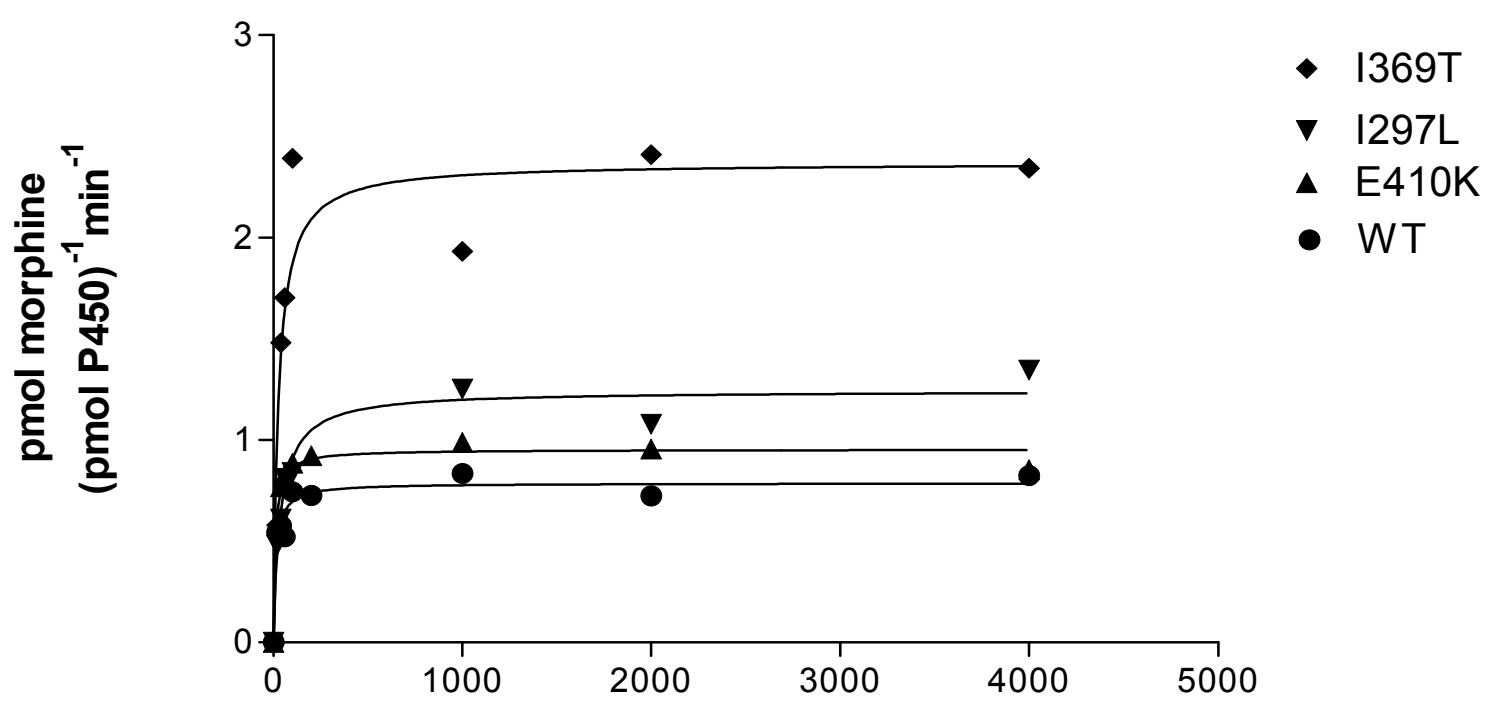

Codeine concentration $(\mu \mathrm{M})$

Figure 8 


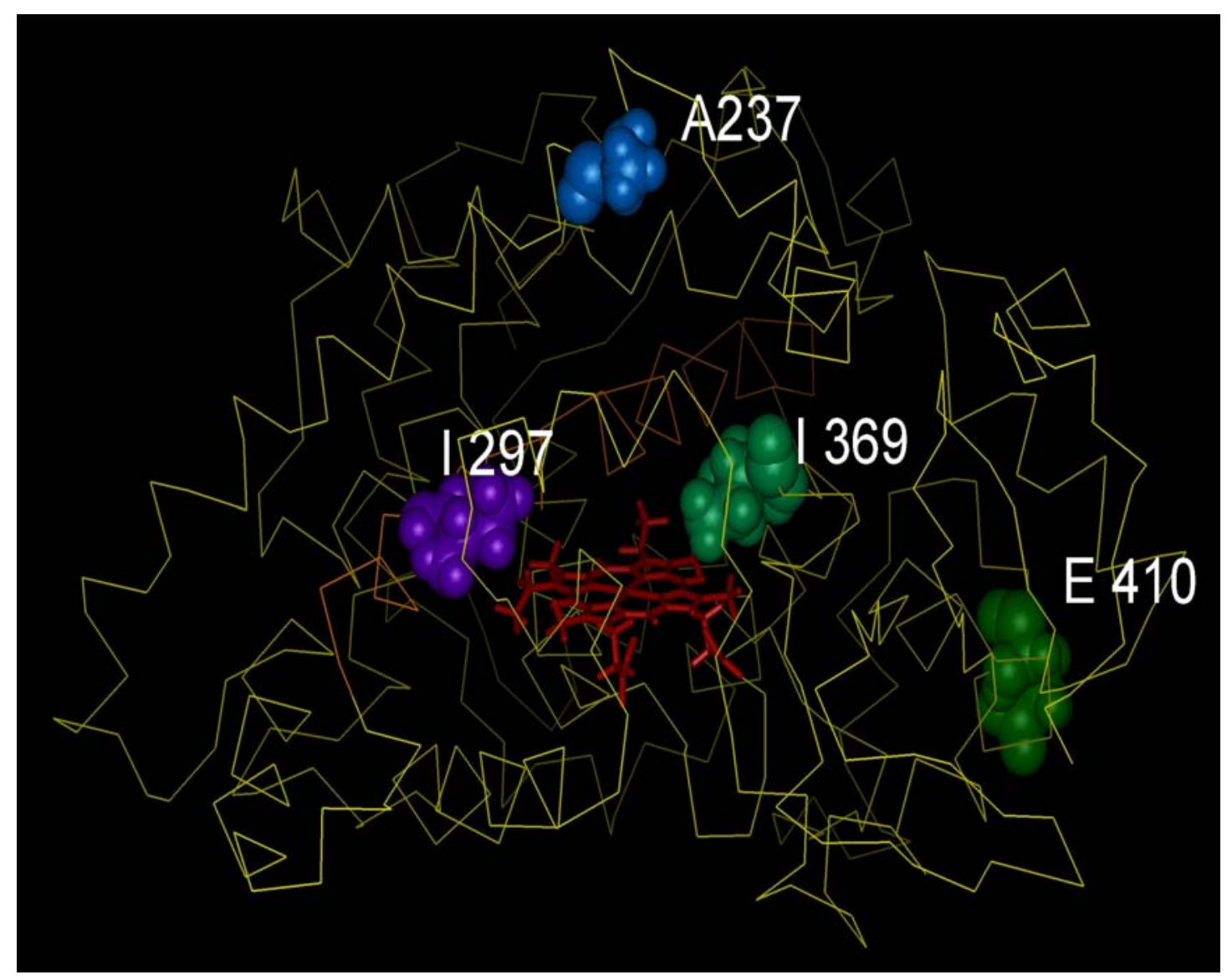

Figure 9 


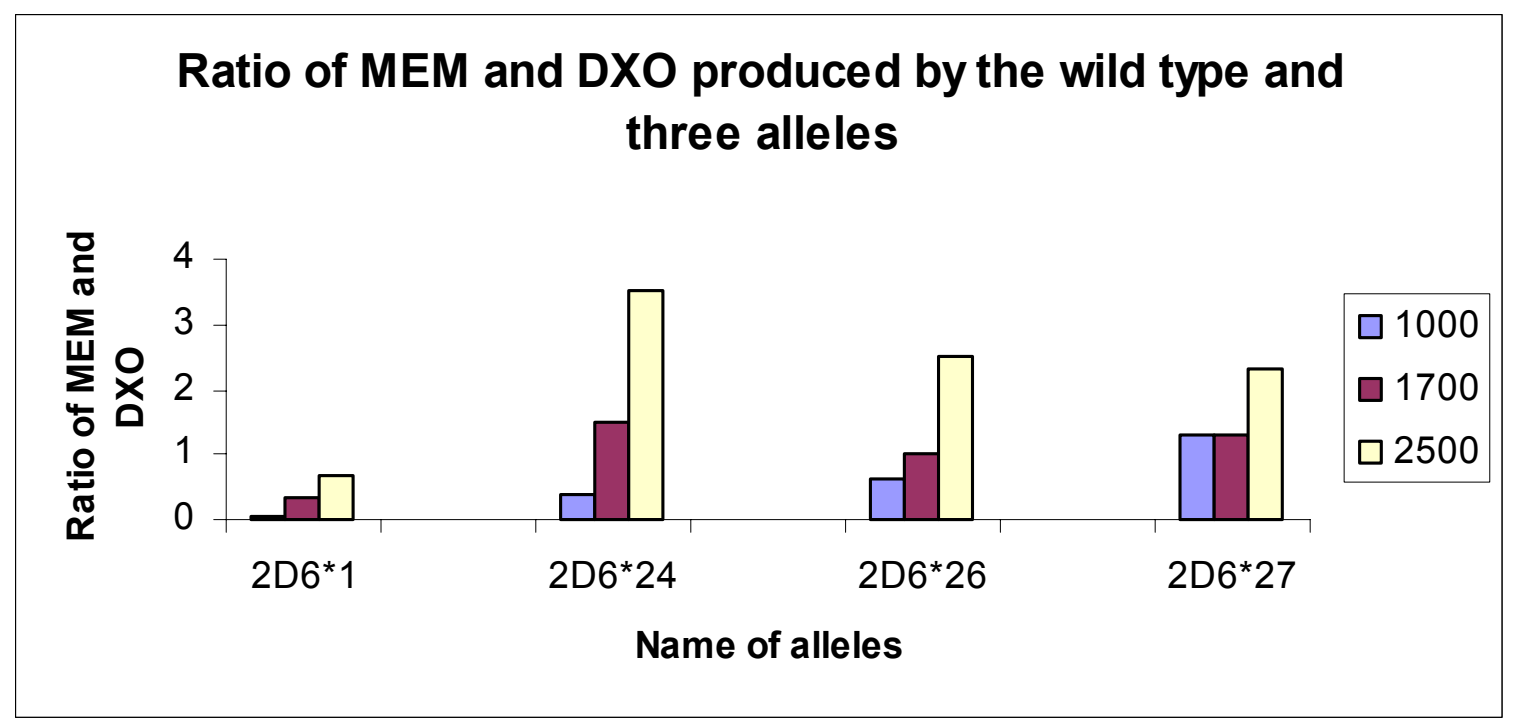

Figure 10 


\title{
Chapter III
}

\section{Creation, Expression and Functional Analysis of Human Brain Cytochrome P450 2D7 Variant}

\author{
Weiyan Zhang, Robert L Haining* \\ Department of Basic Pharmaceutical Science, School of Pharmacy, Robert C. Byrd \\ Health Sciences Center, West Virginia University, Morgantown, West Virginia 26506
}

Running title: Human brain cytochrome P450

Key words (human brain cytochrome P450/CYP2D7/variants)

* Corresponding author mailing address, Department of Basic Pharmaceutical Science,

School of Pharmacy, Robert C. Byrd Health Sciences Center, West Virginia University, Morgantown, West Virginia 26506. Phone: (304) 293-1479, Fax: (304) 293- 257

Electronic mail address: rhaining@hsc.wvu.edu 


\begin{abstract}
Both basic and clinical studies have shown that MPTP (methyl-phenythetra hydropyridine, an inducer of Parkinson's disease) and dopamine are related to Parkinson's disease. Recent studies have shown that CYP2D6 is not only involved in the metabolism of MPTP and biosynthesis of dopamine, but also presents in human brain tissues. These data imply that CYP2D is probably related to Parkinson's disease. However, no functional CYP2D had been identified from human brain tissues until Pai et al recently cloned a very unique $C Y P 2 D 7$ variant in human brain, encoding a functional protein as result of repair and alternative splicing of mRNA from the CYP2D locus. However, the structure and functions of this enzyme are poorly understood compared to those of CYP2D6. In this study, this CYP2D7 variant was successfully crated based on $C Y P 2 D 6$ by using different genetic tools, and further was expressed in a baculovirus expression system. Although the immun-blot analysis showed that the full-length $C Y P 2 D 7$ was successfully expressed, the expressed protein does not have enzymatic activity of P450 based on CO-reduce activity when the heme was used as an iron source. Interestingly, the expressed protein restored the activity when $\Delta$-ALA, a precursor of heme, was used as an iron source. In addition, our preliminary study indicated that the protein of CYP2D7 variant is predominantly present in the mitochondrial fraction instead of endoplasmic reticulum. Along this line, the metabolism studies show that the mitochondrial fraction of the insect cell expressing $C Y P 2 D 7$ variant is capable of metabolizing codeine and probably m-tyramine but not MPTP. In summary, the obtained results could not confirm Pai's study. This study will lead us to further understand the
\end{abstract}


catalytic characteristics of this enzyme and its functions in terms of the metabolism of drugs in human brain tissues and development of CNS diseases.

\section{Introduction}

Cytochrome P450s are a superfamily of heme containing enzymes that catalyze the oxidation of a wide range of xenobiotics chemicals including drugs, carcinogens, and steroids $(13,15,38) . C Y P 2 D$ subfamily includes $C Y P 2 D 6, C Y P 2 D 7$ and $C Y P 2 D 8 P$ at the CYP2D locus. These three genes share $92-97 \%$ similarities with each other (22). The $C Y P 2 D 8 P$ is a pseudogene since there is frame shift mutation and stop codon within its exons while $C Y P 2 D 7$ was found to have an insertion in its first exon that disrupts the reading frame of the protein. Cytochrome P4502D6 (CYP2D6) is one of the most important phase I drug metabolizing enzymes, it is involved in the oxidation of over 40 commonly prescribed drugs including antiarrhythmics, antihypertensives, $\beta$-blockers, opioids, antipsychotics and tricyclic antidepressants $(14,20,30)$. CYP2D6 is associated with polymorphic debrisoquine metabolism.

CYP2D6 is predominantly expressed in human liver and mediates metabolism of a variety of drugs. However, there is increasing evidence that $C Y P 2 D 6$ is also expressed in extrahepatic tissues and may contribute to the local in situ metabolism of drugs and activation of carcinogens and toxins (24). CYP2D6 mRNA was detected in all assayed 
regions of human brain, with highest levels observed in cerebellum and lowest levels in putaman, globus pallidus and substantia nigra (28). In addition, immunoblot studies demonstrated the presence of CYP2D protein in cortex, cerebellum, midbrain, striatum and thalamus of human brain (4). Along these lines, clinical studies showed that defects in the CYP2D6 have been associated with a number of CNS diseases such as Parkinson's disease (39), Alzheimer's disease (42), neuroleptic-induced disorders such as tardive dyskinesia (33) and certain types of CNS cancer $(8,45)$.

The primary deficit in Parkinson's disease is a loss of the neurons in the substantia nigra pars compacta that provide dopaminergic innervation to the striatum (caudate and putamen). This paralleled the loss of neurons from the substantia nigra, suggesting that replacement of dopamine could restore function $(7,19)$. These fundamental observations led to an extensive investigative effort to understand the metabolism and actions of dopamine and to learn how a deficit in dopamine gives rise to the clinical features of Parkinson's disease. Studies indicated that L-tyrosine can be converted to tyramine by aromatic L-amino acid decarboxylase, and tyramine further catalyzed to dopamine by CYP2D6. Among the 11 isoforms of human CYP expressed in yeast, CYP2D6 is the only isoform exhibiting strong ability to convert tyramine to dopamine (17). In addition, CYP2D6 can metabolize MPTP that is a potent inducer of Parkinson's disease. However, the link between CYP2D6 and Parkinson's disease is a controversy. Phenotypic studies have failed to support the relationship between CYP2D6 and Parkinson's disease, the genetic studies initially indicated a link between CYP2D6B 
mutations and Parkinson's disease, but critical analysis of the literature and studies emerging from independent laboratories fail to confirm speculation (39).

The liver is the major organ involved in CYP2D6-mediated metabolism. However, the regional and cellular expression of CYP2D6 in human brain has been identified (28), which implies that human brain may be another target tissue for drug metabolism. We are very interested in finding the fact whether there is a unique CYP2D enzyme found only in human brain that is different from the well-characterized form found in the liver. Recently, Pai found a CYP2D7 variant in human brain, but it is not present in human liver or kidney. The brain variant CYP2D7 has a partial inclusion of intron 6 (57bps) in the transcribed mRNA sequence and contains the 138delT mutation. It has been confirmed that this enzyme can be expressed as a functional protein as result of repair in human and it can metabolize codeine to morphine with greater efficiency compared to the corresponding activity in cells expressing CYP2D6 (36). However, the catalytic characteristics, substrates of this enzyme and its functions in human brain are poorly understood.

In this study, we hypothesized that this human brain unique CYP2D7 variant has specific catalytic ability to metabolize codeine, m-tyramine and other substrates. To test this hypothesis, the cDNA of this variant was successfully constructed by using sitedirected mutagenesis method based on CYP2D6*1 cDNA, and further expressed in baculovirus-mediated expression system. Several potential substrates for this enzyme were analyzed by metabolite study. 


\section{Materials and methods}

Bacterial strains, cell line and culture conditions: Escherichia coli strain BMH 71-18 mutS was used for plasmid amplification (Clontech). E. coli XL1-Blue supercompetent cell (Stratagene) was used to perform site-directed mutagenesis; E. coli DH10B $\mathrm{BC}_{\mathrm{AC}}$ strain (Invitrogen) was used to construct and select recombinant bacmid DNA. The E. coli strains BMH 71-18 mutS and $\mathrm{DH} 10 \mathrm{~B}_{\mathrm{AC}}$ were cultured in Luria Bertani medium and XL1-Blue strain was cultured in $\mathrm{NZY}^{+}$broth at $37^{\circ} \mathrm{C} . T$. $n i$ insect cell line was used for infection of baculovirus and expression of recombinant proteins (Invitrogen). The cell line was cultured in HYQ ${ }^{\circledR S F X-I N S E C T ~ m e d i u m ~(H y C l o n e) ~}$ containing $10 \%$ fetal bovine serum at $27^{\circ} \mathrm{C}$. Penicillin-G $(100 \mu \mathrm{g} / \mathrm{ml})$, streptomycin sulfate $(61 \mu \mathrm{g} / \mathrm{ml})$ and amphoterecin-B $(0.6 \mu \mathrm{g} / \mathrm{ml})$ were routinely added to the medium to reduce contamination by bacteria or fungi.

Chemicals: Dextromethorphan, dextrorphan, 3-methoxymorphinan and cumene hydroperoxide were purchased from Sigma/RBI (Natick, MA). Codeine, nor-codeine, morphine, trifluoroacetic acid (TFA), and 60\% perchloric acid were purchased from Sigma-Aldrich (St.Louis, MO). Methanol and orthophosphoric acid were purchased from Fischer Scientific. Gene PORTER Transfection Reagent was purchased from Gene Therapy System, Inc. 
Primers design and Site-directed mutagenesis: $C Y P 2 D 6^{*} 1 \mathrm{cDNA}$ was used as a template to create the cDNA of human brain $C Y P 2 D 7$ variant by site-directed mutagenesis. The mutation sites and primers for mutations were listed in Table 1. QuikChange® multi site-directed mutagenesis kit was used to create site mutation (Stratagene). The experiments were carried out as the manufacture's recommendation. Briefly, the mutagenesis reactions includes 10 x QuikChange ${ }^{\circledR}$ multi reaction buffer 2.5 $\mu 1$, QuikSolution $0.75 \mu 1$, ds-DNA template (CYP2D6*1) $3 \mu 1$, mutagenic primers $2 \mu 1$, dNTP mix $1 \mu$, QuikChange® multi enzyme blend $1 \mu$, double distilled $\mathrm{H}_{2} \mathrm{O}$ to a final volume of $25 \mu \mathrm{l}$. The PCR cycling parameters includes $95^{\circ} \mathrm{C} 1$ minute, 1 cycle for the first segment; $95^{\circ} \mathrm{C} 1$ minute, $55^{\circ} \mathrm{C} 1$ minute, $65^{\circ} \mathrm{C} 12$ minutes, 30 cycles for the second segment. The resultant PCR products were treated with $1 \mu l$ of $D p n$ I restriction enzyme $(10 \mathrm{U} / \mu \mathrm{l})$ to create mutated single strand DNA, which was further transformed into XL100-Gold Ultracompetent cells. Transformed cells were first plated on agar plates containing ampicillin $(100 \mu \mathrm{g} / \mathrm{ml})$ and incubated at $37{ }^{\circ} \mathrm{C}$ overnight, and then single clones were picked up and transferred into LB broth and grew at $37^{\circ} \mathrm{C}$ overnight in incubator (250 rpm/minute). Plasmids were isolated with Wizard® Plus SV Minipreprs Kit (Promega). All the target mutations were confirmed by DNA sequencing analysis. The resultant construct was named as pFB2D6m.

Cloning and insertion of 57 base pairs fragment: The alignment analysis indicated that there is an extra $57 \mathrm{bp}$ fragment present in the cDNA of $C Y P 2 D 7$ variant, and this fragment encodes 19 amino acids (Figure 1). In order to obtain the full-length $C Y P 2 D 7$ cDNA, the following strategy was used. First, two restriction endonuclease cut 
sites Aat II and Nru I were created on the mutated CYP2D6 (pFB2D6m) by site-directed mutagenesis with a primer (5'-CACTTGGA CGTCCAGCGCCGTCGCGAACAGGAG3'), which will be used as a insertion site of the 57bp fragment. Second, a 57bp DNA fragment was artificially synthesized in Invitrogen, and the resultant product was used as a template to amplify this fragment by PCR with a pair of primers that have the same cut sites. The resultant PCR product was purified, and further cloned into PCR cloning vector pGEM-T easy vector. The inserted 57 bps fragment was digested with Aat II/Nru I, and re-ligated to the same sites on the pFB2D6m, and resulted in the construct pFB2D7m. The mutation sites for Aat II/Nru I located on pFB2D7m were removed by reverse mutation mediated by site-directed mutagenesis with two primers: (5'-CACTTGGAT GTGCAGCGAGGAAGG-3' and 5'-CCAGTCCGTGTCCAACAGGAGATC-3'), and created the final construct $\mathrm{pFB} 2 \mathrm{D} 7 \mathrm{v}$.

DNA sequencing analysis: All the target mutations and insertion for creating the cDNA of $C Y P 2 D 7$ variant were confirmed by DNA sequencing analysis (Northwoods DNA, Inc) with four different primers: 2D6-5' (5'-GGATTATTCATACCGTCC-3'), C82 (5'-CGCTGGGCT GCACGC-3'), C534 (5'-GGACAAAGCCGTGAG-3'), and C1011 (5'-CGTGATAGGGCA GG-3').

Construction of recombinant baculovirus: The construct pFB2D7v was transformed into DH10Bac competent cells (Invitrogen), which contain the bacmid with mini-attTn 7 target site and the help plasmid. After incubating on the Luria agar plates for 24 to 48 hours at $37^{\circ} \mathrm{C}$, white clones which contain recombinant bacmid DNA were 
picked up and transferred into LB medium with $50 \mu \mathrm{g} / \mathrm{ml}$ kanamycin, $7 \mu \mathrm{g} / \mathrm{ml}$ gentamicin, and $10 \mu \mathrm{g} / \mathrm{ml}$ tetracycline, grew at $37{ }^{\circ} \mathrm{C}$ (up to 24 hours), shaking at 250 rpm. The recombinant bacmid DNA was purified and characterized by PCR. The recombinant bacmid DNA was further treated with GenePORTER TM transfection reagent (Gene Therapy System), and transfected into seed 9x10 T.ni cells per 35-mm (of a 6-well plate) at $27^{\circ} \mathrm{C}$ in $2 \mathrm{ml}$ of SFX-INSECT (Hyclone) containing $10 \%$ fetal bovine serum and $100 \mu \mathrm{g} / \mathrm{ml}$ Penicillin-G, $60 \mu \mathrm{g} / \mathrm{ml}$ Streptomycin sulfate, $0.6 \mu \mathrm{g} / \mathrm{ml}$ Amphoterecin-B. The recombinant virus was harvested at 72 hours after transfection. Baculovirus stocks were amplified by subsequent passages onto a new 100-mm dish of T.ni cells with $30 \mathrm{ml}$ medium followed by incubation for 7 to 8 days.

Protein expression and subcellular fraction purification: Seed $\left(2 \times 10^{6}\right)$ T.ni cells per $100-\mathrm{mm}$ at $27^{\circ} \mathrm{C}$ in $10 \mathrm{ml}$ of medium. Suspension culture were inoculated directly from culture dishes and were grown in batches of $250 \mathrm{ml}$ in a 2-liter Erlenmeyer flasks using a spin bar on a magnetic stir platform. Vigorous stirring was used to reduce cell clumping and to ensure adequate oxygenation of the medium. Infection was carried out at a cell density of 1.6 to $2.0 \times 10^{6}$ cells $/ \mathrm{ml}$ using $8-12 \mathrm{ml}$ of amplified viral supernatant. $\Delta$ ALA (finial concentration $500 \mu \mathrm{m}$ ) was added together with virus. Cells were harvested 3 to 4 days post-infection, re-suspended and washed once in storage buffer $(100 \mathrm{mM}$ potassium phosphate, $20 \%$ glycerol, $0.33 \mathrm{mM}$ dithiothreitol, $1 \mathrm{mM}$ EDTA, PH 7.4), repelled and stored at $-80^{\circ} \mathrm{C}$ for further use. 
$250 \mathrm{ml}$ culture was harvested, and the cell pellet was re-suspended in $10 \mathrm{ml}$ homogenization buffer $\left(320 \mathrm{mM}\right.$ sucrose, $10 \mathrm{mM} \mathrm{KH}_{2} \mathrm{PO}_{4}, 1 \mathrm{mM}$ EDTA, $1 \mathrm{mM}$ PMSF, $\mathrm{pH}$ 7.4). The resultant sample was then treated with French Cell Press to break cells followed by centrifuge at $600 \mathrm{~g}$ for 5 minutes to remove insoluble cell debris. The supernatant part was centrifuged at $3000 \mathrm{~g}$ for 20 minutes to collect mitochondria. The pellet containing mitochondria was re-suspended in solubilization buffer (100mM Kpi, pH 7.4, $20 \%$ glycerol, 1mM EDTA, 0.1mM DTT, 0.2mM PMSF, 1\% cholate). The supernatant was then re-centrifuged at 40,000rpm for 1 hour, and the pellet, which contains rough ER, smooth ER and microsomes, was re-suspended in freezing buffer (100mM Kpi, 20\%(v/v) glycerol, 1mM EDTA, 1mM PMSF, pH 7.4).

SDS-PAGE and Western-blot analysis: SDS-PAGE and Western-blotting with the enhanced chemiluminescence detection method were carried out as reported. Polyclonal and monoclonal antibodies against human CYP2D6 were purchased from BD GentestTM and PANVERA. Briefly, the same amounts of samples were loaded in $10 \%$ SDS-PAGE. After electrophoresis, the samples were transferred to immuno-blot PDVF membrane. The resultant blots were blocked in 5\% fat free milk at room temperature for 1 hour, and then incubated in $2 \%$ milk containing primary antibodies for 1 hour at room temperature followed by three times wash by using TPBS. The blots were developed by using horseradish peroxidase-conjugated secondary antibody with the ECL luminal assay.

Metabolite analysis of CYP2D7 variant: Kinetic studies of CYP2D7 were carried out as previous studies. Briefly, reactions were performed in $100 \mathrm{mM}$ potassium 
phosphate buffer, $\mathrm{pH} 7.4$, containing mitochondria fraction $(0.27 \mu \mathrm{M})$, cumene hydroperoxide $(\mathrm{CuOOH}, 500 \mu \mathrm{M})$, and substrates in a final volume of $200 \mu 1$. CYP2D7 variant, the substrates and potassium phosphate buffer were first added together, then incubate at $37^{\circ} \mathrm{C}$ for 5 minutes. Reactions were initiated by addition of $\mathrm{CuOOH}$, and terminated by addition of $10 \mu 160 \%$ perchloric acid. The mixtures were subjected to centrifugation at 14,000rpm for 10 minutes before HPLC injection and analysis. When codeine was used as substrate, the substrate concentration was $2000 \mu \mathrm{M}$, the incubation was carried out at $37^{\circ} \mathrm{C}$ for 30 minutes. When m-tyramine was used as substrate, the substrate concentration was $500 \mu \mathrm{M}$, the reaction was incubated for 20 minutes at $37^{\circ} \mathrm{C}$. When MPTP was used as substrate, the concentration of substrate was $250 \mu \mathrm{M}$.

HPLC analysis was carried out on a Waters Alliance System (Milford, MA) consisting of the 2690 separation module, the 2487 dual wavelength absorbance detector and the 474 scanning fluorescence detector. The data was analyzed with Millennium 32 software. A 250 x $4.6 \mathrm{~mm}$ i.d. phenyl column was used to separate codeine and its metabolite. A 150 x 4.6mm Phenomenex deactivated column was used to separate mtyramine and its metabolite; MPTP and its metabolite PTP. The flow rate through the column at room temperature was $1 \mathrm{ml} /$ minute. Separations of codeine and its metabolites were achieved with a mobile phase containing $50 \%$ water (with $0.1 \%$ TFA) and $50 \%$ acetonitrile with water $(400: 600, \mathrm{v} / \mathrm{v})$. The excitation and emission wavelength of the fluorescence detector were set at 280 and $335 \mathrm{~nm}$. A mobile phase consisting of $98 \% 10$ $\mathrm{mM} \mathrm{KH}_{2} \mathrm{PO} 4(\mathrm{pH} 3.5)$ and $2 \%$ acetonitrile and methanol $(250: 200, \mathrm{v} / \mathrm{v})$ was used to separate m-tyramine and dopamine. The excitation and emission wavelength of the 
fluorescence detector was set at 280 and $380 \mathrm{~nm}$. A mobile phase consisting of $40 \%$ acetonitrile and $60 \% 25 \mathrm{mM}$ potassium phosphate (PH7.4) was used to separate MPTP and PTP. The excitation and emission wavelength of fluorescence detector was set at 244 and $307 \mathrm{~nm}$.

Mass spectrometry: ESI-MS was used to identify the metabolites as previously described. Briefly, nitrogen was used as sheath gas (100psi) at a flow rate of 20 arbitrary units. An electrospray voltage of $4.5 \mathrm{kV}$ and a capillary temperature of $200{ }^{\circ} \mathrm{C}$ were used. The infusion rate was $10 \mu \mathrm{l} / \mathrm{min}$. The maximum ion injection time was set to $800 \mathrm{~ms}$. The ion isolation window was set at $1 \mathrm{Th}$ and collision energies were set at $20-35 \%$. Ultrahigh purity helium was used as the buffer gas. For m-tyramine metabolism, the reaction mixture was diluted in $50 \%$ methanol and $50 \%$ acetonitrile to the final concentration of 1 $\mu \mathrm{g} / \mathrm{ml}$ just before analysis.

\section{Results}

Construction the cDNA of human brain CYP2D7 variant. The cDNA of CYP2D6 and the CYP2D7 variant shares about $97 \%$ identity. Sequence alignment analysis indicated that there are 30 different genetic codes that cause alternation of amino acids (Figure 1). In order to obtain the cDNA of $C Y P 2 D 7$ variant, these sites were alternated by site-directed mutagenesis based on the cDNA of CYP $2 D 6 * 1$. The sites of mutation and the primers for mutagenesis were listed in Table 1. After many cycles of mutations, all these sites were successfully altered and identical to those of $C Y P 2 D 7$ variant. In 
addition, $C Y P 2 D 7$ variant contains an extra 57 bps DNA fragment, which encodes 19 amino acids. In order to obtain the full-length cDNA of $C Y P 2 D 7$ variant, the strategy described in the method was used to insert this fragment into the target site at the mutated CYP2D6. The final construct was confirmed by DNA sequencing analysis, and the results indicated that the amino acid sequence encoded by the constructed $C Y P 2 D 7$ variant are $100 \%$ identical to that described by Pai (36).

Construction of recombinant bacmid DNA. To create recombinant baculovirus, the constructed 2D7 variant cDNA was transformed into DH10Bac competent cells containing the bacmid, constructed 2D7 variant cDNA can combine with bacmid DNA by homogeneous recombination. The recombinant bacmid DNA was confirmed by PCR (Figure 2a). If CYP2D6 is integrated into baculovirus DNA, The size of PCR product is expected to be 2,074bps. 2D7 variant is 57 -bp bigger than 2D6, it is expected to be $2,131 \mathrm{bps}$. The result indicated that the constructed 2D7 variant cDNA was successfully integrated into baculovirus DNA.

Expression of CYP2D7 variant. Several P450 enzymes including CYP2D6 and CYP2C9 were successfully expressed in the insect cell lines mediated by baculoviurs. In order to obtain the active CYP2D7 variant enzyme, the same expression system was used. The creation of high titer baculovirus stock, the growth of baculovirus, the media conditions, the infection of $T$. ni cells with baculovirus were described previously (16, 46). To detect whether the CYP2D7 variant was expressed in the transfected insect cells, Western-blot analysis was carried out with the polyclonal and monoclonal antibodies against to CYP2D6, and results showed that CYP2D7 variant reacted to both antibodies 
(Figure 2b). As shown in Figure 2b, the molecular weight of CYP2D6 is about 50kD; and the molecular weight of CYP2D7 variant is about $57 \mathrm{kD}$, which is the same as the predicted molecular weight based on the sequence of amino acids. These data showed that the protein of CYP2D7 variant was successfully expressed in baculovirus-mediated expression system.

Enzymatic analysis and localization of human brain CYP2D7 variant. In order to determine the enzymatic activity of expressed CYP2D7 variant, the carbon monoxide difference spectra was performed as previously described. However, no activity was detected when Heme was used as a resource of $\mathrm{Fe}^{3+}$. The same pattern was observed with different experimental conditions such as different cell culture, different amount and preparation and addition time of Heme (data not shown). $\delta$-aminolevulinic acid ( $\Delta$-ALA) is the other commonly used resource providing $\mathrm{Fe}^{3+}$ for $\mathrm{P} 450$ (37). When $\Delta$-ALA was used, carbon monoxide difference spectra analysis of the expressed protein exhibited Soret maxima at $450 \mathrm{~nm}$ characteristic of P450. It also showed a strong absorption at $420 \mathrm{~nm}$, indicating there is denature of some active enzyme (Figure 3).

Different cell fractions were prepared from $T$. $n i$ insect cells transfected with $C Y P 2 D 7$ variant. Mitochondria and microsomes were isolated separately. Interestingly, no enzymatic activity was detected in the microsome fraction by carbon monoxide difference spectra analysis. Instead, the enzymatic activity was present in the mitochondrial fractions, which implied that CYP2D7 variant might locate at the mitochondria of insect cells. To detect this hypothesis, Western-blot analysis was performed to detect the location of CYP2D7 variant. As shown in Figure 4, the CYP2D7 
variant was predominantly present in the mitochondrial fraction instead of microsome fraction. In contrast, CYP2D6 is predominantly present in microsome fraction. These results implied that human brain CYP2D7 variant might have different cellular location compared to human liver CYP2D6.

\section{Metabolism of codeine, tyramine and MPTP by human brain CYP2D7 variant.}

This unique variant was identified in human brain, and it has not been found in other organs. It implies that this variant may have tissue specificity, and might have unique catalytic activity in terms of the metabolism of neuro-drugs, transmitter and toxins. To test this hypothesis, the following substrates were chosen for the metabolism analysis: Codeine, a commonly used neuro-drug; m-tyramine, precursor of dopamine that is related to Parkinson's disease; MPTP, an inducer of dopaminergic neurotoxicity. As mentioned above, the CYP2D7 variant was predominantly present in the mitochondrial fraction from the transfected insect cells. Thus, this mitochondrial fraction was used for the following metabolism studies.

a. Codeine $\boldsymbol{O}$-demethylation by CYP2D7 variant. Reconstitution conditions were described previously (see methods). Following incubation, reaction mixtures were injected directly onto the column for the HPLC assay to identify the metabolites by comparison with retention times of authentic standards. Using the HPLC conditions described, the metabolites morphine and nor-codeine were clearly separated from substrate codeine. Morphine, nor-codeine and codeine eluted at 7.699, 12.543 and 16.891min, respectively (Figure 5a), they were verified by fluorescence detection. 
Kinetic analysis of codeine $O$-demethylation activities was carried out with CYP2D7 variant and CYP2D6*1. As shown in Figure 5b, both CYP2D6*1 and CYP2D7 could metabolize codeine to morphine. However, the velocity value for the metabolism of codeine by CYP2D7 was $1.23 \mathrm{pmol} / \mathrm{min}$, which is faster than that of CYP2D6*1 (velocity value $0.53 \mathrm{pmol} / \mathrm{min}$ ) (Table 2). These results implied that human brain CYP2D7 variant might have a unique capability to metabolize the drugs predominantly present in human brain.

b. M-tyramine metabolism by CYP2D7 variant. The standard m-tyramine and dopamine mixture was injected directly onto the column for the HPLC assay to identify the retention times of the standards. Using the HPLC conditions described in the method, m-tyramine and dopamine were clearly separated, with retention times of 3.913 and $7.901 \mathrm{~min}$, respectively (Figure 6a). The same products were also detected in the reaction mediated by CYP2D7 variant, which indicated that CYP2D7 variant could also convert m-tyramine to dopamine (Figure $6 \mathrm{~b}$ ). The velocity value for the metabolism of tyramine to dopamine was $2.0 \mathrm{pmol} / \mathrm{min}$ (Table2). However, the same product (retention time, $3.913 \mathrm{~min}, 7.901 \mathrm{~min}$ ) was also found in the negative control that is mitochondrial fraction isolated from $T . n i$ cells (Figure 6c). Because constructed 2D7 variant is mostly located in mitochondria fraction of insect cells, mitochondria fractions were used for kinetic studies. Both mitochondria fractions, from insect cells and from insect cells expressing 2D7 variant were isolated from the same amount of T.ni insect cells in suspension culture. As described in method, two mitochondria fractions were resuspended in the same amount of solubilization buffer, and the same volume was used for 
kinetic studies. ESI-MS analysis indicates that the $\mathrm{m} / \mathrm{z}$ ratio of the metabolite that is produced by mitochondria fraction from insect cells expressing $2 \mathrm{D} 7$ variant is about 149.3 (Figure 7c), which is the same as the $m / z$ of standard dopamine (Figure $7 \mathrm{a}$ ), and the $\mathrm{m} / \mathrm{z}$ ratio of the product produced by mitochondria fraction from insect cells is also the same as the $m / z$ of standard dopamine (Figure $7 \mathrm{~b}$ ). These data indicated that some proteins or enzymes present in $T . n i$ cells could also convert m-tyramine to dopamine.

c. MPTP metabolism by CYP2D7. The activity of constructed CYP2D7 variant was determined by examining the metabolism of MPTP to PTP. The standard MPTP and PTP mixture were injected directly onto the column for the HPLC assay to identify the retention times of the standards. Using the HPLC conditions described, MPTP and PTP were clearly separated, with retention times of $8.842 \mathrm{~min}$ and $4.026 \mathrm{~min}$, respectively. However, no product was detected at retention time $4.026 \mathrm{~min}$ in the reaction catalyzed by CYP2D7 variant, which indicated that it could not metabolize MPTP to PTP (data not shown).

\section{Discussion}

Siegle provided evidence that $C Y P 2 D 6$ is expressed in certain regions of the human central nervous system (CNS) (41). This report shed light on the genetic polymorphism of this enzyme that might be responsible for a number of drug interactions not only in the liver, but also in the human brain. Pai reported the presence of a unique variant of P450 named CYP2D7 in the human brain and not in human live or kidney (36). Further tests 
showed that codeine was predominantly converted into morphine by this brain-specific variant, while the major metabolite of human liver CYP2D6 is an inactive chemical called nor-codeine. These results demonstrated the existence of a pathway, distinct from known pathways in the liver, which may contribute to a number of drug interactions that are of potential clinical importance for neurological diseases.

To obtain cDNA of this unique variant, we tried different techniques. First, we tried to screen and clone this variant from the cDNA library of human brain substantia nigra, and no positive clone has been probed. Second, we tried to amplify this variant by RTPCR from freshly isolated messenger RNA from human brain tissues. Several PCR products were obtained. However, DNA sequencing analysis showed that these fragments do not share any homolog to $C Y P 2 D$ family (data not shown). Third, we tried to construct this $C Y P 2 D 7$ variant based on $C Y P 2 D 6^{*} 1 c D N A$ sequence by site-directed mutagenesis and insertion. After many cycles mutation followed by an insertion of extra 57 bp DNA fragment, we successfully obtained the full-length cDNA of $C Y P 2 D 7$ variant. DNA sequencing and alignment analysis indicated that the predicted amino acids of the constructed $C Y P 2 D 7$ variant were $100 \%$ identical to the brain CYP2D7 variant. Western blot showed that CYP2D7 variant reacted to both polyclonal and monoclonal antibodies against CYP2D6. These results are consistent to the high identity between CYP2D6 and CYP2D7 variant. The detected molecular weight is about $57 \mathrm{kD}$ that is the same as previously reported (36). 
In this study, CYP2D7 variant exhibited Soret maxima at $450 \mathrm{~nm}$ based on carbon monoxide difference spectral analysis. However, it also showed a strong absorbance at $420 \mathrm{~nm}$. This phenomenon was observed in different P450 enzymes. It has been reported that the enzymes at P420 are the inactive form of P450, which are deficient in the catalytic activity of P450 $(21,34)$. Many investigators have reported that the inactive form could be converted to the catalytically active form by treatment with sulfhydryl compounds such as cysteine, thioglycolic acid, $\beta$-mercaptoethanol, or dithioerythritol (47). In order to increase the active form of CYP2D7 variant, cysteine was added in the cell culture (Final concentration is $50 \mu \mathrm{g} / \mathrm{ml}$ ). However, the ratio between these two forms remained the same after the treatment (data not show), which implied that cysteine could not convert the inactive form of CYP2D7 variant to the active form in the expression system mediated by baculovirus.

Heme and $\Delta$-ALA are two commonly used resources for providing $\mathrm{Fe}^{3+}$ to $\mathrm{P} 450$ enzymes. $\Delta$-ALA is a heme precursor, and it can be converted to heme by a biosynthesis pathway catalyzed by eight different enzymes such as ALA synthase and protophorphyrinogen oxidase. Among those enzymes, the first and the last three enzymes in this pathway are located in mitochondria of different cells. In this study, no catalytic activity was observed based on CO-reduce difference spectral analysis when Heme was used. Instead, the activity of CYP2D7 variant was restored when $\Delta$-ALA was added into the culture medium. Previous studies showed that the incorporation of heme into the catalytic domain is probably one of the critical steps in the folding process of P450 enzymes. Compared to heme, $\Delta$-ALA is more soluble and stable. It could promote the correct 
folding of P450 enzymes by increasing the availability of heme in E. coli expression system by using $\Delta$-ALA (25).

The hepatic CYP2D6 primarily locates at microsome fraction. However, CYP2D6 was also found in plasma membrane, mitochondria and other intracellular membranes(18, 27, 31, 40). In brain tissues, several forms of P450 were found in mitochondrial membranes $(1,2,29,43)$. In this study, Western-blot analysis indicated that CYP2D7 variant was predominantly present in the mitochondrial fraction of insect cells. This results is consistent with CO-reduce difference spectra analysis of microsome fraction, in which no activity was observed. Instead, the activity was observed in the mitochondrial fraction. This result implied that human brain CYP2D7 variant probably has a unique tissue target and plays very unique physiological and pathological roles in the human brain.

Nonfunctional CYP2D6 genotypes have great impacts on the metabolism of drugs. For example, codeine and its analogues are commonly prescribed drug for the treatment of patients with chronic pain $(3,44)$. Codeine is converted to morphine by CYP2D6, which is effective form. These drugs will be completely ineffective if the patients are the poor metabolizers. Therefore, it is very important to identify the CYP2D6 genotypes of patients. In this study, it was found that the brain variant CYP2D7 could metabolite codeine to morphine with higher efficiency than CYP2D6. It is probably responsible for the metabolism of drugs targeting human brain. Thus, whether this type of CYP2D7 variant is present in patients may have great influence on the metabolism of these drugs 
in human brain. However, the specific substrates for this variant have not been characterized yet.

Both p-tyramine and m-tyramine can be metabolized to dopamine by CYP2D6 (17). The $K m$ values of CYP2D6, for p-tyramine and m-tyramine were $190.1 \pm 19.5$ microM and 58.2 \pm 13.8 microM, respectively. Because the affinity between 2D6 and m-tyramine is higher than that between 2D6 and p-tyramine, m-tyramine was selected for kinetic analysis. In this study, it was found that the constructed CYP2D7 variant is probably capable of metabolizing m-tyramine to dopamine (Figure 7c). However, dopamine was also present in the negative control (Figure 7b). Ottaviani also has found that insect cells were able to metabolize and/or detoxify dopamine-derived catecholic TIQs (dopaminederived tetrahydro-isoquinoline) (35). These observations implied that unknown enzymes present in the insect cells could also metabolize m-tyramine to dopamine. In the current study, the mitochondria fraction from insect cells can metabolize more m-tyramine to dopamine than the mitochondria fraction from insect cells expressing 2D7 variant based on the area under the curves, the probability is that the expression of these enzymes that can metabolize m-tyramine to dopamine are limited in insect cells expressing 2D7 variant. For the future study, the purified enzyme or the enzyme expressed in different systems will help us to confirm that if the constructed CYP2D7 variant is able to metabolize m-tyramine to dopamine.

In the brain, MPTP is oxidized by mitochondrial monoamine oxidase to the active 1mithyl-4-phenylpyridinium ion $\left(\mathrm{MPP}^{+}\right)$, which is selectively toxic to cells of the 
substantia nigra (26) - the region of the brain affected in Parkinson's disease. In-vitro studies have shown that MPTP and $\mathrm{MPP}^{+}$may be metabolized by CYP2D6 $(10)(5,12)$ which is localized to this region of the brain (32). Boopathi et al indicated that in rat brains, CYP1A1 in the microsomes and mitochondria follow different kinetic patterns. Under chronic BNF ( $\beta$ - naphthoflavone) treatment conditions both in rat brain and cultured C6 glioma cells, the mitochondria form continued to accumulate and become a major part of the total $1 \mathrm{~A} 1$ pool and exhibited high $\mathrm{N}$-demethylation activity with a variety of antidepressant and antinvulsant drugs (2). In our study, the CYP2D7 variant was predominantly present in the mitochondrial fraction from the transfected insect cells. This result indicated that the human brain CYP2D7 variant may have unique tissue targets and play important physiological or pathological roles. For these reasons, although it is not clear that what kinds of neuroactive drugs can be metabolized by CYP2D7 variant, it is very important that individuals with 2D7 variant should be considerate in the proper selection of drugs as well as determining the drug dose.

The brain's defense against MPTP and similar compounds is the system of monooxygenases associated with cytochrome P450, particularly the subset CYP2D6 $(6,26)$. In theory, individuals that have deficit CYP2D6 protein are at increased risk of Parkinson's disease because they have no defense against neurotoxins such as MPTP. In current study, it was shown that brain CYP2D7 variant was unable to metabolite MPTP, and a more probable role for the splice variant is the posttranscriptional down-regulation of the expression of CYP2D6. The individuals with CYP2D7 variant may have poor protection against MPTP neurotoxins and result in greater risk of Parkinson's disease 
than individuals without this genotype. In addition, alternative splicing variant CYP2D7 can convert non-active form of drug into active one within target tissue brain, it may contribute to a better understanding of the potential clinical importance for central nervous system diseases.

Both Asp301 and Glu216 are important for CYP2D6 for the metabolism of basic substrates (23). Investigation into the relationship between Asp301 and Glu216containing system suggests that both residues are necessary for metabolism of a basic substrate. If either residue is missing then the specificity of the enzyme is altered. Although both residues appear necessary for the metabolism of basic substrates, Glu216 does not replace Asp301 in the binding of basic substrates. There is an accepted model for binding of MPTP by formation of an ion pair of the protonated amine with the carboxylate anion of Asp301 in the enzyme active site and subsequent oxidation at a distant site of the molecule. In 2D7 variant sequence, Asp301 is replaced by Asn, Glu216 is not been changed. Because Glu216 does not replace Asp301 in the binding of basic substrates, substitution of Asp301 in 2D7 variant sequence may affect MPTP metabolism. Previous study indicated that Phe120 contributed to determining the specificity of substrate oxidation by CYP2D6(9), while in 2D7 sequence, residue Phe120 is replaced by Ile, this may affect the substrate orientation. The substitutions of D301N and F120I may be one of the reasons that constructed 2D7 variant cannot_metabolize MPTP. It is important to take into account the influential role of D301N and F120I in 2D7 sequence in terms of characterizing 2D7 variant enzyme efficiency. 
In summary, the understanding of this unique CYP2D7 variant is still on the early stage since this unique variant has only been found in the part of Indian population (36). A functional CYP2D7 transcript has not been observed in other population such as Asian, Caucasian and African American populations (11). In addition, our results were unable to confirm Pai's study based on the analysis of the constructed CYP2D7.

\section{Figure legends}

\section{Figure 1}

Alignment of CYP2D6 and CYP2D7. amino acid sequence alignment between CYP2D6 and CYP2D7. In addition to 19 extra amino acids (57bps) in CYP2D7, the different amino acids between CYP2D6 and CYP2D7 are indicated.

\section{Figure 2}

Construction and expression of brain variant CYP2D7 based on CYP2D6. (a) The pFastBac I with 2D7 gene and 2D6 gene was transformed into DH10Bac competent cells, these cells contain bacmid DNA. Recombinant bacmid DNAs can be obtained after homologious recombination. The recombinant bacmid DNAs were confirmed by PCR. The forward primer is 2D6 5'that can bind to 2D6 gene, the reverse primer is M13 reverse that can bind to bacmid DNA. The size of PCR product of 2D6 is 2074bps, and the size of PCR product of 2D7 is 2131 bps. (b) Western blot analysis of CYP2D7 variant protein expression. CYP2D7 gene was expressed in insect cell line. The T. ni whole cell lyses were loaded in SDS-PAGE gel, then proteins were transferred into PVDF membrane. CYP2D6 monoclonal antibody was used for western blot. The molecular weight of CYP2D7 is around $57.7 \mathrm{KD}$. 


\section{Figure 3}

Carbon monoxide difference spectroscopy of CYP2D7 variant. Spectra were determined by the method of Omura and Sato (1964). The reduced carbon monoxide difference spectra of the expressed protein exhibited Soret maxima at $454 \mathrm{~nm}$ characteristic of P450. It also showed absorbance at $418 \mathrm{~nm}$.

\section{Figure 4}

\section{Analysis of CYP2D7 protein expression in different subcellular fraction by western}

blot. Constructed CYP2D7 variant was over-expressed in T.ni insect cells using baculovirus expression system. Different cell fractions were obtained according to different centrifugation and time. Mitochondria and microsomes were isolated separately. Both these fractions were analysed by western blot using anti-CYP2D6 monoclonal antibody. Lane 1: insect cells; lane 2: cell lyses with CYP2D6; lane3: cell lyses with CYP2D7 variant; lane4: CYP2D7 (microsomes); lane5: CYP2D7 (mitochondria); lane6: purified CYP2D6 enzyme.

\section{Figure 5}

Codeine metabolism by constructed CYP2D7 variant. Codeine and its two metabolites, morphine and nor-codeine, were separated by different retention time by HPLC (Figure 5a). HPLC separation of codeine and its metabolites morphine and norcodeine by CYP2D7 variant with retention times of $7.668 \mathrm{~min}$ (morphine), $11.379 \mathrm{~min}$ (nor-codeine) and 13.648 min (codeine) (Figure 5b). 


\title{
Figure 6
}

M-tyramine metabolism by constructed CYP2D7 variant. M-tyramine and its metabolite dopamine were separated by different retention time by HPLC (Figure 6a). HPLC separation of m-tyramine and its metabolite dopamine by CYP2D7 variant was carried out by different retention times of 4.183(dopamine), 8.434 (m-tyramine) (Figure 6b). HPLC separation of m-tyramine and its metabolite dopamine by mitochondria fraction from insect cells was done by different retention times of 3.978 (dopamine), 7.482 (m-tyramine) (Figure 6c).

\section{Figure 7}

MS analysis of dopamine formed from m-tyramine by constructed CYP2D7 variant. Dopamine formation from m-tyramine was determined by ESI-MS. The $m / z$ of dopamine is 149.3 . For m-tyramine metabolism, the reaction mixture was diluted in $50 \%$ methanol and $50 \%$ acetonitrile to the final concentration of $1 \mu \mathrm{g} / \mathrm{ml}$ just before analysis. (a)

Standard; (b) m-tyramine metabolized by the mitochondrial fraction from the $T$. $n i$ insect cells; (c) m-tyramine metabolized by the mitochondrial fraction from the $T$. $n i$ cells expressing CYP2D7 variant

\author{
Reference List
}

1. Bhagwat, S. V., M. R. Boyd, and V. Ravindranath. 1995. Brain mitochondrial cytochromes P450: xenobiotic metabolism, presence of multiple forms and their selective inducibility. Arch.Biochem Biophys. 320:73-83.

2. Boopathi, E., H. K. Anandatheerthavarada, S. V. Bhagwat, G. Biswas, J. K. Fang, and N. G. Avadhani. 2000. Accumulation of mitochondrial P450MT2, $\mathrm{NH}(2)$-terminal truncated cytochrome P4501A1 in rat brain during chronic treatment with beta-naphthoflavone. A role in the metabolism of neuroactive drugs. J Biol Chem. 275:34415-34423. 
3. Cascorbi, I. 2003. Pharmacogenetics of cytochrome p4502D6: genetic background and clinical implication. Eur.J Clin Invest 33 Suppl 2:17-22.

4. Chinta, S. J., H. V. Pai, S. C. Upadhya, M. R. Boyd, and V. Ravindranath. 2002. Constitutive expression and localization of the major drug metabolizing enzyme, cytochrome P4502D in human brain. Brain Res Mol Brain Res 103:4961.

5. Coleman, T., S. W. Ellis, I. J. Martin, M. S. Lennard, and G. T. Tucker. 1996. 1-Methyl-4-phenyl-1,2,3,6-tetrahydropyridine (MPTP) is N-demethylated by cytochromes P450 2D6, 1A2 and 3A4--implications for susceptibility to Parkinson's disease. J Pharmacol.Exp.Ther. 277:685-690.

6. Coleman, T., S. W. Ellis, I. J. Martin, M. S. Lennard, and G. T. Tucker. 1996. 1-Methyl-4-phenyl-1,2,3,6-tetrahydropyridine (MPTP) is N-demethylated by cytochromes P450 2D6, 1A2 and 3A4--implications for susceptibility to Parkinson's disease. J Pharmacol.Exp.Ther. 277:685-690.

7. Cotzias, G. C., P. S. Papavasiliou, and R. Gellene. 1969. Modification of Parkinsonism--chronic treatment with L-dopa. N.Engl.J Med. 280:337-345.

8. Elexpuru-Camiruaga, J., N. Buxton, V. Kandula, P. S. Dias, D. Campbell, J. McIntosh, J. Broome, P. Jones, A. Inskip, J. Alldersea, and . 1995. Susceptibility to astrocytoma and meningioma: influence of allelism at glutathione S-transferase (GSTT1 and GSTM1) and cytochrome P-450 (CYP2D6) loci. Cancer Res 55:4237-4239.

9. Flanagan, J. U., J. D. Marechal, R. Ward, C. A. Kemp, L. A. McLaughlin, M. J. Sutcliffe, G. C. Roberts, M. J. Paine, and C. R. Wolf. 2004. Phe120 contributes to the regiospecificity of cytochrome P450 2D6: mutation leads to the formation of a novel dextromethorphan metabolite. Biochem J 380:353-360.

10. Fonne-Pfister, R., M. J. Bargetzi, and U. A. Meyer. 1987. MPTP, the neurotoxin inducing Parkinson's disease, is a potent competitive inhibitor of human and rat cytochrome P450 isozymes (P450bufI, P450db1) catalyzing debrisoquine 4-hydroxylation. Biochem Biophys.Res Commun. 148:1144-1150.

11. Gaedigk, A., R. Gaedigk, and J. S. Leeder. 2005. CYP2D7 splice variants in human liver and brain: does CYP2D7 encode functional protein? Biochem Biophys.Res Commun. 336:1241-1250.

12. Gilham, D. E., W. Cairns, M. J. Paine, S. Modi, R. Poulsom, G. C. Roberts, and C. R. Wolf. 1997. Metabolism of MPTP by cytochrome P4502D6 and the demonstration of 2D6 mRNA in human foetal and adult brain by in situ hybridization. Xenobiotica 27:111-125. 
13. Gonzalez, F. J., T. Aoyama, and H. V. Gelboin. 1990. Activation of promutagens by human cDNA-expressed cytochrome P450s. Prog.Clin Biol Res 340B:77-86.

14. Gonzalez, M. V., V. Alvarez, M. F. Pello, M. J. Menendez, C. Suarez, and E. Coto. 1998. Genetic polymorphism of N-acetyltransferase-2, glutathione Stransferase-M1, and cytochromes P450IIE1 and P450IID6 in the susceptibility to head and neck cancer. J Clin Pathol. 51:294-298.

15. Guengerich, F. P. 1992. Characterization of human cytochrome P450 enzymes. FASEB J 6:745-748.

16. Haining, R. L., A. P. Hunter, M. E. Veronese, W. F. Trager, and A. E. Rettie. 1996. Allelic variants of human cytochrome P450 2C9: baculovirus-mediated expression, purification, structural characterization, substrate stereoselectivity, and prochiral selectivity of the wild-type and I359L mutant forms. Arch.Biochem Biophys. 333:447-458.

17. Hiroi, T., S. Imaoka, and Y. Funae. 1998. Dopamine formation from tyramine by CYP2D6. Biochem.Biophys.Res.Commun. 249:838-843.

18. Honkakoski, P., A. Kojo, H. Raunio, M. Pasanen, R. Juvonen, and M. A. Lang. 1988. Hepatic mitochondrial coumarin 7-hydroxylase: comparison with the microsomal enzyme. Arch.Biochem Biophys. 267:558-567.

19. Hornykiewicz, O. 1993. Parkinson's disease and the adaptive capacity of the nigrostriatal dopamine system: possible neurochemical mechanisms. Adv.Neurol. 60:140-147.

20. Idle, J. R. and R. L. Smith. 1979. Polymorphisms of oxidation at carbon centers of drugs and their clinical significance. Drug Metab Rev 9:301-317.

21. Imai, Y. and R. SATO. 1967. Conversion of P-450 to P-420 by neutral salts and some other reagents. Eur.J Biochem 1:419-426.

22. Kimura, S., M. Umeno, R. C. Skoda, U. A. Meyer, and F. J. Gonzalez. 1989. The human debrisoquine 4-hydroxylase (CYP2D) locus: sequence and identification of the polymorphic CYP2D6 gene, a related gene, and a pseudogene. Am.J.Hum.Genet. 45:889-904.

23. Kirton, S. B., C. A. Kemp, N. P. Tomkinson, S. St Gallay, and M. J. Sutcliffe. 2002. Impact of incorporating the 2C5 crystal structure into comparative models of cytochrome P450 2D6. Proteins 49:216-231.

24. Krishna, D. R. and U. Klotz. 1994. Extrahepatic metabolism of drugs in humans. Clin Pharmacokinet. 26:144-160. 
25. Kusano, K., M. Sakaguchi, N. Kagawa, M. R. Waterman, and T. Omura. 2001. Microsomal p450s use specific proline-rich sequences for efficient folding, but not for maintenance of the folded structure. J Biochem (Tokyo) 129:259-269.

26. Langston, J. W. 1985. MPTP neurotoxicity: an overview and characterization of phases of toxicity. Life Sci. 36:201-206.

27. Loeper, J., V. Descatoire, M. Maurice, P. Beaune, G. Feldmann, D. Larrey, and D. Pessayre. 1990. Presence of functional cytochrome P-450 on isolated rat hepatocyte plasma membrane. Hepatology 11:850-858.

28. Miksys, S., Y. Rao, E. Hoffmann, D. C. Mash, and R. F. Tyndale. 2002. Regional and cellular expression of CYP2D6 in human brain: higher levels in alcoholics. J Neurochem. 82:1376-1387.

29. Miksys, S., Y. Rao, E. M. Sellers, M. Kwan, D. Mendis, and R. F. Tyndale. 2000. Regional and cellular distribution of CYP2D subfamily members in rat brain. Xenobiotica 30:547-564.

30. Nebert, D. W. 1997. Polymorphisms in drug-metabolizing enzymes: what is their clinical relevance and why do they exist? Am.J Hum.Genet. 60:265-271.

31. Neve, E. P., E. Eliasson, M. A. Pronzato, E. Albano, U. Marinari, and M. Ingelman-Sundberg. 1996. Enzyme-specific transport of rat liver cytochrome P450 to the Golgi apparatus. Arch.Biochem Biophys. 333:459-465.

32. Niznik, H. B., R. F. Tyndale, F. R. Sallee, F. J. Gonzalez, J. P. Hardwick, T. Inaba, and W. Kalow. 1990. The dopamine transporter and cytochrome P45OIID1 (debrisoquine 4-hydroxylase) in brain: resolution and identification of two distinct $[3 \mathrm{H}] \mathrm{GBR}-12935$ binding proteins. Arch.Biochem Biophys. 276:424432.

33. Ohmori, O., T. Suzuki, H. Kojima, T. Shinkai, T. Terao, T. Mita, and K. Abe. 1998. Tardive dyskinesia and debrisoquine 4-hydroxylase (CYP2D6) genotype in Japanese schizophrenics. Schizophr.Res 32:107-113.

34. Omura, T., R. SATO, D. Y. Cooper, O. Rosenthal, and R. W. Estabrook. 1965. Function of cytochrome P-450 of microsomes. Fed.Proc. 24:1181-1189.

35. Ottaviani, E., A. J. Nappi, and E. Vass. 2002. Resistance of the insect cell line IPLB-LdFB to salsolinol-induced apoptosis. Arch.Insect Biochem Physiol 49:1-9.

36. Pai, H. V., R. P. Kommaddi, S. J. Chinta, T. Mori, M. R. Boyd, and V. Ravindranath. 2004. A frameshift mutation and alternate splicing in human brain generate a functional form of the pseudogene cytochrome P4502D7 that demethylates codeine to morphine. J Biol Chem. 279:27383-27389. 
37. Qu, W., J. A. Bradbury, C. C. Tsao, R. Maronpot, G. J. Harry, C. E. Parker, L. S. Davis, M. D. Breyer, M. P. Waalkes, J. R. Falck, J. Chen, R. L.

Rosenberg, and D. C. Zeldin. 2001. Cytochrome P450 CYP2J9, a new mouse arachidonic acid omega-1 hydroxylase predominantly expressed in brain. J Biol Chem. 276:25467-25479.

38. Rendic, S. 2002. Summary of information on human CYP enzymes: human P450 metabolism data. Drug Metab Rev 34:83-448.

39. Riedl, A. G., P. M. Watts, P. Jenner, and C. D. Marsden. 1998. P450 enzymes and Parkinson's disease: the story so far. Mov Disord. 13:212-220.

40. Robin, M. A., M. Le Roy, V. Descatoire, and D. Pessayre. 1997. Plasma membrane cytochromes P450 as neoantigens and autoimmune targets in druginduced hepatitis. J Hepatol. 26 Suppl 1:23-30.

41. Siegle, I., P. Fritz, K. Eckhardt, U. M. Zanger, and M. Eichelbaum. 2001. Cellular localization and regional distribution of CYP2D6 mRNA and protein expression in human brain. Pharmacogenetics 11:237-245.

42. Tanaka, S., X. Chen, Y. Xia, D. E. Kang, N. Matoh, M. Sundsmo, R. G. Thomas, R. Katzman, L. J. Thal, J. Q. Trojanowski, T. Saitoh, K. Ueda, and E. Masliah. 1998. Association of CYP2D microsatellite polymorphism with Lewy body variant of Alzheimer's disease. Neurology 50:1556-1562.

43. Walther, B., J. F. Ghersi-Egea, A. Minn, and G. Siest. 1986. Subcellular distribution of cytochrome P-450 in the brain. Brain Res 375:338-344.

44. Wilcox, R. A. and H. Owen. 2000. Variable cytochrome P450 2D6 expression and metabolism of codeine and other opioid prodrugs: implications for the Australian anaesthetist. Anaesth.Intensive Care 28:611-619.

45. Wundrack, I., E. Meese, R. Mullenbach, and N. Blin. 1994. Debrisoquine hydroxylase gene polymorphism in meningioma. Acta Neuropathol.(Berl) 88:472-474.

46. Yu, A., H. Dong, D. Lang, and R. L. Haining. 2001. Characterization of dextromethorphan $\mathrm{O}$ - and $\mathrm{N}$-demethylation catalyzed by highly purified recombinant human CYP2D6. Drug Metab Dispos. 29:1362-1365.

47. Yu, C. and I. C. Gunsalus. 1974. Cytochrome P-450cam. II. Interconversion with P-420. J Biol Chem. 249:102-106. 


\begin{tabular}{|c|c|}
\hline Mutations & Primer sequences \\
\hline V11M & 5'-CCCCTGGCCATGATAGTGGCC-3' \\
\hline $\mathrm{R} 26 \mathrm{H}$ & 5'ATGCACCGGCACCAACGCTGG-3' \\
\hline S70N & 5'-GACGTGTTCAACCTGCAGCTG-3' \\
\hline F120I, A122S & 5'-CCAAGGGGTGATCCTGTCGCGCTATGGG-3' \\
\hline N166D, H167Q, S168A & 5'-GCCGCCTTCGCCGACCAGGCCGGACGCCCC \\
\hline L231P & 5'-CCCCGTCCTCCCGCATATCCCAG-3' \\
\hline Q258H & 5'-CTAACTGAGCACAGGATGACCTGG-3' \\
\hline P325L & 5'-GATCCTACATCTGGATGTGCAGCG-3' \\
\hline A351V, C355Y & $\begin{array}{l}\text { 5'-GGTGACCAGGTTCACATCCCTA } \\
\text { CACCACTGCC-3' }\end{array}$ \\
\hline M374V & $\begin{array}{l}\text { 5'-GGGGACATCGTCCCCCTGGGTGT } \\
\text { GACCCATATG-3' }\end{array}$ \\
\hline P469A, T470A & 5'-GCTTCTCGGTGGCCGCTGGACAGCCCC-3' \\
\hline L91M, H94R & $\begin{array}{l}\text { 5'-GGCTGGCGGCCGCGCGCGCCGCCATGGT } \\
\text { GACCCGCGGCGAGGAC-3' }\end{array}$ \\
\hline V104A, T107Y, I109V & $\begin{array}{l}\text { 5'-CGCCCGCCTGCGCCCATCTACCAGGTCCT } \\
\text { GGGTTTCG-3' }\end{array}$ \\
\hline E278K, M279K, N285S & $\begin{array}{l}\text { 5'-GGCCTTCCTGGCAAAGAAGGAGAAGGCC } \\
\text { AAGGGGAGCCCTGAGAGC-3' }\end{array}$ \\
\hline A300G, D301N, S304L & $\begin{array}{l}\text { 5'-GCATAGTGGTGGGTAACCTGTTCCTTGCC } \\
\text { GGGATGG-3' }\end{array}$ \\
\hline $\begin{array}{l}\text { H478S, G479R, F481A } \\
\text { A482S, S486T }\end{array}$ & $\begin{array}{l}\text { 5'-GGCCCAGCCACTCTCGTGTCGTTTCTTTC } \\
\text { CTGGTGACCCCATCCCCC-3' }\end{array}$ \\
\hline
\end{tabular}

Table1. Primers for site-directed mutagenesis 
CYP2D6 MGLEALVPLAVIVAIFLLLVDLMHRRQRWAARYPPGPLPLPGLGNLLHVD 50 CYP2D7 MGLEALVPLAMIVAIFLLLVDLMHRHQRWAARYPPGPLPLPGLGNLLHVD 50

FQNTPYCFDQLRRRFGDVESLQLAWT PVVVLNGLAAVREALVTHGEDTAD 100 FQNTPYCFDQLRRRFGDVFNLQLAWT PVVVLNGLAAVREAMVTRGEDTAD100

RPPVPITQILGFGPRSQGVFLARYGPAWREQRRESVSTLRNLGLGKKS LE 150 RPPAPIYQVLGFGPRSQGVILSRYGPAWREQRRFSVSTLRNLGLGKKSLE 150 QWVTEEAACLCAAFANHS GRPERPNGLLDKAVSNVIASLTCGRREEYDDP200 OWVTEEAACLCAAFADOAGRPERPNGLLDKAVSNVIASLTCGRREEYDDP 200

RELRLLDLAQEGLKEESGFLREVLNÁVPVLLHIPALAGKVLRFQKAFLTQ 250 RFLRLLDLAQEGLKEESGFLREVLNAVPVLPHIPALAGKVLRFQKAFLTQ 250

LDELLTEHRMTWDPAQPPRDLTEAFLAEMEKAKGNPES S FNDENLCIVVA 300 LDELLTEHRMTWDPAQPPRDLTEAFLAKKEKAKGSPES S FNDENLRIVVG 300

DLESAGMVTTSTTLAWGLLLMILHPDVQR-------------------RV 331 NLFLAGMVTTLTTLAWGLLLMILHLDVQRGRRVS P GCS P IVGTHVCPVRV 350 QQEIDDVIGQVRRPEMGDQAHMPYTTAVIHEVQREGDIVPLGVTHMTSRD 381 QQEIDDVIGQVRRPEMGDQVHMPYTTAVI HEVQRFGDIVPLGVTHMT SRD 400

IEVQGFRIPKGTTLITNLSSVLKDEAVWEKPERFHPEHFLDAQGHEVKPE 431 IEVQGFRIPKGTTLITNLSSVLKDEAVWEKP FRFHPEHELDAQGHEVKPE 450

AFLPESAGRRACLGEPLARMELFLFFTSLLQHESESVPTGQPRPSHHGVE 481 AFLPFSAGRRACLGEPLARMELFLFETSLLQHFSFSVAAGQPRPSHSRVV 500

AFLVTPS PYELCAVPR 497
SELVTPSPYELCAVPR 516

Figure 1 

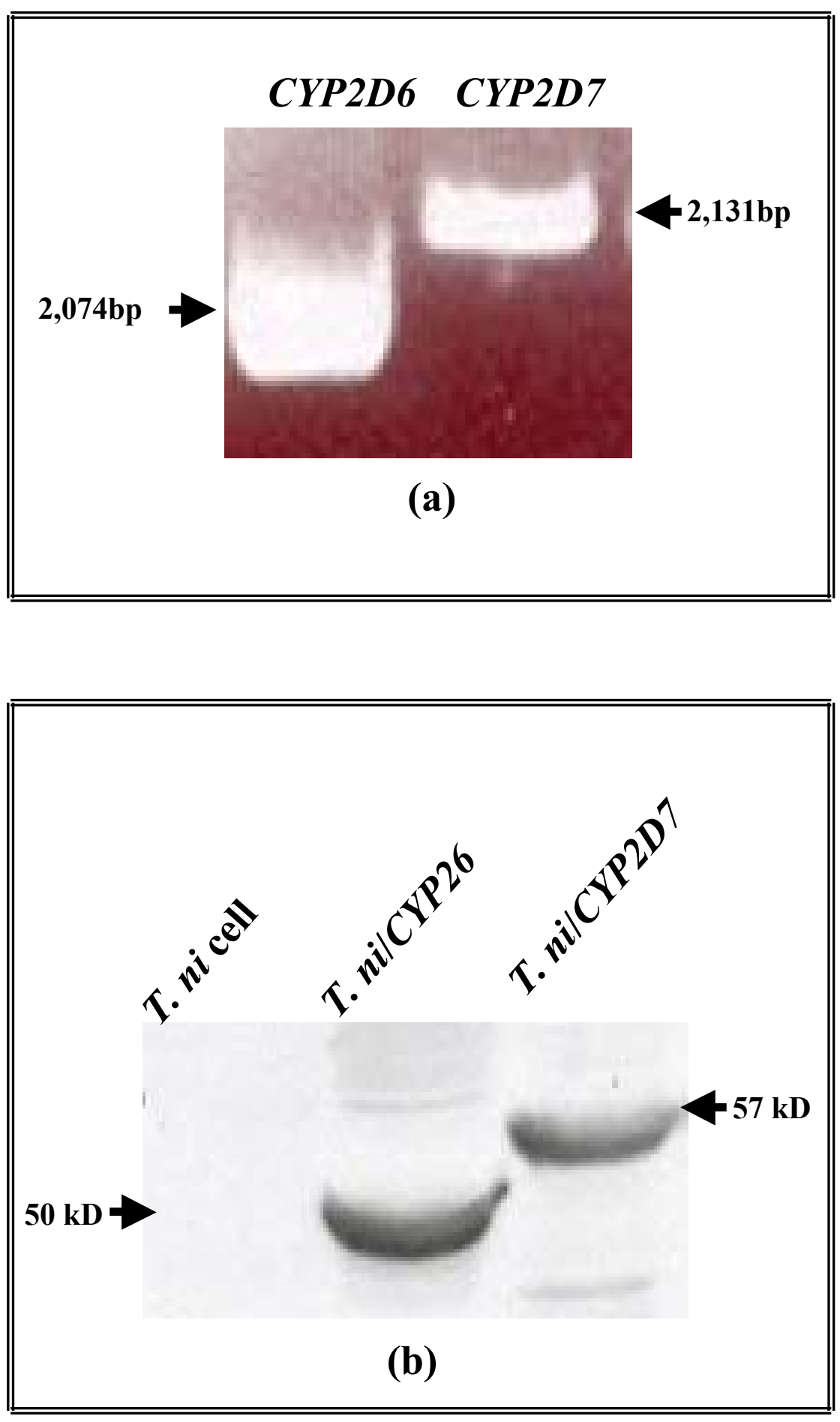

Figure 2 


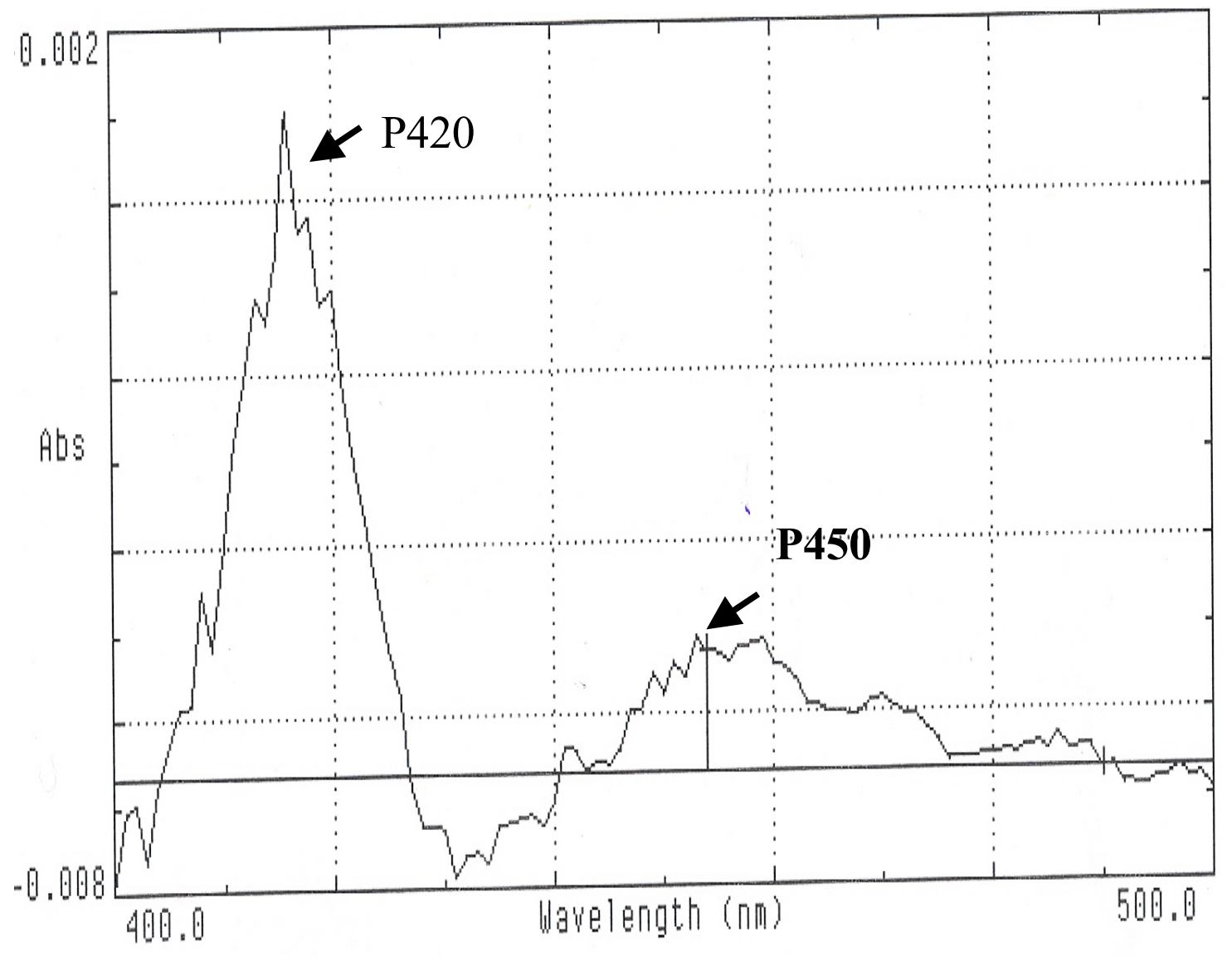

Figure 3 


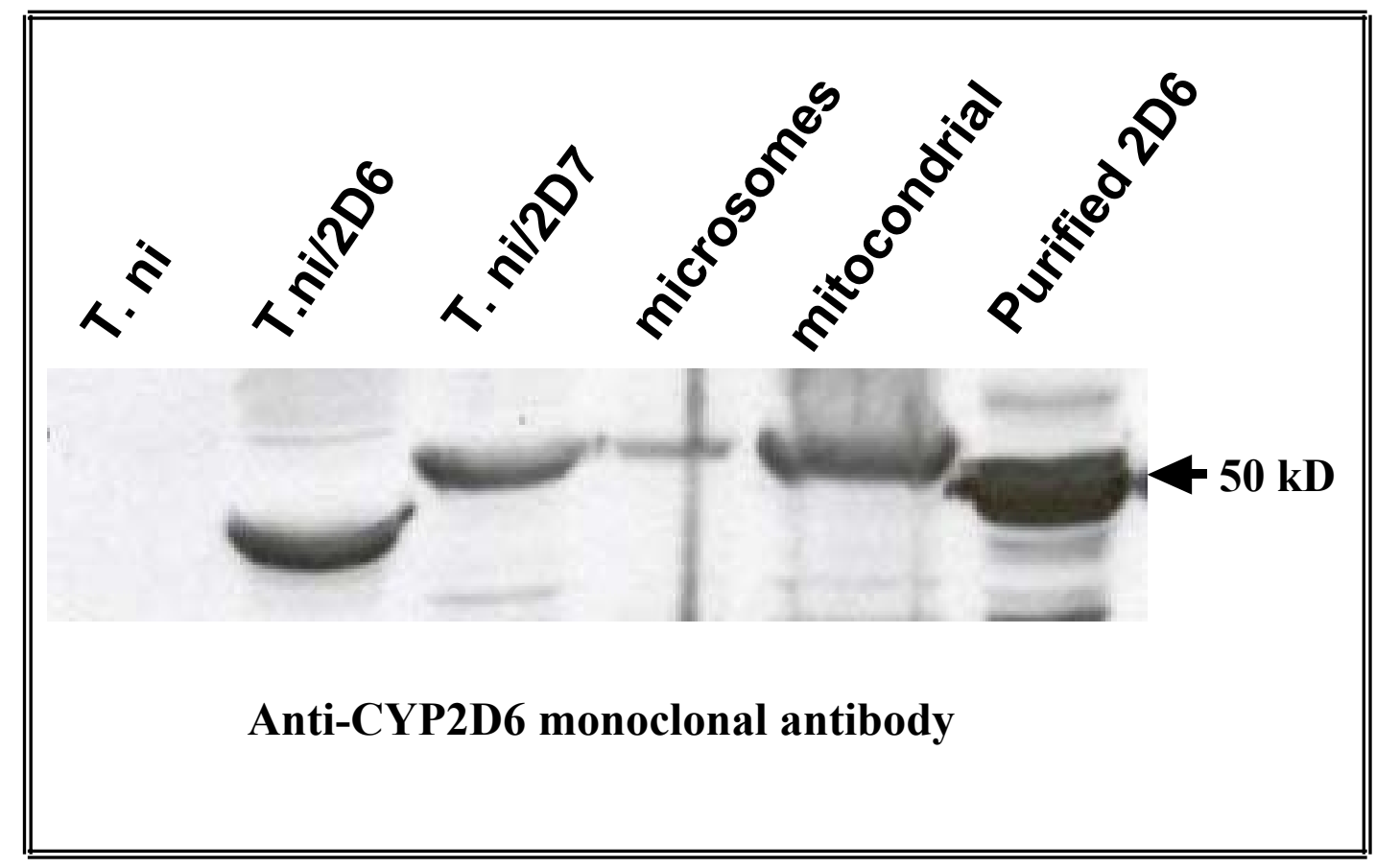

Figure 4 


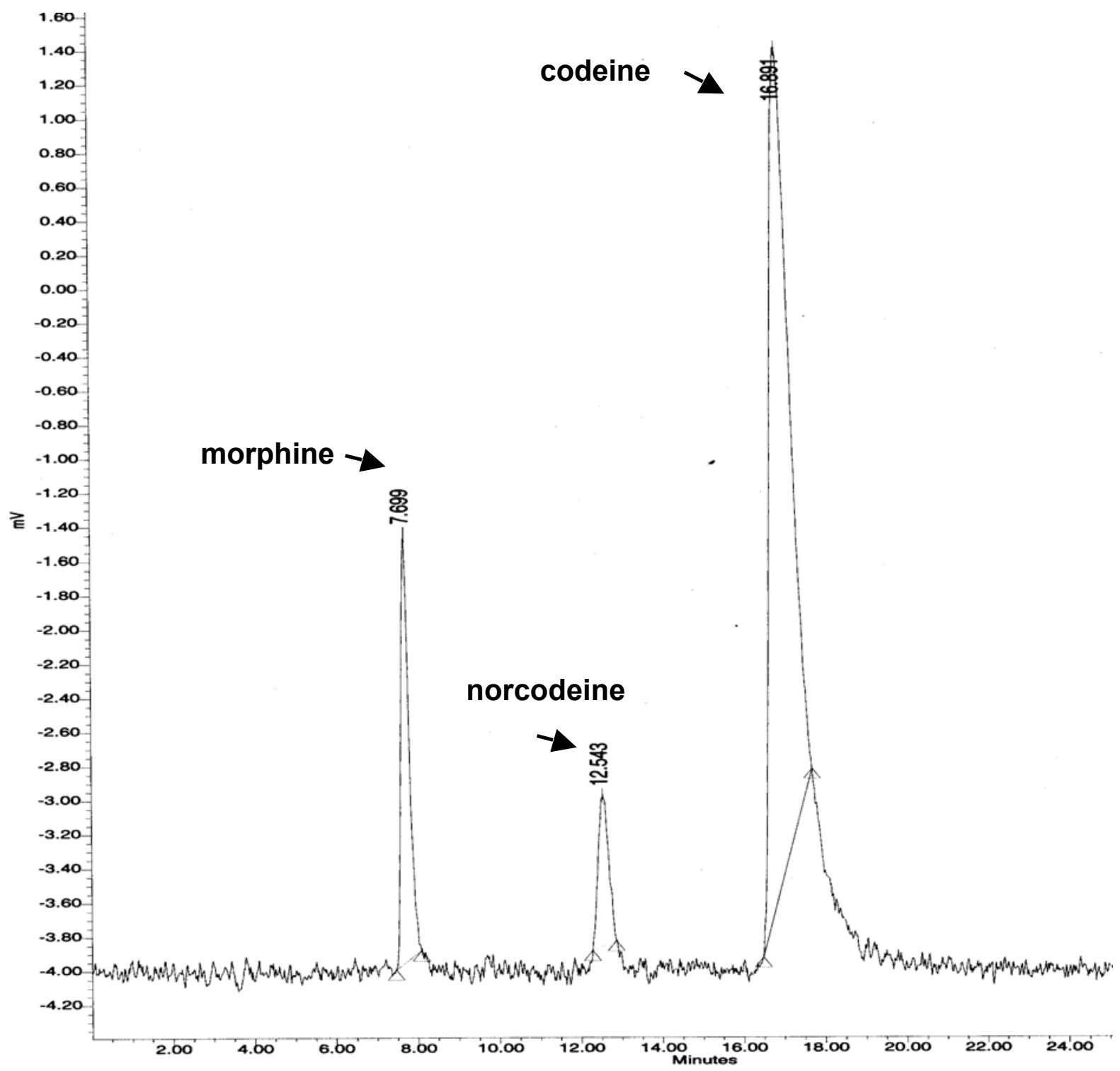

Figure 5(a) Standard of codeine, morphine and nor-codeine) 


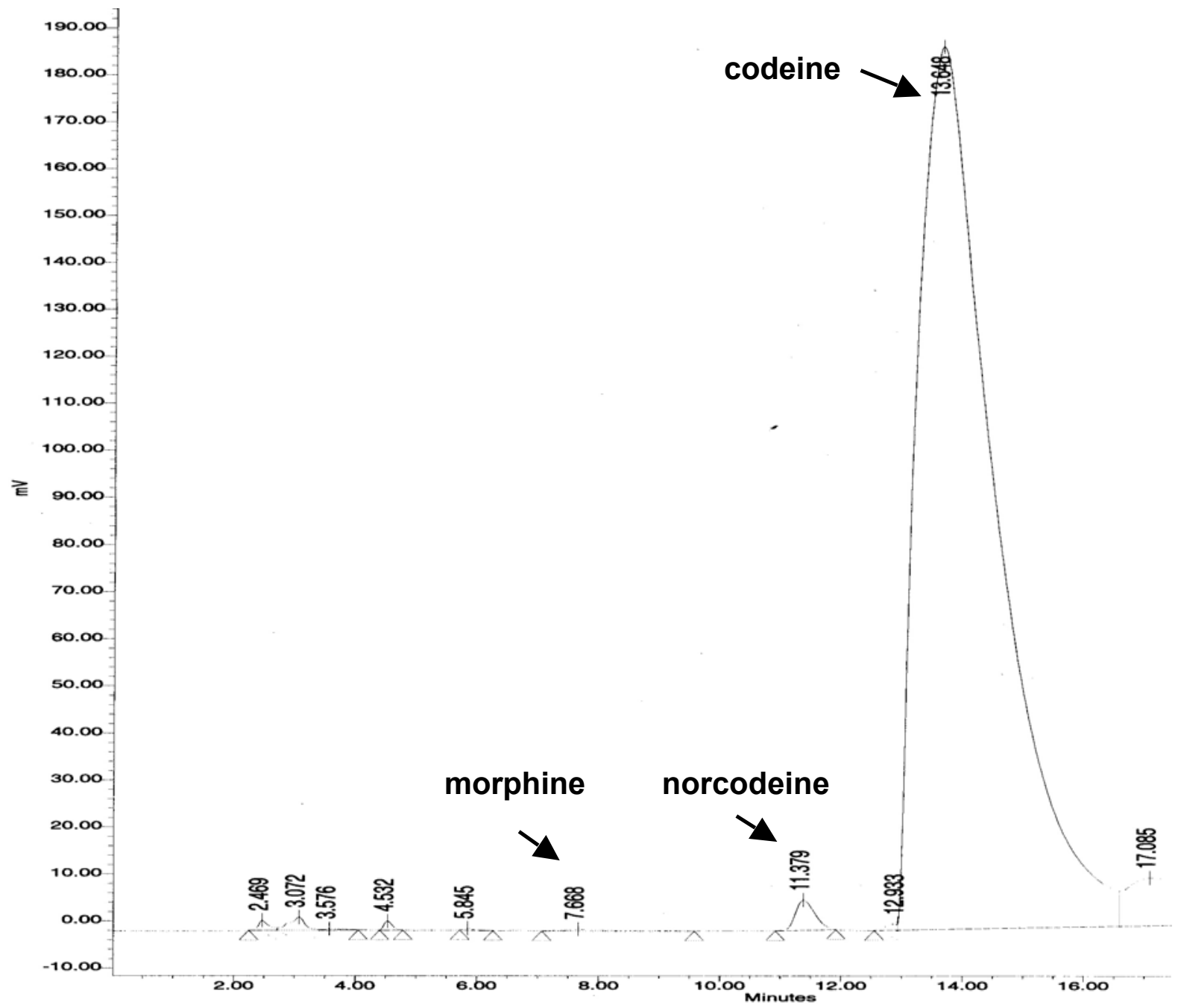

Figure 5 (b) Metabolism of codeine by CYP2D7 variant 


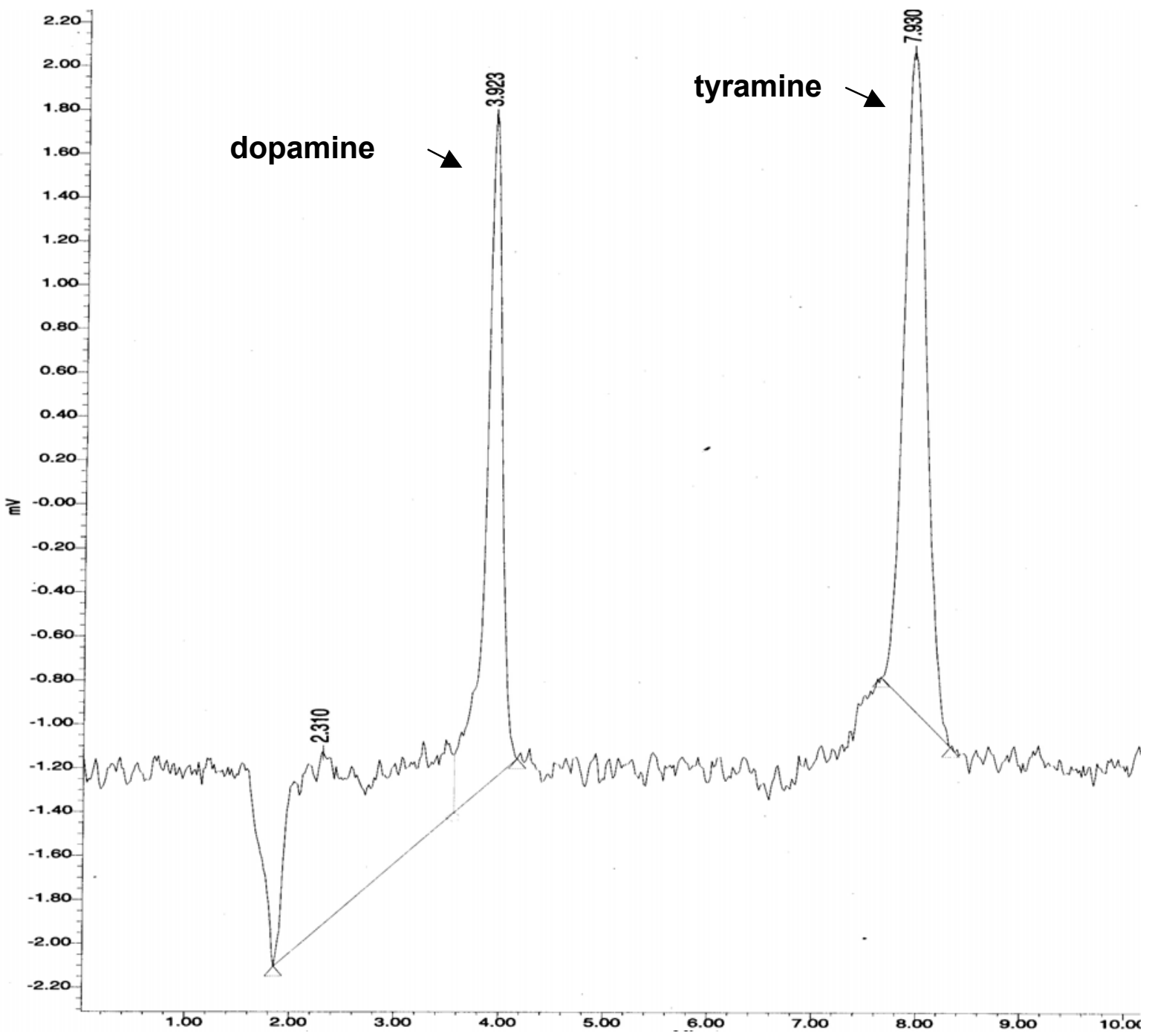

Figure 6(a) Standard of dopamine and tyramine 


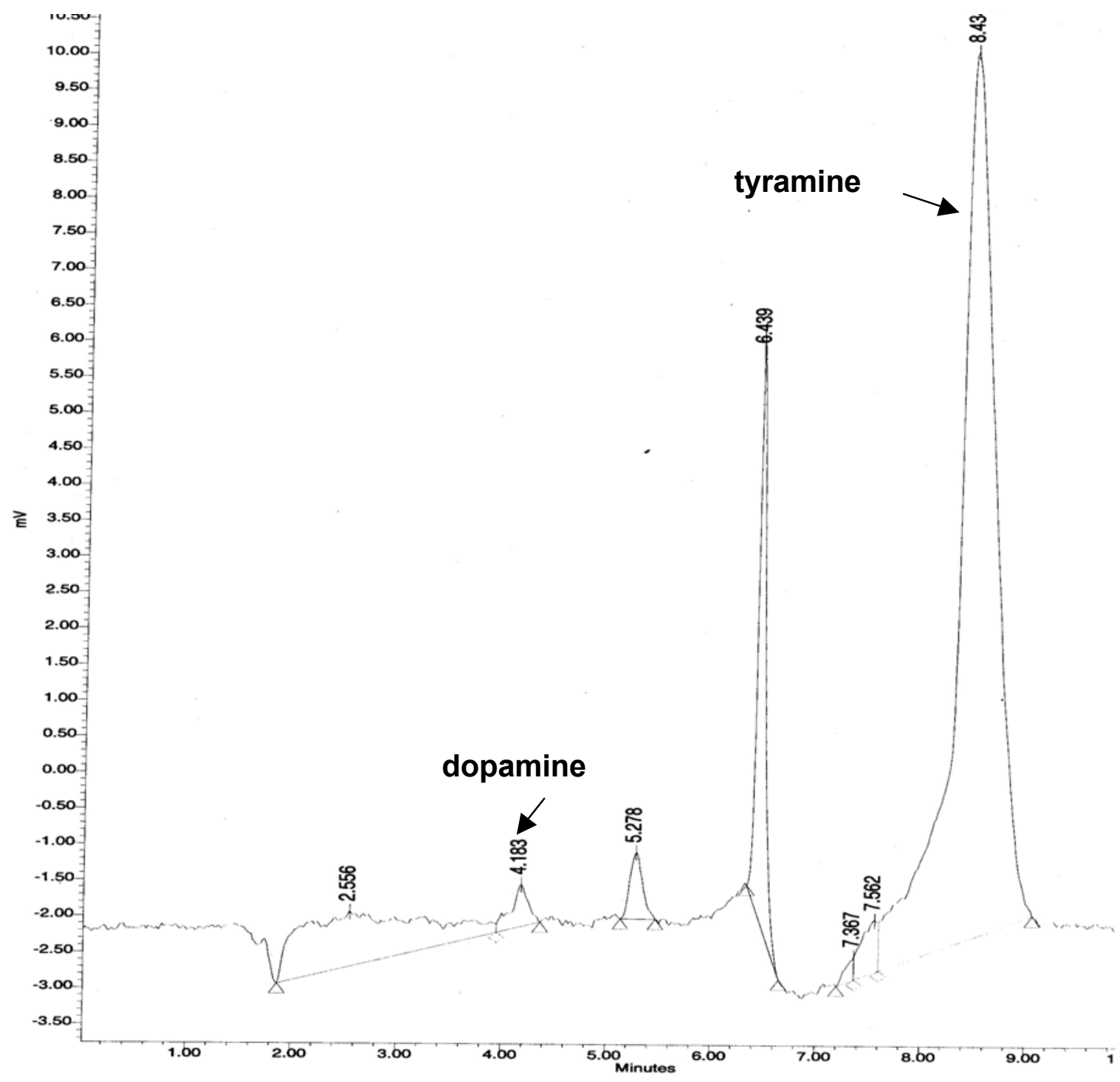

Figure 6 (b) Metabolism of Tyramine by CYP2D7 variant 


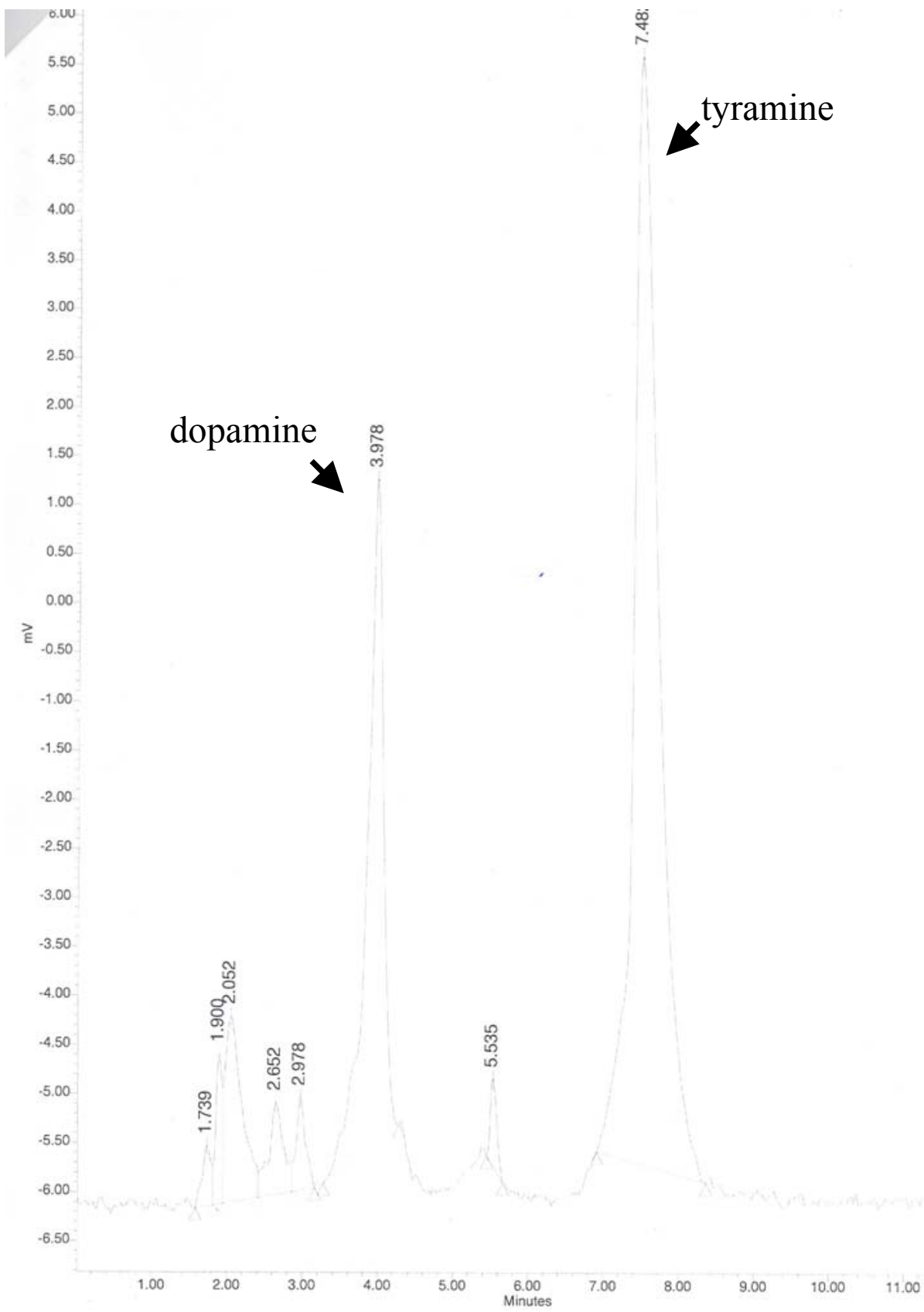

Figure 6 (c) Metabolism of Tyramine by mitochondrial fraction from $T . n i$ insect cells 


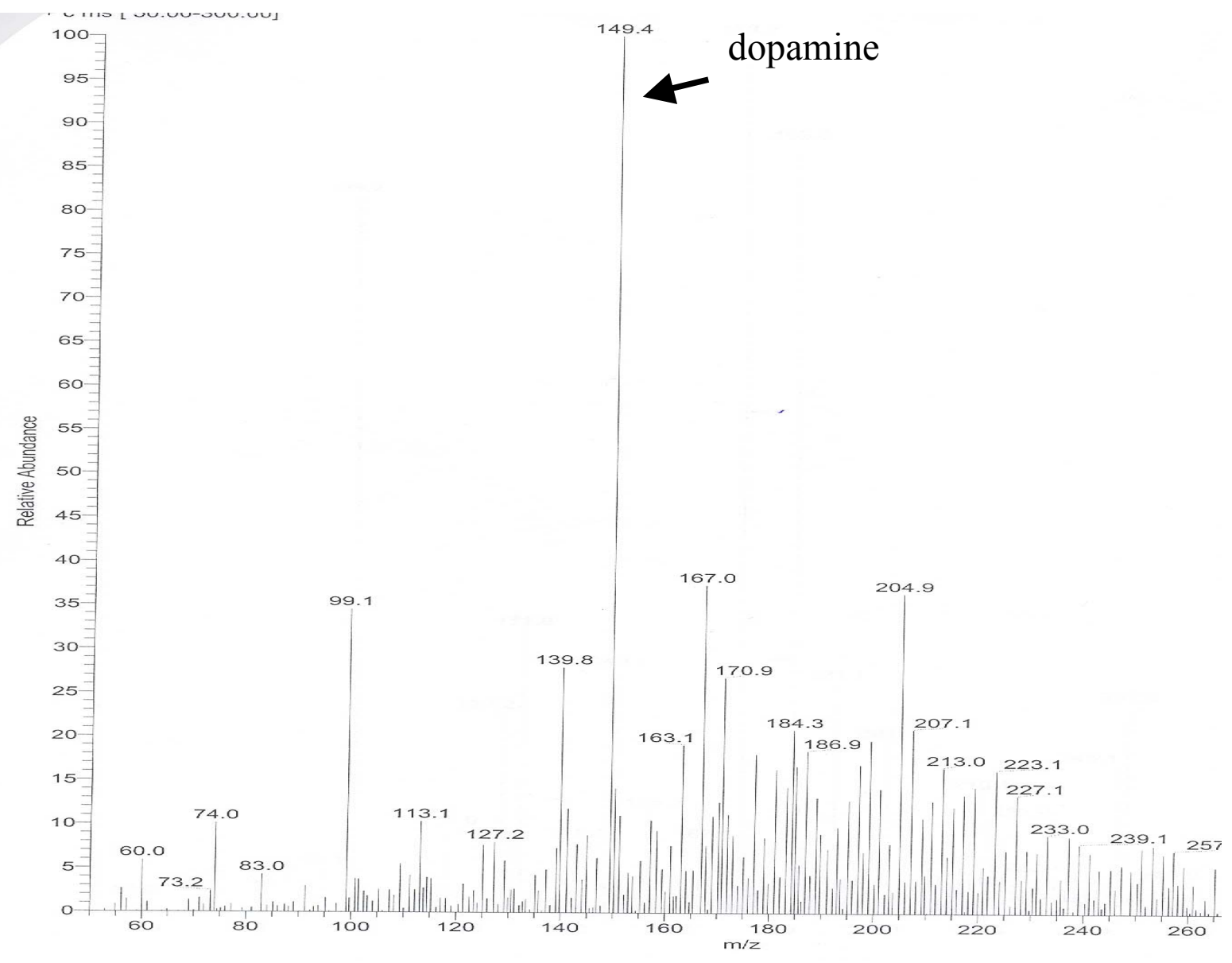

Figure 7(a) Standard of dopamine 


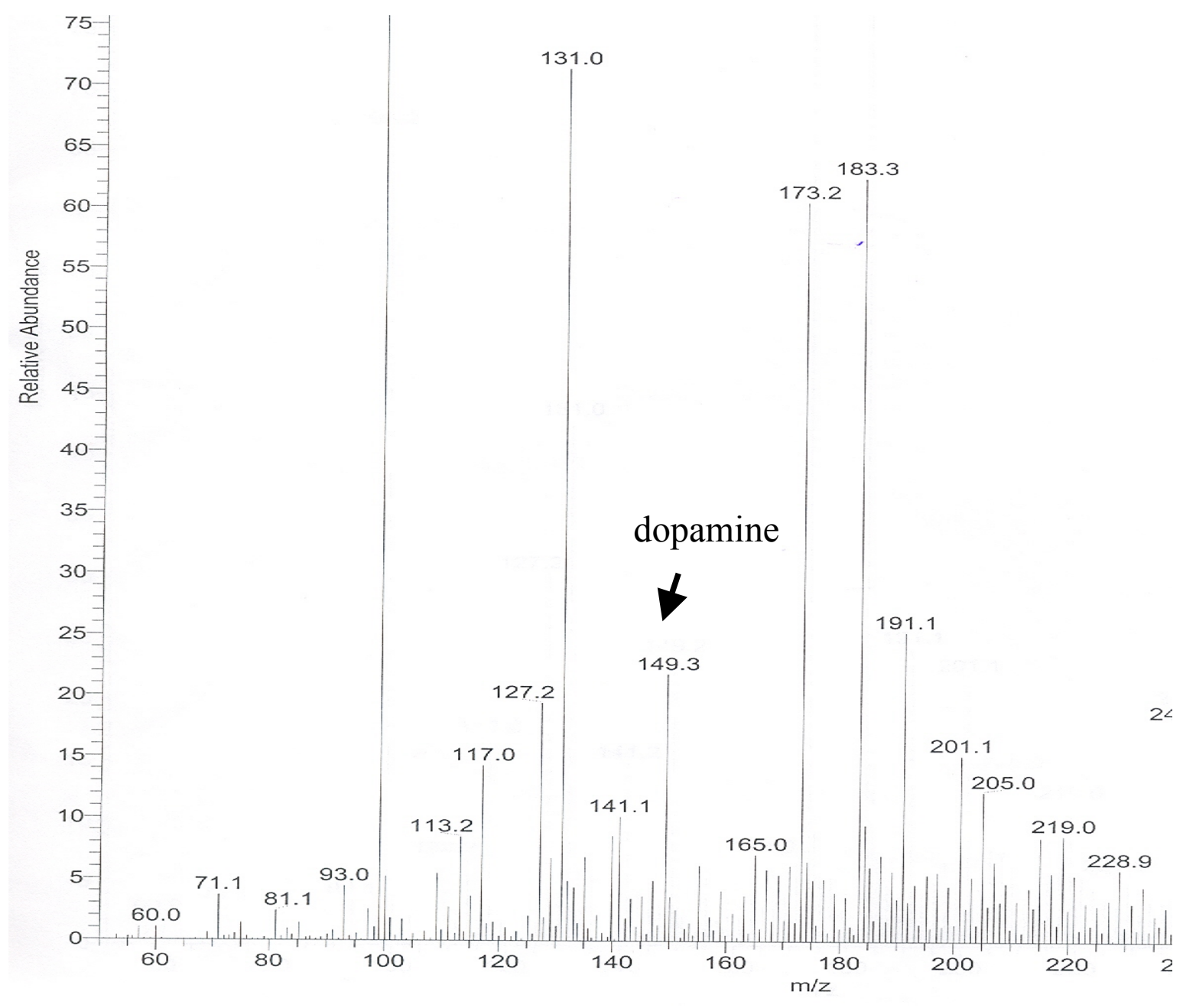

Figure 7(b) Tyramine treated with mitochondrial fraction from $T . n i$ cells 


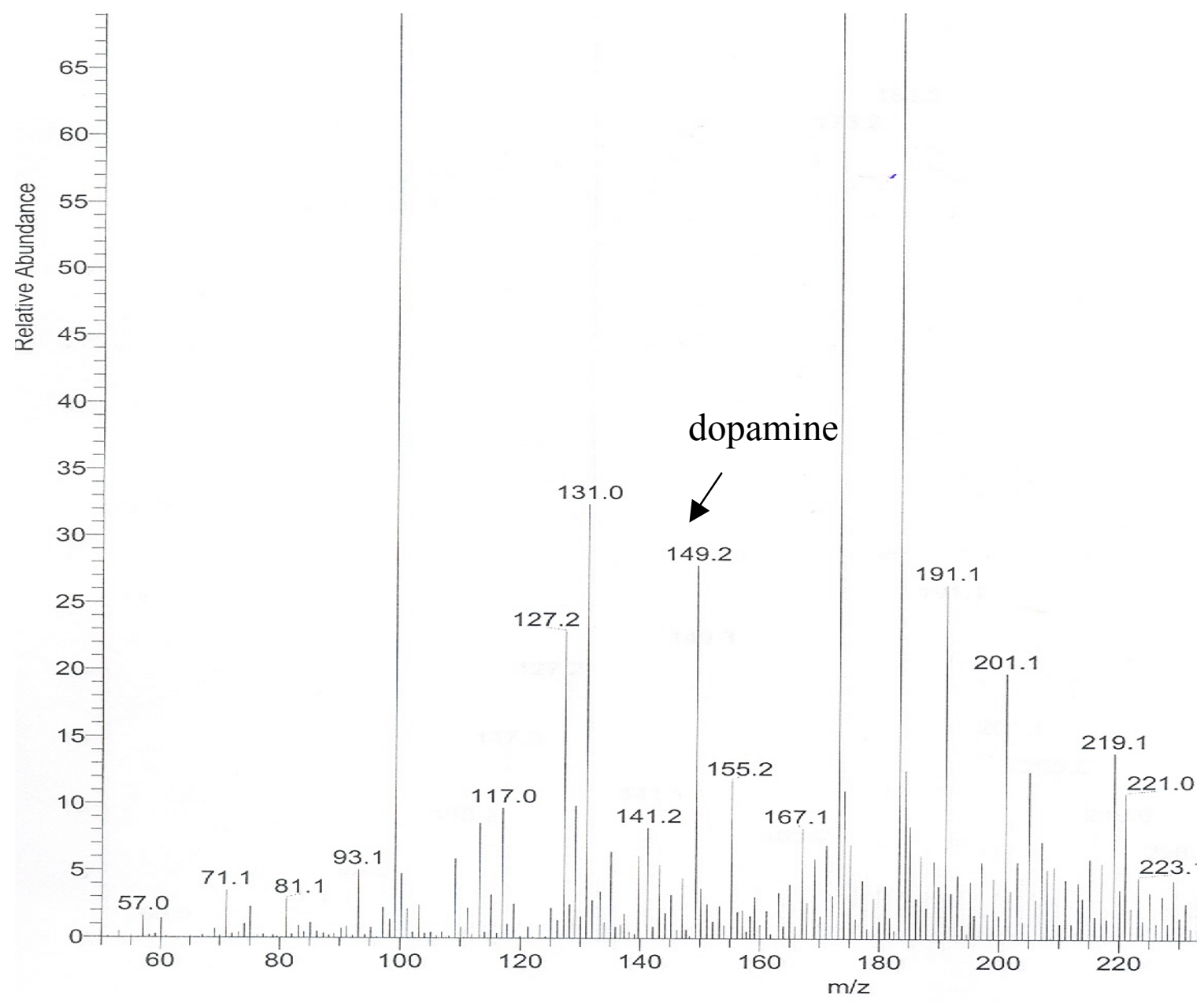

Figure 7(c) Tyramine treated with the mitochondrial fraction from $T$. $n i$ cells expressing CYP2D7 
Table 2. Kinetics of m-tyramine and codeine metabolism by CYP2D7 and CYP2D6

\begin{tabular}{lccc}
\hline & $\begin{array}{c}\text { Amount of Dopamine } \\
(\mathrm{pmol})\end{array}$ & Velocity $\left(\mathbf{V}_{\mathbf{0}}\right)$ \\
\hline $\begin{array}{l}\text { m-tyramine } \\
\left(500 \mu_{\mathrm{m}}\right)\end{array}$ & $2 \mathrm{D} 6^{*} 1$ & 72.2 & 7.2 \\
& $2 \mathrm{D} 7$ & 40.0 & 2.0 \\
& & & Amount of Morphine \\
$(\mathrm{pmol})$ & Velocity $\left(\mathbf{V}_{\mathbf{0}}\right)$ \\
\hline $\begin{array}{l}\text { Codeine } \\
\left(2000 \mu_{\mathrm{m}}\right)\end{array}$ & $2 \mathrm{D} 6 * 1$ & 24.0 & 0.53 \\
& $2 \mathrm{D} 7$ & 37.0 & 1.23 \\
\hline
\end{tabular}




\section{Chapter IV}

\section{Cloning and Sequencing of CYP2D Genes from EST Library of Extrahepatic Human Tissue}

Weiyan Zhang, Robert L Haining*

Department of Basic Pharmaceutical Science, School of Pharmacy, Robert C. Byrd

Health Sciences Center, West Virginia University, Morgantown, West Virginia 26506

Running title: Human brain cytochrome P450

Key words (human brain cytochrome P450/EST /RNA alternative splicing)

* Corresponding author mailing address, Department of Basic Pharmaceutical Science, School of Pharmacy, Robert C. Byrd Health Sciences Center, West Virginia University, Morgantown, West Virginia 26506. Phone: (304) 293-1479, Fax:

Electronic mail address: rhaining@hsc.wvu.edu 


\begin{abstract}
CYP2D6 polymorphism has been associated with various human cancer susceptibilities including lung cancer, breast cancer, skin cancer, bladder cancer, liver cancer and prostate cancer. Except for liver CYP2D6, the genotype and function of these extrahepatic $C Y P 2 D 6$ are still unknown. $C Y P 2 D$ alternatively splicing variants have been found in liver and extrahepatic tissues. However, these splicing variants are minor forms in liver. The factors required for tissue-selective expression of CYP $2 D$ splice variants are unknown. It has hypothesized that the existence of these alternatively splicing variants may impact the expression and functions of CYP2D6 in extrahepatic tissues, and the alternation of CYP2D6 might play an important role in determining cancer risk.
\end{abstract}

The objective of this study is to test the genotype and function of CYP2D6 or CYP2D variants in different human tissues including liver, brain, skin, eye and prostate. To achieve this goal, a human brain cDNA library was screened by using CYP2D6 as a probe. However, no positive clone has been found. Next, the sequence of $C Y P 2 D 6$ was used as a query to search the EST library of these tissues, and five clones were found to be homologs of CYP2D6. These five clones were amplified, and the insert cDNAs were further sequenced. The results indicated that the clone from brain did not share any homolog to $C Y P 2 D$. As expected, the clone from liver was identical to CYP2D6. Interestingly, the clones from eye, skin and prostate shared very high identify (99\%) to the recently identified brain variant $C Y P 2 D 7$, but a part of exon 6 (91bp) and the adjacent extra 57bp 
from intron 6 in $C Y P 2 D 7$ variant are absent in these clones. Sequencing analysis indicated that these alternative splicing transcripts can not translate to full length due to the deletion of a part of exon 6. To further confirm the sequencing analysis, the full-length skin CYP2D6 variant was created and expressed by using a baculovirus expression system. Western blot analysis showed that a $27 \mathrm{kD}$ truncated protein was detected, which is consistent with the sequencing analysis. Except for the CYP2D7 variant in brain, several other alternative splicing $C Y P 2 D$ variants have been identified in the different tissues of human. However, none of them have been shown to be functional and process P450 activity (7). Nevertheless, the existence of these variants might cause the posttranscriptional down-regulation of the expression of $C Y P 2 D 6$, further influencing the physiological or pathological functions of CYP2D6 in these tissues.

\section{Introduction}

Alternative splicing of pre-mRNA has been reported to be not only involved in regulating gene expression both quantitatively and qualitatively (25) but also specifically and developmentally regulating many human gene expression in different tissues. Likewise, it was found that alternative splicing also occurred among $C Y P 2 D$ genes $(8,11)$. The $C Y P 2 D$ subfamily includes $C Y P 2 D 6, C Y P 2 D 7$ and $C Y P 2 D 8 P$ at the $C Y P 2 D$ locus, and these three genes share 92 to $97 \%$ identity $(9,15)$. CYP2D8P was found to be a pseudogene since there is a frame shift mutation and a stop codon within its exons, while the $C Y P 2 D 7$ gene was found to have an insertion in its first exon that disrupts the reading 
frame of the protein (15). The alternative splicing of these genes result in different variants. These variants include a (intron 5 included); b (intron 6 included); b' (3' portion of exon 6 deleted); c (exon 6 deleted); d (3' 57-bp portion of intron 6 included); e (3' portion of exon 6 deleted, 3' 57-bp potion of intron 6 included) $(12,31)$. These variants are mainly found in extrahepatic tissues such as brain, lung, breast and other tissues $(7,8,12,13)$.

There are at least five alternatively spliced $C Y P 2 D$ transcripts have been reported in brain tissues: the most commonly found transcript was $\mathbf{c}$ variant, followed by $\mathbf{b}$ ' and the wild type, the b, $\mathbf{d}$ and $\mathbf{e}$ transcripts were the least abundant (7, 31); A full-length mRNA and variant $\mathbf{c}, \mathbf{b}$ ', e, $\mathbf{d}$ and $\mathbf{b}$ were detected in human breast tissues (29). Full-length mRNA was a minor form whereas variants $\mathbf{b}$ ' and $\mathbf{c}$ predominated. The messenger RNA of $C Y P 2 D$ was not only probed in the normal tissues, but also detected in the cancer tissues such as breast, lung and prostate cancers $(13,14,17,23,29)$. The functions of CYP2D6 and its variants in these tissues are still unknown in terms of the metabolism of drugs and toxins, pathogenesis and carcinogenesis. In brain, defects in the CYP2D6 gene have been associated with a number of CNS diseases such as Parkinson's disease $(1,6,16,26)$, Alzheimer's disease (28), neuroleptic-induced disorders such as tardive dyskinesia (19) and certain types of CNS cancer $(3,32)$. In skin, it was shown that mutant alleles (e.g. $C Y P 2 D 6^{* 4)}$ are associated with increased susceptibility to malignant melanoma and basal cell carcinomas $(22,27)$. The allelic variants of the CYP2D6 gene have also been implicated in susceptibility to lung and breast carcinogenesis $(2,30)$. However, the types of variants in these tissues have not been characterized yet. No functional CYP2D enzymes have been obtained from these tissues with the exception of brain, in which a functional 
CYP2D7 variant has recently been identified in Indian population (20). These limitations have hampered the investigation of the physiological and pathological roles of $C Y P 2 D$ in these extrahepatic tissues. To detect whether a functional CYP2D6 or variants are present in these extrahepatic tissues, human brain cDNA libraries and the EST libraies of these tissues were probed by using CYP2D6. No positive clones were identified in the human brain cDNA libraries examined. However, several positive clones were obtained from EST libraries and sequenced. A full-length skin variant was constructed and further expressed in a $T . n i$ insect cell line mediated by baculovirus.

\section{Materials and Methods}

\section{Human brain cDNA library and the clones from EST libraries: A human} substantia nigra cDNA library was bought from Stratagene (Cat\# 936210). Human eye EST clones (EST number: UI-E-EJ0-AIM-I-13-0-UI.S1 and UI-E-EJ0-AIN-J-13-0UI.R1) were bought from OPEN Biosystems. A human liver cDNA clone (EST number: 602614603F1), a prostate cDNA clone (EST number: 602650030F1) and a skin cDNA clone (EST number: 602634230F1) were bought from Invitrogen.

Labeling of $C Y P 2 D 6$ with DIG labeled probe: The full-length $C Y P 2 D 6$ DNA was obtained by PCR amplification from plasmid pFB2D6*1 $(18,34)$. The resultant PCR product was purified by PCR Purification Kit (Qiagen). 100_g purified PCR product was denatured with alkaline followed by purification with ethanol. The CYP2D6 probe was labeled with digoxigenin-dUTP by using a DIG Labeling and Detection Kit (Roche, 
Indianapolis) following manufacture's recommendation. The digoxigenin-dUTP was incorporated into CYP2D6 DNA by using random primed DNA labeling. A 15_l of DNA (3_g) was mixed with Hexanucleotide 2_1, dNTP 2_1 and Klenow enzyme 1_1, and mixture was incubated at $37^{\circ} \mathrm{C}$ for 6 hours. The labeled probe was further purified by using a Nucleotide Removing Kit (Qiagen) to remove free digoxigenin-dUTP. The resultant probe was quantified according to the manufacture's recommendation. The probe was detected with Anti-Digoxigenin-AP Detection Kit (Roche). The sensitivity of labeled probe was detected by dot-blot.

Screening of human brain cDNA library: A standard procedure was used to screen the human brain cDNA library from substantia nigra. Briefly, a bacteriophage library was first plated at about 30,000 - 50,000 pfu per $150 \mathrm{~mm}$ Petri dish by adding an appropriate amount of bacteriophage in $500 \mu 1$ E. coli $\left(\mathrm{A}_{600}=0.5\right) \mathrm{MgSO}_{4}$-stored. Following 15 minute incubation at $37^{\circ} \mathrm{C}$ without shaking, the cells were plated with $7 \mathrm{ml} \mathrm{LB}$ top agar on LB agar plates. Once the top agar has solidified, the plates were inverted and incubated overnight at $37^{\circ} \mathrm{C}$. The plates were cooled at $4^{\circ} \mathrm{C}$ for at least one hour to prevent the top agar from lifting off the plate during the blotting process. A nitrocellulose filter was slowly laid on the agar surface from the center to the side. The filters were handled only by their edges with forceps. The position of filter on the plate was marked by piercing the filter with a $25 \mathrm{G}$ needle dipped briefly in India ink in three asymmetrically positioned spots per filter. Following the transferring, the nitrocellulose the membranes were sequentially treated with the $1.5 \mathrm{M} \mathrm{NaCl}$ and $0.5 \mathrm{M} \mathrm{NaOH}$ for $2 \mathrm{~min}$, 1.5M NaCl and $0.5 \mathrm{M}$ Tris. $\mathrm{Cl}(\mathrm{pH} 8.0)$ for $5 \mathrm{~min}$, and $2 \mathrm{xSSC}$ (300mM sodium chloride, 30 
$\mathrm{mM}$ sodium citrate, $\mathrm{pH} 7.5)$ and $0.2 \mathrm{M}$ Tris. $\mathrm{Cl}(\mathrm{pH} 7.5)$ for $5 \mathrm{~min}$. The treated membranes were dried on $3 \mathrm{~mm}$ Whatman paper at room temperature for $10 \mathrm{~min}$.

For DNA hybridization, the membranes were put in hybridization bag that contains 5 $\mathrm{ml}$ standard hybridization buffer (1\% blocking reagent, $0.1 \mathrm{M}$ maleic acid, $0.15 \mathrm{M} \mathrm{NaCl}$, $\mathrm{pH} 7.5$ ) and incubated at $68^{\circ} \mathrm{C}$ for 1 hour. Following the incubation, the denatured DIGlabeled 2D6 probe was added into the bag and incubated at $65^{\circ} \mathrm{C}$ for over 16 hours with gentle agitation. After hybridization, the membranes were sequentially washed with the following solutions: $2 \mathrm{x}$ SSC and $0.1 \%$ SDS for $5 \mathrm{~min}$ at room temperature for a total of 2 times, and $0.1 \mathrm{x} \mathrm{SSC}$ and $0.1 \% \mathrm{SDS}$ at $68^{\circ} \mathrm{C}$ for $15 \mathrm{~min}$ for a total of 2 times washes.

For the detection, the membranes were first treated with maleic acid buffer $(0.1 \mathrm{M}$ maleic acid, $0.15 \mathrm{M} \mathrm{NaCl}, \mathrm{pH} 7.5$ ) for 5 minutes, and then transferred into boxes containing $20 \mathrm{ml}$ blocking solution followed by 30 minutes incubation. After incubation, 2.0_l anti-DIG-AP conjugate (1:4000) was added and incubated for 1 hour. Pouring off the buffer, the membranes were first washed with $50 \mathrm{ml}$ maleic acid buffer for $15 \mathrm{~min}$ for 2 times, and then rinsed with $20 \mathrm{ml}$ Detection buffer $(0.1 \mathrm{M}$ Tris.Cl, $0.1 \mathrm{M} \mathrm{NaCl}, \mathrm{pH}$ 9.5). Finally, pouring off buffer, the membranes were treated with $5 \mathrm{ml}$ detection buffer containing 30_1 NBT solution and 17_1 X-phosphate solution. The membranes were incubated in dark room for 30 minutes to 12 hours.

Amplification of EST clones and DNA sequencing: The cDNA clones were amplified in JM109 E. coli cells (Promega). Plasmids were purified with Mini-Plasmid 
Purification Kit (Promega). Standard primers (T7, M13F and M13R), which bind at the flank region of inserted cDNA, were used for the double-stranded DNA sequencing (Northwood DNA, Inc.). DNA homolog search were carried out with BLAST (NCBI).

Construction of full length human skin CYP2D cDNA: Full length skin $C Y P 2 D$ cDNA was constructed by a two-step PCR process as shown in Figure 1. Briefly, Skin CYP2D cDNA from ESTs was first amplified by PCR by using a pair of primers as follows: Skin5' (5'-GGCGC GAGCAGAGGCGCTTCT-3') and skin3' (5'-AAGCTT GGAACTACCA CATTGCTT-3'). The wild type CYP2D6 fragment including exon 1and 2 was amplified by PCR by using the primers 2D6 5' (5'-GGATTATTCATACC GTCC-3') and 2D6 3' (5'-AGAAGCGCCTCTGCTCGCGCC-3'). The PCR thermocycling programs consisted of a three-step cycle repeated 30 times: denaturing at $95^{\circ} \mathrm{C}$ for $1 \mathrm{~min}$, annealing at $59^{\circ} \mathrm{C}$ for $1 \mathrm{~min}$, and extension at $72^{\circ} \mathrm{C}$ for $1 \mathrm{~min}$, followed by a finial extension at $72^{\circ} \mathrm{C}$ for 5 minutes. The full length skin CYP2D cDNA was amplified by PCR by using the primers 2D65' and skin 3'. The thermo-cycling programs are the same with the exception of annealing at $62^{\circ} \mathrm{C}$ for $1 \mathrm{~min}$. An endonuclease restriction enzyme cutting site (Hind III) (highlight in bold) was engineered in the primer skin 3'. The resultant PCR product was cloned into PCR cloning vector pGEM-T (Promega). The final construct was reconfirmed by DNA sequencing analysis.

Cloning the constructed CYP2D cDNA into baculovirus: The constructed skin CYP2D gene was cut from the PCR cloning vector with Bam HI and Hind III. The resultant fragment was cloned into the vector pFastBac (Invitrogen) to create the 
recombinant plasmid pFBCYP2D*S, which was further transformed into DH10Bac competent cells (Invitrogen). After incubating on Luria agar plates for 24 to 48 hours at $37^{\circ} \mathrm{C}$, white clones which contain recombinant bacmid DNA were picked into LB medium containing kanamycin $\left(50 \_\mathrm{g} / \mathrm{ml}\right)$, gentamicin $\left(7 \_\mathrm{g} / \mathrm{ml}\right)$ and tetracycline $\left(10 \_\mathrm{g} / \mathrm{ml}\right)$ and grow at $37{ }^{\circ} \mathrm{C}$ with shaking at $250 \mathrm{rpm}$ overnight. A DNA purification system (Promega) was used to isolate the recombinant bacmid DNA.

To create viral stocks, $9 \times 10^{5}$ T.ni cells per 35-mm (of a 6-well plate) was seeded at $27^{\circ} \mathrm{C}$ in $2 \mathrm{ml}$ of SFX-INSECT (Hyclone) containing $10 \%$ fetal bovine serum, 100_g/ml Penicillin-G, 60_g/ml Streptomycin sulfate, and 0.6_g/ml Amphoterecin-B. GenePORTER $^{\mathrm{TM}}$ reagent (Gene Therapy System) was used to accomplish the transfection of T.ni cells with recombinant bacmid DNA. Recombinant virus was harvested 72 hours post-transfection. Baculoviral stocks were amplified by subsequent passages onto a new 100-mm dish of T.ni cells with $30 \mathrm{ml}$ medium followed by incubation for 7 to 8 days.

Protein expression and Western blot analysis: Infection was carried out at a cell density of 1.6 to $2.0 \times 10^{6}$ cells $/ \mathrm{ml}$ using $200 \mu 1$ of amplified viral supernatant. Heme (finial concentration 4_g/ml) was added together with virus. Cells were harvested 3 to 4 days post-infection, re-suspended and washed once in storage buffer $(100 \mathrm{mM}$ potassium phosphate, $20 \%$ glycerol, $0.33 \mathrm{mM}$ dithiothreitol, $1 \mathrm{mM}$ EDTA, pH 7.4). The cell pellets were stored at $-80^{\circ} \mathrm{C}$ for further analyses. SDS-PAGE and Western-blotting with the enhanced chemiluminescence detection method were carried out as the manufacture's 
recommendation (Amersham Biosciences). Polyclonal and monoclonal antibodies (Catalog NO.458246) against human CYP2D6 were purchased from BD Gentest ${ }^{\mathrm{TM}}$ and PANVERA. Briefly, identical amounts of proteins were loaded into each lane of a $10 \%$ polyacrylamide gel. Following electrophoresis, the sample proteins were transferred to PDVF membrane. The resultant blots were blocked in 5\% fat-free milk at room temperature for 1 hour, and then incubated in $2 \%$ milk containing primary antibodies for 1 hour at room temperature followed by three times wash by using T-PBS $(0.15 \%$ Tween-20, 0.067 M phosphate-buffered saline, $\mathrm{pH}$ 7.5). The blots were developed by using horseradish peroxidase-conjugated secondary antibody with the ECL luminal assay.

\section{Results and Discussions}

The screening of human brain cDNA library from substantia nigra. Previous studies indicated that CYP2D6 RNA was detected in several regions of human brains and the level of mRNA varied significantly among regions. The highest level was observed in cerebellum and the lowest levels in putamen, globus pallidus and substantia nigra (18). In the current study, human brain substantia nigra cDNA library was probed with CYP2D6. Of the approximate 300 plaques present in each membrane, total of 24 membranes probed with $C Y P 2 D 6$, no positive plaques were identified (Figure 2). Thus, no $C Y P 2 D$ cDNA clones were screened from this library. This negative result may be explained by the following reasons: First, the abundance of $C Y P 2 D$ cDNA is very low in the library of human brain substantia nigra. Indeed, the mRNA of CYP2D6 was found to be the lowest 
in substantia nigra and putamen versus other brain regions (24). In future studies, cDNA libraries from different parts of human brain including cerebellum should be used for detection. Secondly, the sensitivity of labeled probe of CYP2D6 is about 100pg (Figure 1) and this sensitivity which may not be enough to detect the cDNA of CYP2D6 from the library. In the future, different labeling techniques can be used such as a radio-labeled probe that is much sensitive than a DIG-labeled probe.

\section{Sequencing analysis of $C Y P 2 D$ clones from EST libraries of human eye, liver,}

prostate and skin. EST means "expressed sequence tags". What they did was that they isolated RNA from tissue, then using poly-A to do RT-PCR to get cDNAs, cloning these cDNA into vectors. Usually they are just a few hundred base pairs at length. Currently, there are many EST libraries from human tissues available. To detect if there are CYP2D cDNA present in these libraries, the sequence of CYP2D6 was used as a query for searching. Among them, five clones were found to share high identity to CYP2D6. Each of these five clones was further confirmed by sequencing analysis. The results are completely consistent the sequences present in the EST libraries, except for the clone from the brain EST library, which did not share homology to the CYP2D genes (data not shown).

As expected, the clone from liver is a partial cDNA of CYP2D6 (data not shown). The clones from human eye, skin and prostate share the highest identity (99\%) to a recently identified human brain $C Y P 2 D 7$ variant (Figure 3). The human prostate cDNA 
clone contains exon 3 to 5, exon 6 with 91 bps deletion, exon 7 to exon 9 . Human skin cDNA clone contains exon 3 to 9 , with 91 base pairs deletion in exon 6 . The clone from human eye only contained exons 7, 8, and 9 (Figure 3), and it is unknown if 91 base pairs is deleted from the exon 6 . These results indicate that the alternatively spliced variants do exist in these tissues, and that the identified transcripts are probably caused by the alternative splicing of $C Y P 2 D 7$. As noted, similar alternative splicing variants from $C Y P 2 D 7$ have been identified from tissues such as liver and brain (7). Among those variants, they only showed parts of $C Y P 2 D$ genes the genetic information in the rest part of the genes is not available. Thus, it is hard to determine their genotypes and whether these transcripts are translatable. Among those variants whose full-length cDNA sequences have been decoded, none of them could be translated to functional proteins except for the variant identified in Indian population $(7,20)$.

Construction and expression of human skin CYP2D variant. To experimentally test whether these transcripts are translatable, the skin cDNA clone was chosen for further analysis. As mentioned above, the skin cDNA contains only exons 3 to 9 . It dose not contain exon 1 and 2. To create the full-length cDNA, the exon 1 and 2 from CYP2D6* 1 were ligated to the 5' end of the transcript by 2-Step PCR (Figure 4). The first step PCR was used to respectively amplify exon 1 to 2 (352 bp) from CYP2D6 and exon 3 to 9 (1,049 bp) from the skin clone (Figure 5). In the second step PCR, the above PCR products were used as templates, and two fragments were ligated together. As shown in Figure 5, the exon 1 and 2 were successfully ligated to the 5' end of the transcript and resulted in a 1,401bp PCR product. DNA sequencing analysis further 
confirmed that a presumably full-length skin cDNA was constructed, and that no additional mutations were created during the PCR reactions. However, the gene translation analysis indicated that the deletion of $91 \mathrm{bp}$ in exon 6 resulted in a frame shift mutation, and the portion of the gene before this deletion is only able to translate to a 27 $\mathrm{kD}$ protein.

To further confirm this prediction, the full-length skin $C Y P 2 D$ was expressed in insect cells by using a baculovirus-mediated expression system. The creation of high titer baculovirus stock, the growth of baculovirus, the media conditions, the addition of heme, the infection of $T$. $n i$ cells with baculovirus were as described previously (34). The expressed product was detected by Western-blot analysis with monoclonal antibodies against CYP2D6. As shown in Figure 6, an approximately 50kD protein was detected in the positive control (insect cells infected with baculovirus containing $C Y P 2 D 6^{*} 1$ ). However, only a $27 \mathrm{kD}$ protein was found in insect cells infected with baculovirus containing the skin $C Y P 2 D$, indicating that a truncated protein was translated from the constructed skin $C Y P 2 D$. This result is consistent with the translational analysis, and further confirmed that the identified human skin $C Y P 2 D$ could not be translated to a fulllength functional protein.

Due to the lack of crystal structure, Gotoh modeled the CYP2D6 structure based on the similarity between CYP2D6 and P450 101 A (10). In this model, six separate regions were tentatively assigned as substrate recognition sites (SRSs) in CYP2D6, including B' and flanking areas (103-126), the C-terminal end of Helix F (209-216), the N-terminal 
end of Helix G (248-255), the N-terminal half of Helix I (302-320), the 3 area (378-385) and a central region of 5 (485-493). In addition, several functional residues have been identified in terms of the drug-enzyme interaction. Residue Asp301 has been characterized as being involved in electrostatic interactions with substrates on the basis of homology modeling and site-directed mutagenesis (4). Residue Glu216 also plays an important role in the binding of the basic nitrogen of CYP2D6 substrates (21). One recent study indicated that Phe120, located on the B'-C loop, contributes to determining the specificity of substrate oxidation by CYP2D6 (5). This skin variant encodes a 27kD truncated protein that contains $\mathrm{N}$-terminus 327 amino acids. It contains four substrate recognition sites and all the functional residues mentioned above. Thus, this truncated protein may still play important physiological or pathological roles in the skin tissue even it lost the enzymatic activity of P450.

Huang et al. found that there were six different alternatively spliced forms of $C Y P 2 D$ mRNA, including a full-length form, in human breast and lung tissues in the region of exons 5-8 $(12,13)$. Woo et al. found that the $C Y P 2 D$ genes resulted in at least five alternatively spliced transcripts in the human brain (31). Importantly, these brain $C Y P 2 D$ variants are the same as the variants found in the breast and lung, albeit occur at different frequency. Recently, several other variants were identified in human liver and human brain (7). In this study, a variant from $C Y P 2 D 7$ with a deletion of part of exon 6 (91bp) was found in skin and prostate. DNA sequencing and expressional analysis showed that this variant could not be translated to a functional protein. Yengi found that CYP2D6 mRNA levels was highest in skin, and thus there was significant inter-individual variation (over 
10-fold) (33). However, the genotypes and functions of $C Y P 2 D$ in human skin are still unknown. It cannot be excluded that the existence of this splice variant has the posttranscriptional down-regulation of the expression of CYP2D6, nor that a $27 \mathrm{kD}$ protein could serve a functional role.

\section{Figure legends}

\section{Figure 1}

CYP2D6 probe labeled with DIG. The CYP2D6 probe was labeled with digoxigenindUTP by using a DIG Labeling and Detection Kit following manufacture's recommendation. The sensitivity of labeled probe of $C Y P 2 D 6$ is about $100 \mathrm{pg}$.

\section{Figure 2}

Human brain cDNA library screening. A human brain substantia nigra cDNA library was probed with CYP2D6. The right panel shows the positive plaques used as a control. The left panel shows the plaques present in the nitrocellulose membrane of the brain library which was probed with CYP2D6.

Figure 3

EST clones amplification and DNA sequencing. The cDNA clones from ESTs were amplified in JM109 E. coli cells. The commercial primers T7, M13F and M13R which bind at the flank regions of inserted cDNA were used for double-stranded DNA sequencing. DNA homology searches were carried out with BLAST. The clones from human eye, skin and prostate share the highest identity (99\%) to a recently identified 
human brain $C Y P 2 D 7$ variant. The human prostate cDNA clone contains exons 3 to 5, exon 6 with 91 bps deleted, and exon 7 to exon 9. The hman skin cDNA clone contains exon 3 to 9 , also with a 91 base-pair deletion in exon 6 . The clone from human eye contains exon 7, exon 8 and exon 9. The re-constructed human skin cDNA contains exons 1 to 9 with the $91 \mathrm{bp}$ deletion in exon 6 .

Figure 4

Full-length human skin $C Y P 2 D$ cDNA construction. Full length skin $C Y P 2 D$ cDNA was constructed by two-step PCR. Skin CYP2D cDNA from ESTs and the wild type CYP2D6 fragment including exon 1and 2 were amplified by the first PCR. The amplified two fragments were ligated by the second PCR.

Figure 5

Full-length human skin CYP2D cDNA construction and amplification by PCR. Skin CYP2D cDNA (from ESTs library) was first amplified by PCR by using a pair of primers: (5'-GGCGC GAGCAGAGGCGCTTCT-3') and (5'-AAGCTTGGAACTACCA CATTGCTT-3'). The size of the resultly predicted PCR product is 352bps. The wild type CYP2D6 fragment including exon 1and 2 was amplified by PCR by using the primers 2D6 5' (5'-GGATTATTCATACCGTCC-3') and 2D6 3' (5'-AGAAGCGCCTCT GCTCGCGCC-3'). The size of PCR product is 1049bps. The whole length skin CYP2D cDNA was amplified by PCR by using the primers 2D65' and skin 3'. The size of PCR product is $1401 \mathrm{bps}$. 
Figure 6

Western blot analysis of human skin CYP2D proein expression. Human skin CYP2D was over-expressed in T.ni insect cells using baculovirus-mediated expression system. The expressed proteins were separated by SDS-PAGE, and transferred onto PVDF membrane. CYP2D6 monoclonal antibody was used for detection. An approximately 50kD CYP2D6 protein was detected from insect cells infected with baculovirus containing $C Y P 2 D 6^{*} 1$. A $27 \mathrm{kD}$ protein was found in the insect cells infected with baculovirus containing skin $C Y P 2 D$.

\section{Reference List}

1. Agundez, J. A., F. J. Jimenez-Jimenez, A. Luengo, M. L. Bernal, J. A. Molina, L. Ayuso, A. Vazquez, J. Parra, J. Duarte, F. Coria, and . 1995. Association between the oxidative polymorphism and early onset of Parkinson's disease. Clin Pharmacol.Ther. 57:291-298.

2. Christensen, P. M., P. C. Gotzsche, and K. Brosen. 1997. The sparteine/debrisoquine (CYP2D6) oxidation polymorphism and the risk of lung cancer: a meta-analysis. Eur.J Clin Pharmacol. 51:389-393.

3. Elexpuru-Camiruaga, J., N. Buxton, V. Kandula, P. S. Dias, D. Campbell, J. McIntosh, J. Broome, P. Jones, A. Inskip, J. Alldersea, and . 1995. Susceptibility to astrocytoma and meningioma: influence of allelism at glutathione S-transferase (GSTT1 and GSTM1) and cytochrome P-450 (CYP2D6) loci. Cancer Res 55:4237-4239.

4. Ellis, S. W., G. P. Hayhurst, G. Smith, T. Lightfoot, M. M. Wong, A. P. Simula, M. J. Ackland, M. J. Sternberg, M. S. Lennard, G. T. Tucker, and . 1995. Evidence that aspartic acid 301 is a critical substrate-contact residue in the active site of cytochrome P450 2D6. J Biol Chem. 270:29055-29058.

5. Flanagan, J. U., J. D. Marechal, R. Ward, C. A. Kemp, L. A. McLaughlin, M. J. Sutcliffe, G. C. Roberts, M. J. Paine, and C. R. Wolf. 2004. Phe120 contributes to the regiospecificity of cytochrome P450 2D6: mutation leads to the formation of a novel dextromethorphan metabolite. Biochem J 380:353-360. 
6. Fonne-Pfister, R., M. J. Bargetzi, and U. A. Meyer. 1987. MPTP, the neurotoxin inducing Parkinson's disease, is a potent competitive inhibitor of human and rat cytochrome P450 isozymes (P450bufI, P450db1) catalyzing debrisoquine 4-hydroxylation. Biochem Biophys.Res Commun. 148:1144-1150.

7. Gaedigk, A., R. Gaedigk, and J. S. Leeder. 2005. CYP2D7 splice variants in human liver and brain: does CYP2D7 encode functional protein? Biochem Biophys.Res Commun. 336:1241-1250.

8. Gonzalez, F. J., R. C. Skoda, S. Kimura, M. Umeno, U. M. Zanger, D. W. Nebert, H. V. Gelboin, J. P. Hardwick, and U. A. Meyer. 1988. Characterization of the common genetic defect in humans deficient in debrisoquine metabolism. Nature 331:442-446.

9. Gonzalez, F. J., F. Vilbois, J. P. Hardwick, O. W. McBride, D. W. Nebert, H. V. Gelboin, and U. A. Meyer. 1988. Human debrisoquine 4-hydroxylase (P450IID1): cDNA and deduced amino acid sequence and assignment of the CYP2D locus to chromosome 22. Genomics 2:174-179.

10. Gotoh, O. 1992. Substrate recognition sites in cytochrome P450 family 2 (CYP2) proteins inferred from comparative analyses of amino acid and coding nucleotide sequences. J Biol Chem. 267:83-90.

11. Gough, A. C., J. S. Miles, N. K. Spurr, J. E. Moss, A. Gaedigk, M. Eichelbaum, and C. R. Wolf. 1990. Identification of the primary gene defect at the cytochrome P450 CYP2D locus. Nature 347:773-776.

12. Huang, Z., M. J. Fasco, and L. S. Kaminsky. 1997. Alternative splicing of CYP2D mRNA in human breast tissue. Arch.Biochem.Biophys. 343:101-108.

13. Huang, Z., M. J. Fasco, S. Spivack, and L. S. Kaminsky. 1997. Comparisons of CYP2D messenger RNA splice variant profiles in human lung tumors and normal tissues. Cancer Res. 57:2589-2592.

14. Kaminsky, L. S. and S. D. Spivack. 1999. Cytochromes P450 and cancer. Mol.Aspects Med. 20:70-84, 137.

15. Kimura, S., M. Umeno, R. C. Skoda, U. A. Meyer, and F. J. Gonzalez. 1989. The human debrisoquine 4-hydroxylase (CYP2D) locus: sequence and identification of the polymorphic CYP2D6 gene, a related gene, and a pseudogene. Am.J.Hum.Genet. 45:889-904.

16. Kurth, M. C. and J. H. Kurth. 1993. Variant cytochrome P450 CYP2D6 allelic frequencies in Parkinson's disease. Am.J Med.Genet. 48:166-168.

17. Ladona, M. G., R. E. Abildua, J. M. Ladero, J. M. Roman, M. A. Plaza, J. A. Agundez, J. J. Munoz, and J. Benitez. 1996. CYP2D6 genotypes in Spanish women with breast cancer. Cancer Lett. 99:23-28. 
18. Miksys, S., Y. Rao, E. Hoffmann, D. C. Mash, and R. F. Tyndale. 2002. Regional and cellular expression of CYP2D6 in human brain: higher levels in alcoholics. J Neurochem. 82:1376-1387.

19. Ohmori, O., T. Suzuki, H. Kojima, T. Shinkai, T. Terao, T. Mita, and K. Abe. 1998. Tardive dyskinesia and debrisoquine 4-hydroxylase (CYP2D6) genotype in Japanese schizophrenics. Schizophr.Res 32:107-113.

20. Pai, H. V., R. P. Kommaddi, S. J. Chinta, T. Mori, M. R. Boyd, and V. Ravindranath. 2004. A frameshift mutation and alternate splicing in human brain generate a functional form of the pseudogene cytochrome P4502D7 that demethylates codeine to morphine. J Biol Chem. 279:27383-27389.

21. Paine, M. J., L. A. McLaughlin, J. U. Flanagan, C. A. Kemp, M. J. Sutcliffe, G. C. Roberts, and C. R. Wolf. 2003. Residues glutamate 216 and aspartate 301 are key determinants of substrate specificity and product regioselectivity in cytochrome P450 2D6. J Biol Chem. 278:4021-4027.

22. Ramachandran, S., J. T. Lear, H. Ramsay, A. G. Smith, B. Bowers, P. E. Hutchinson, P. W. Jones, A. A. Fryer, and R. C. Strange. 1999. Presentation with multiple cutaneous basal cell carcinomas: association of glutathione Stransferase and cytochrome P450 genotypes with clinical phenotype. Cancer Epidemiol.Biomarkers Prev. 8:61-67.

23. Romkes-Sparks, M., A. Mnuskin, H. D. Chern, R. Persad, C. Fleming, G. N. Sibley, P. Smith, G. R. Wilkinson, and R. A. Branch. 1994. Correlation of polymorphic expression of CYP2D6 mRNA in bladder mucosa and tumor tissue to in vivo debrisoquine hydroxylase activity. Carcinogenesis 15:1955-1961.

24. Siegle, I., P. Fritz, K. Eckhardt, U. M. Zanger, and M. Eichelbaum. 2001. Cellular localization and regional distribution of CYP2D6 mRNA and protein expression in human brain. Pharmacogenetics 11:237-245.

25. Smith, C. W., J. G. Patton, and B. Nadal-Ginard. 1989. Alternative splicing in the control of gene expression. Annu Rev Genet. 23:527-577.

26. Stefanovic, M., E. Topic, A. M. Ivanisevic, M. Relja, and M. Korsic. 2000. Genotyping of CYP2D6 in Parkinson's disease. Clin Chem.Lab Med. 38:929-934.

27. Strange, R. C., T. Ellison, F. Ichii-Jones, J. Bath, P. Hoban, J. T. Lear, A. G. Smith, P. E. Hutchinson, J. Osborne, B. Bowers, P. W. Jones, and A. A. Fryer. 1999. Cytochrome P450 CYP2D6 genotypes: association with hair colour, Breslow thickness and melanocyte stimulating hormone receptor alleles in patients with malignant melanoma. Pharmacogenetics 9:269-276.

28. Tanaka, S., X. Chen, Y. Xia, D. E. Kang, N. Matoh, M. Sundsmo, R. G. Thomas, R. Katzman, L. J. Thal, J. Q. Trojanowski, T. Saitoh, K. Ueda, and 
E. Masliah. 1998. Association of CYP2D microsatellite polymorphism with Lewy body variant of Alzheimer's disease. Neurology 50:1556-1562.

29. Topi inverted question, m. E., m. M. Stefanovi inverted question, Ivanisevi inverted question markc AM, m. R. Petrinovi inverted question, and q. m. Curci inverted, I. 2000. The cytochrome P450 2D6 (CYP2D6) gene polymorphism among breast and head and neck cancer patients. Clin.Chim.Acta 296:101-109.

30. Wolf, C. R., C. A. Smith, T. Bishop, D. Forman, A. C. Gough, and N. K. Spurr. 1994. CYP2D6 genotyping and the association with lung cancer susceptibility. Pharmacogenetics 4:104-106.

31. Woo, S. I., L. A. Hansen, X. Yu, M. Mallory, and E. Masliah. 1999. Alternative splicing patterns of CYP2D genes in human brain and neurodegenerative disorders. Neurology 53:1570-1572.

32. Wundrack, I., E. Meese, R. Mullenbach, and N. Blin. 1994. Debrisoquine hydroxylase gene polymorphism in meningioma. Acta Neuropathol.(Berl) 88:472-474.

33. Yengi, L. G., Q. Xiang, J. Pan, J. Scatina, J. Kao, S. E. Ball, R. Fruncillo, G. Ferron, and W. C. Roland. 2003. Quantitation of cytochrome P450 mRNA levels in human skin. Anal.Biochem 316:103-110.

34. Yu, A., H. Dong, D. Lang, and R. L. Haining. 2001. Characterization of dextromethorphan O- and N-demethylation catalyzed by highly purified recombinant human CYP2D6. Drug Metab Dispos. 29:1362-1365. 


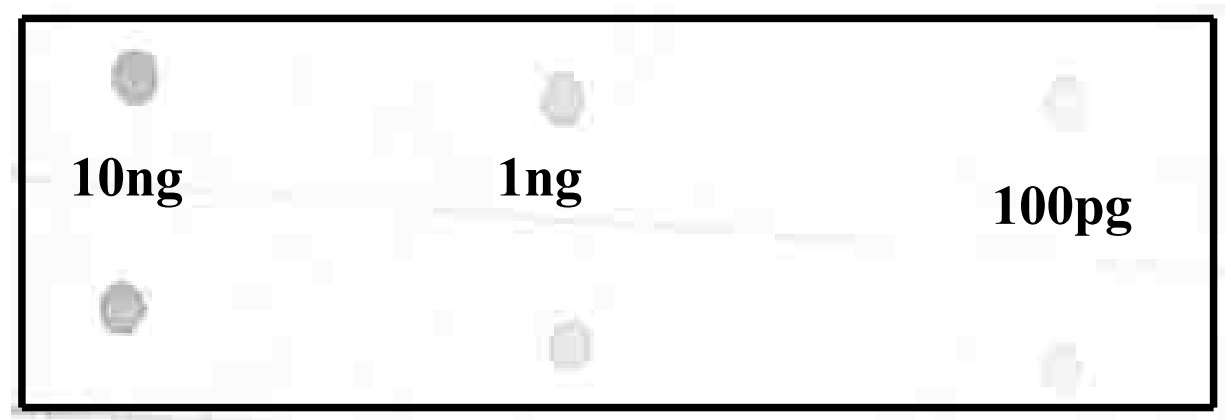

Figure 1 
Sample

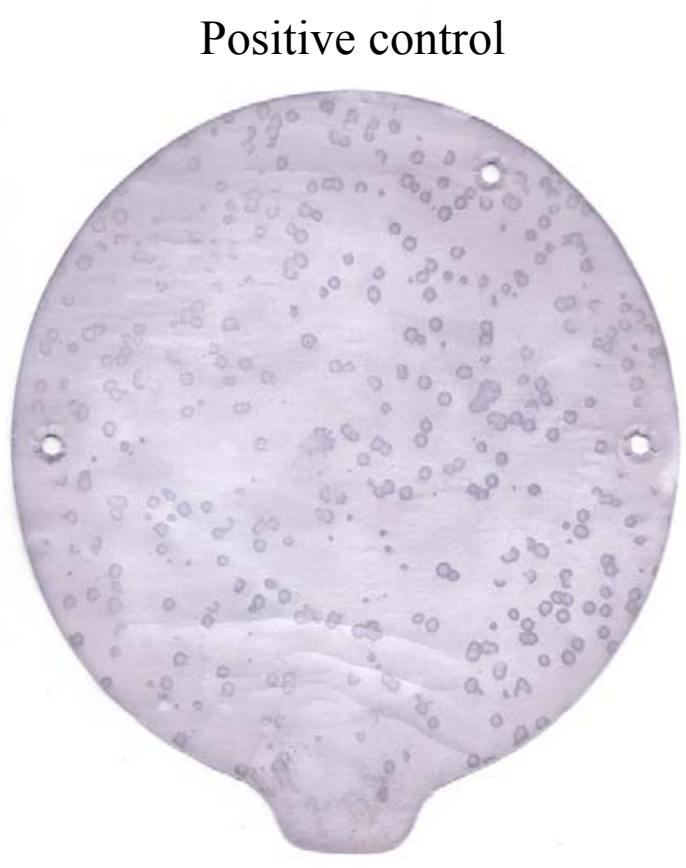

Figure 2 

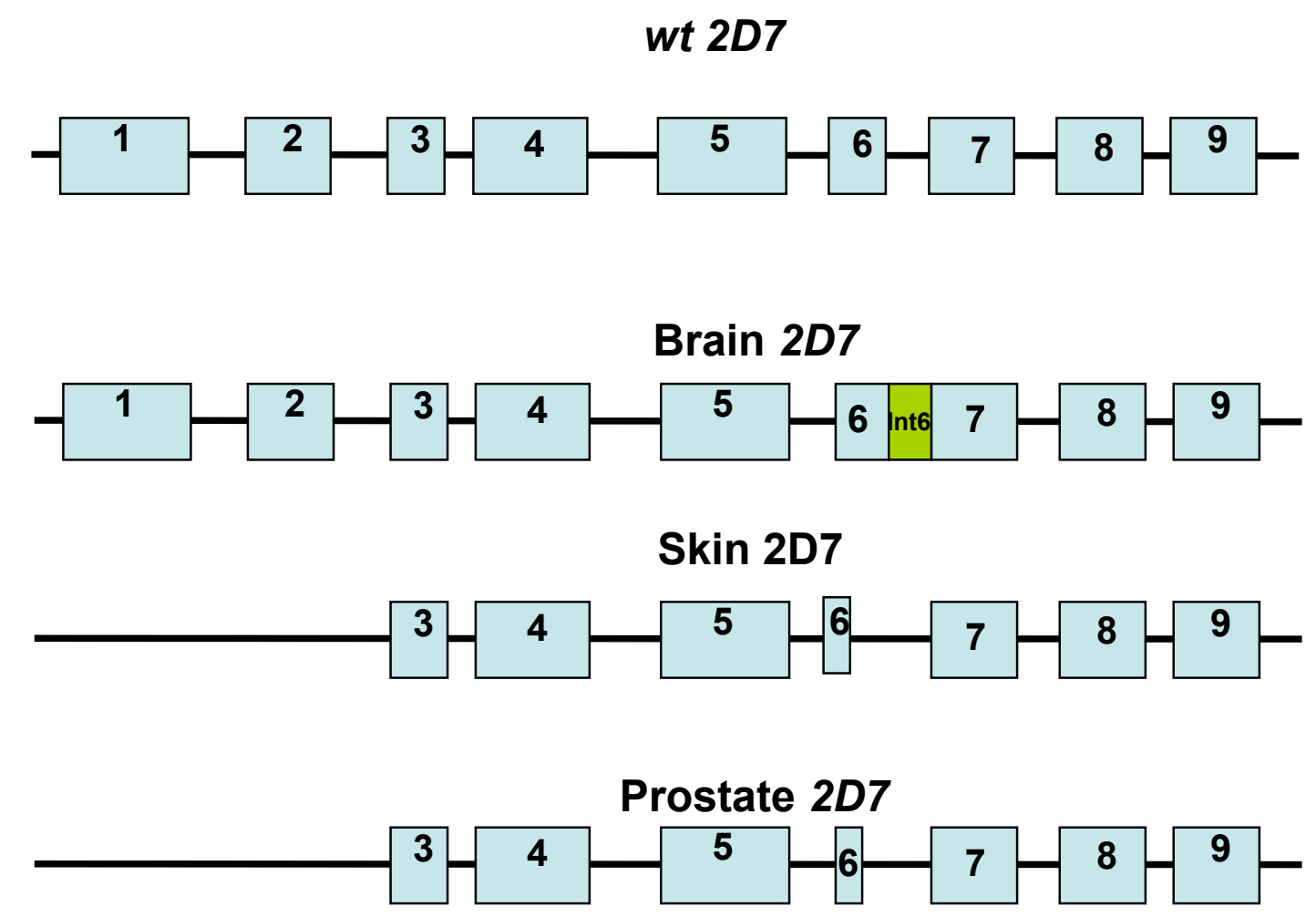

Eye 2D7
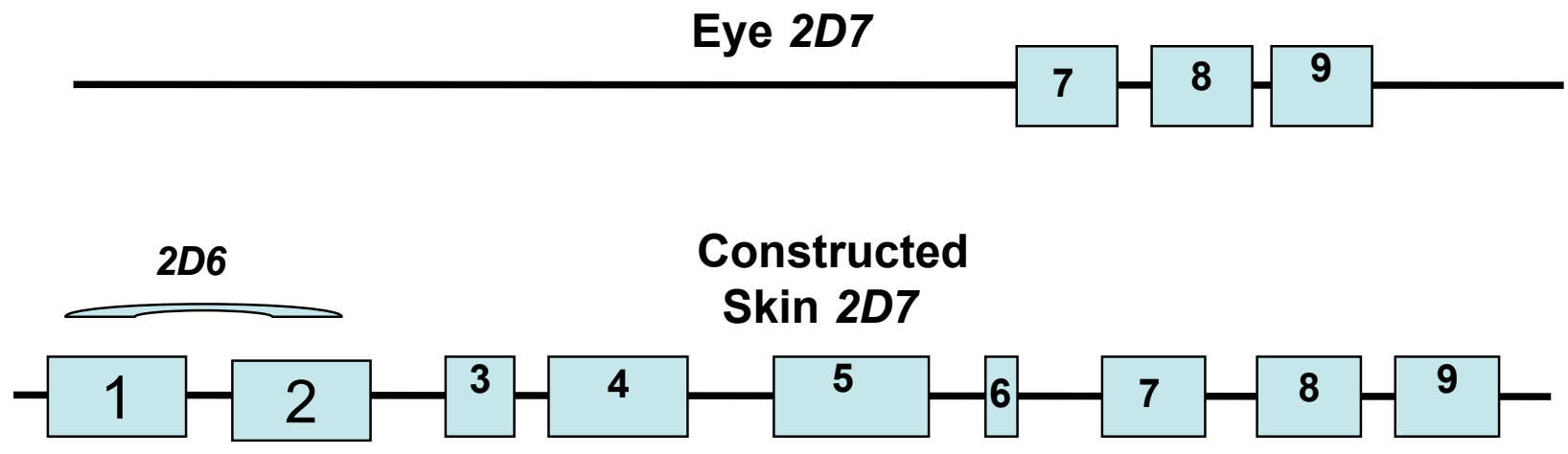

次 Insertion mutation

Figure 3 

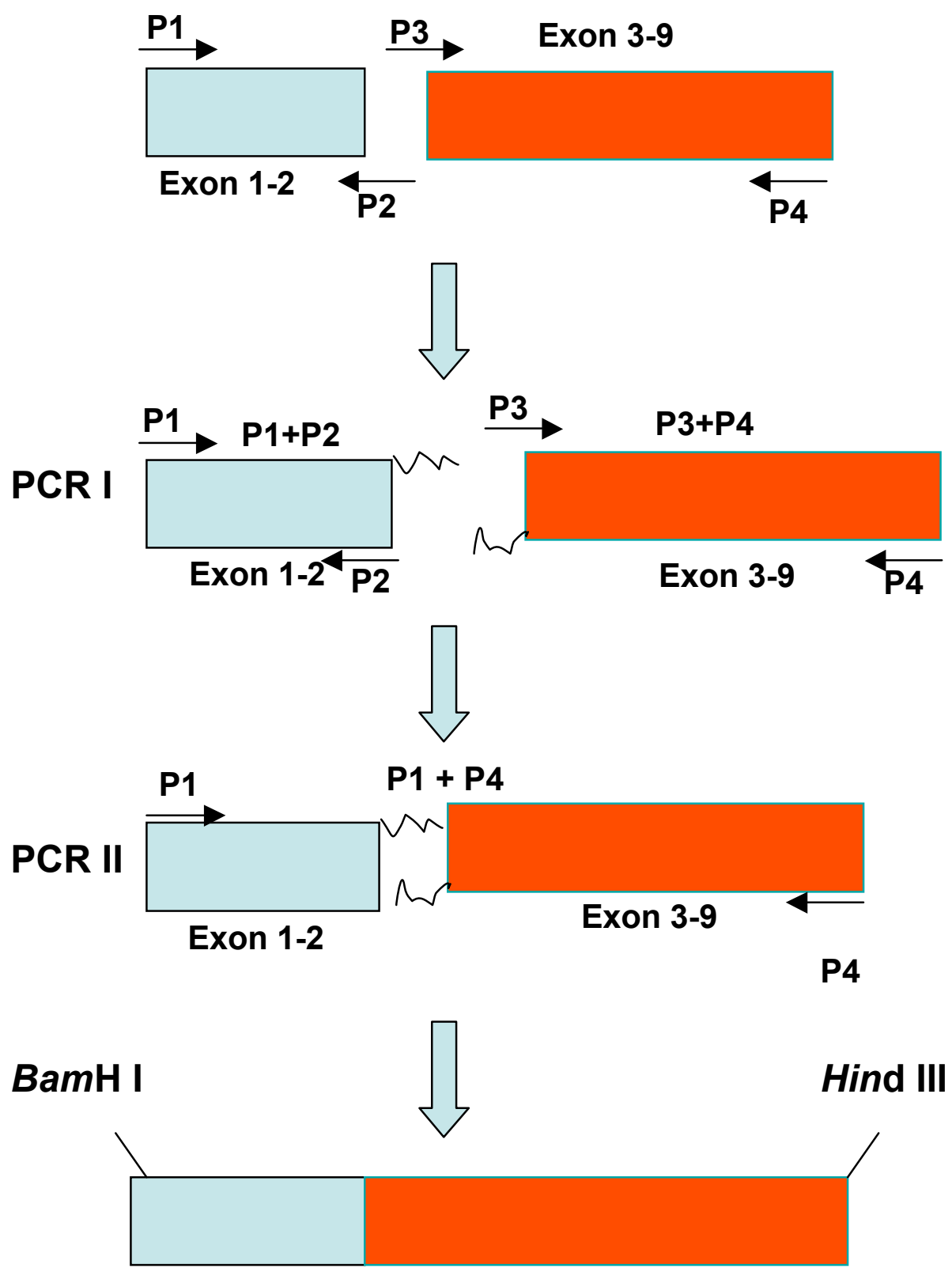

Full-length skin CYP2D gene

Figure 4 

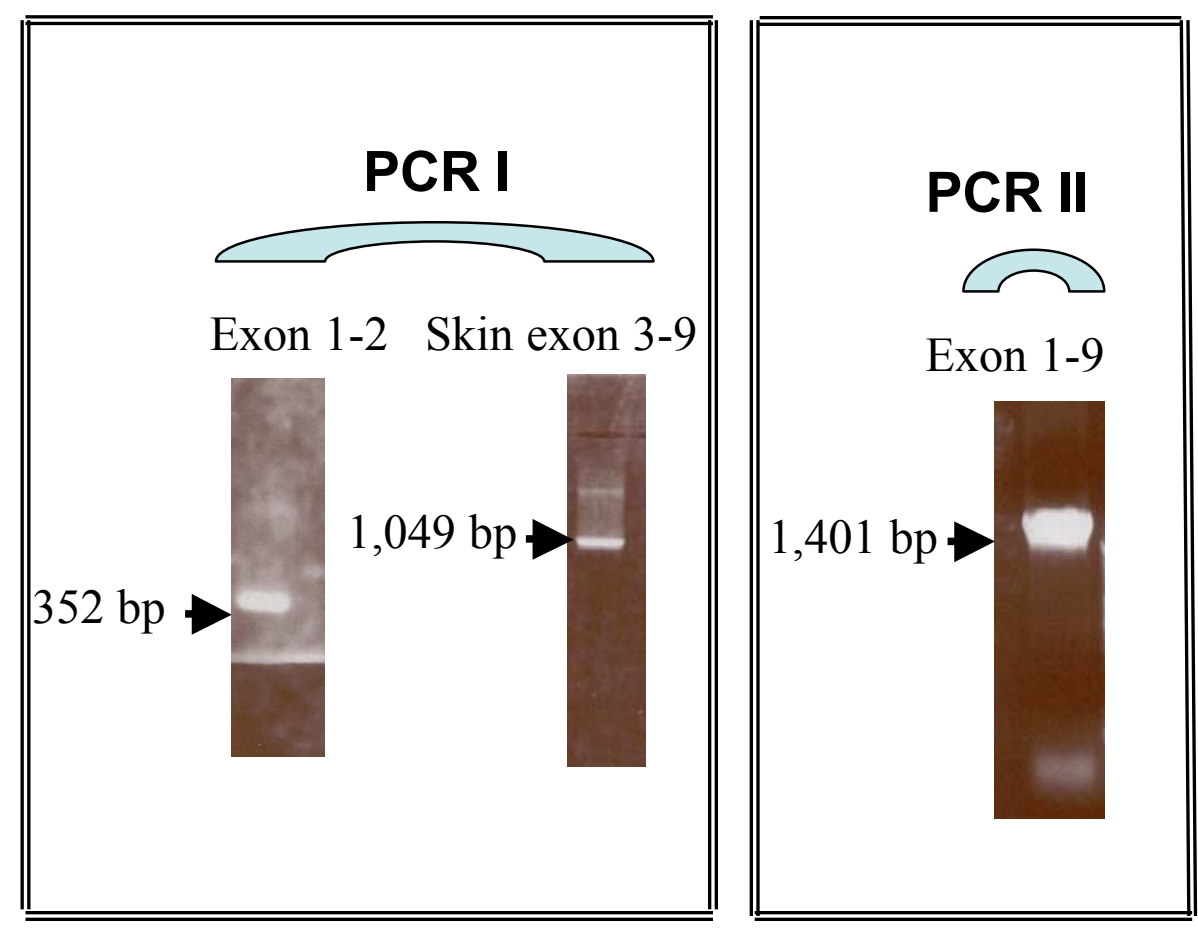

Figure 5 


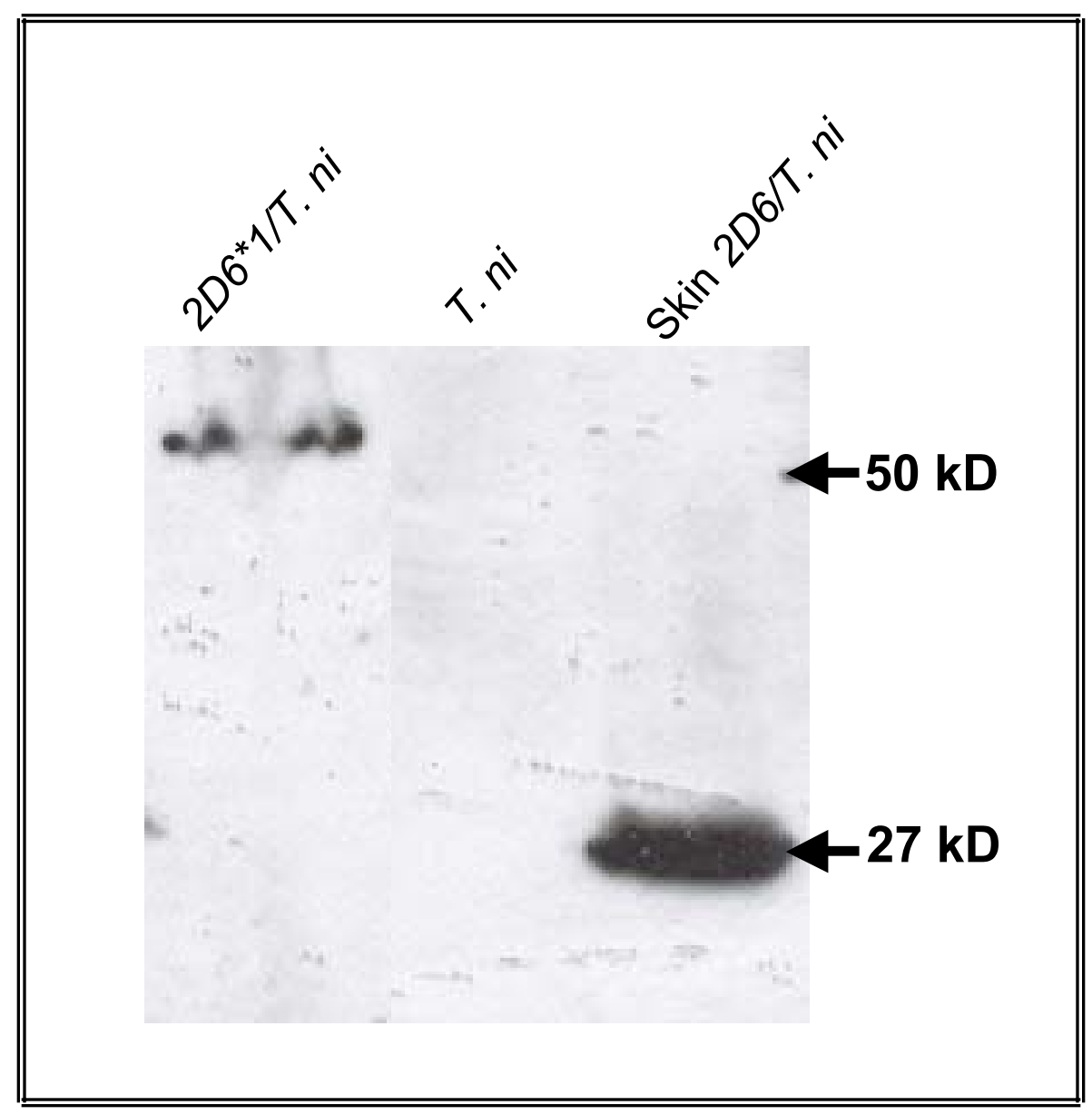

Figure 6 